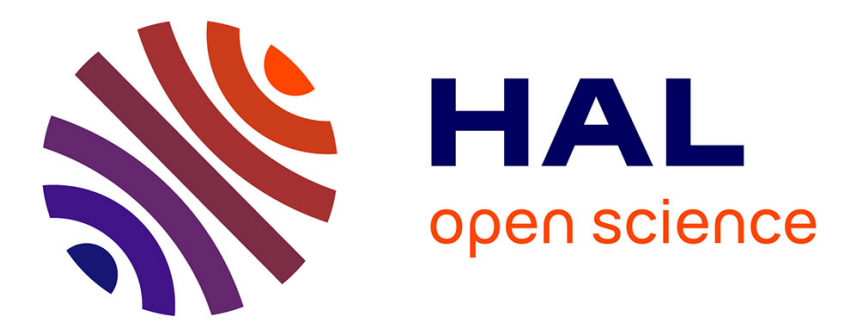

\title{
Proteasome inhibitors: recent advances and new perspectives in medicinal chemistry
}

\author{
Emilie Génin, Michèle Reboud-Ravaux, Joëlle Vidal
}

\section{To cite this version:}

Emilie Génin, Michèle Reboud-Ravaux, Joëlle Vidal. Proteasome inhibitors: recent advances and new perspectives in medicinal chemistry. Current Topics in Medicinal Chemistry, 2010, 10 (3), pp.232-256. 10.2174/156802610790725515 . hal-00807658

\section{HAL Id: hal-00807658 \\ https://hal.science/hal-00807658}

Submitted on 4 Apr 2013

HAL is a multi-disciplinary open access archive for the deposit and dissemination of scientific research documents, whether they are published or not. The documents may come from teaching and research institutions in France or abroad, or from public or private research centers.
L'archive ouverte pluridisciplinaire HAL, est destinée au dépôt et à la diffusion de documents scientifiques de niveau recherche, publiés ou non, émanant des établissements d'enseignement et de recherche français ou étrangers, des laboratoires publics ou privés. 
Published in Current Topics in Medicinal Chemistry, 2010, 10, 232-256

\section{Title page}

\section{Proteasome inhibitors: recent advances and new perspectives in medicinal chemistry}

E. Genin ${ }^{1}$, M. Reboud-Ravaux ${ }^{2}$ and J. Vidal ${ }^{*}$

${ }^{1}$ Chimie et photonique moléculaires, Université de Rennes 1, CNRS UMR 6510, bâtiment 10A, case 1012, Campus de Beaulieu, 35042 RENNES CEDEX, France.

${ }^{2}$ Enzymologie Moléculaire et Fonctionnelle, UR4-UPMC, case 256, $6{ }^{\text {ème }}$ étage A, 7 Quai StBernard, 75252 PARIS CEDEX 05, France.

E-mail correspondance to these authors: joelle.vidal@univ-rennes1.fr and michele.reboud@upmc.fr 


\begin{abstract}
The search for proteasome inhibitors began fifteen years ago. These inhibitors proved to be powerful tools for investigating many important cellular processes regulated by the ubiquitinproteasome pathway. Targeting the proteasome pathway can also lead to new treatments for disorders like cancer, muscular dystrophies, inflammation and immune diseases. This is already true for cancer; the FDA approved bortezomib, a potent proteasome inhibitor, for treating multiple myeloma in 2003, and mantle cell lymphoma in 2006. The chemical structures identified in some of the early proteasome inhibitors have led to the development of new anti-cancer drugs (CEP-18770, Carfilzomib, NPI-0052). All these molecules are covalent bonding inhibitors that react with the catalytic $\mathrm{Thr} 1-\mathrm{O}^{\gamma}$ of the three types of active site.

This review covers recent developments in medicinal chemistry of natural and synthetic proteasome inhibitors. Advances in non-covalent inhibitors that have no reactive group will be highlighted as they should minimize side-effects. New structures and new modes of action have been recently identified that open the door to new drug candidates for treating a range of diseases.
\end{abstract}

\title{
Key words
}

Proteasome, inhibitors, anti-cancer drugs, bortezomib, medicinal chemistry, natural products 


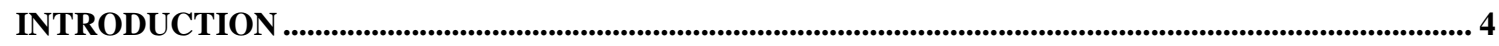

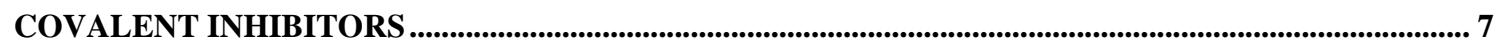

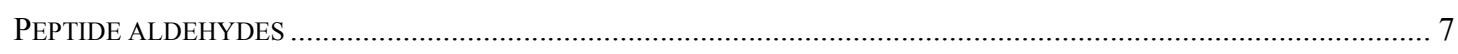

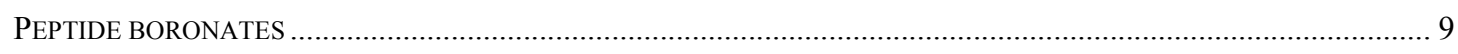

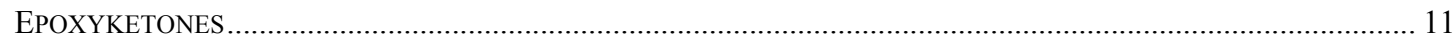

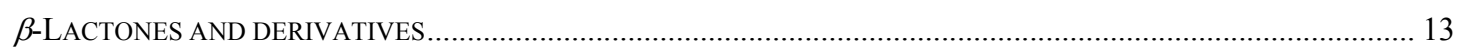

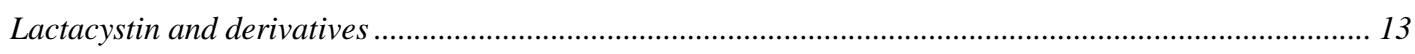

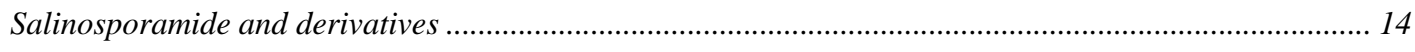

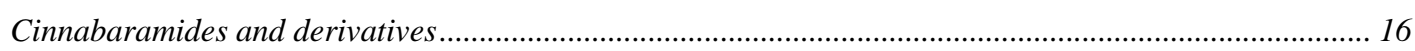

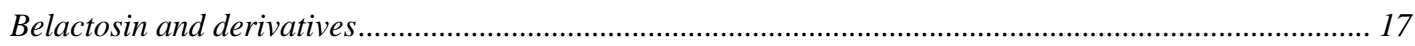

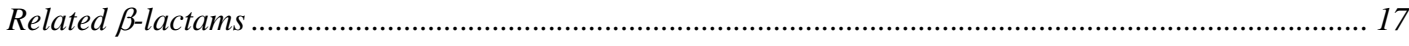

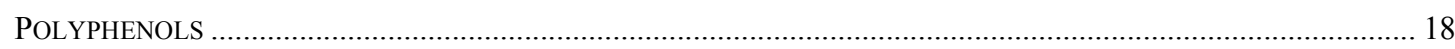

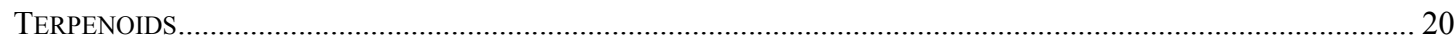

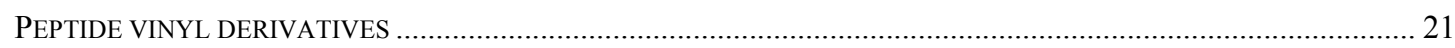

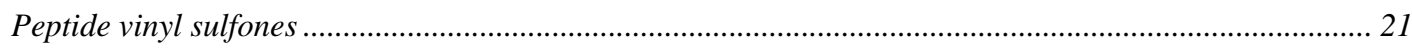

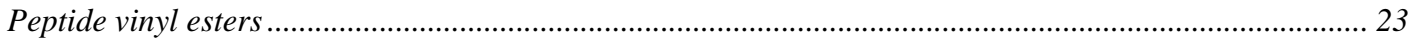

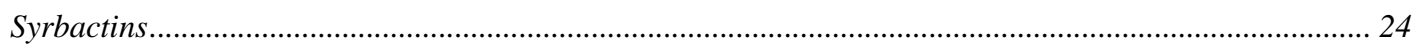

OTHER PEPTIDES OR PSEUDOPEPTIDES BEARING AN ELECTROPHILIC WARHEAD .......................................... 26

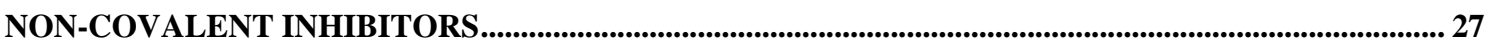

RITONAVIR, AMINOBENZYLSTATIN DERIVATIVES AND ANALOGUES ......................................................... 27

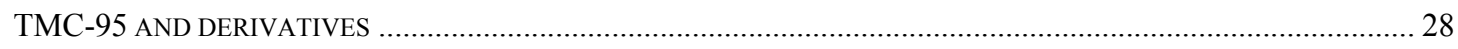

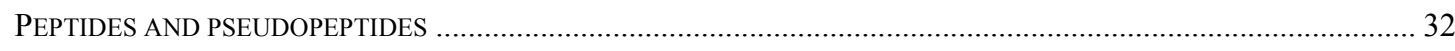

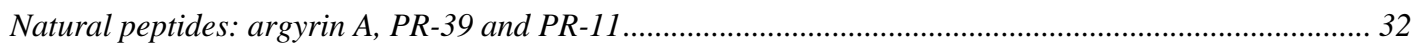

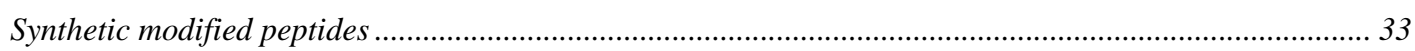

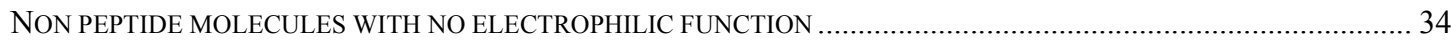

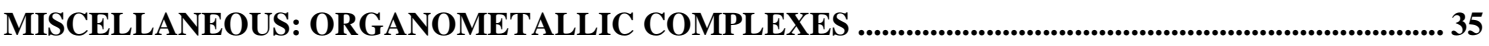

CONCLUSION

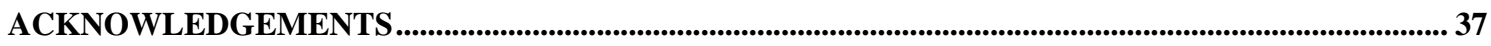

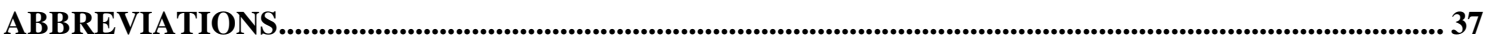

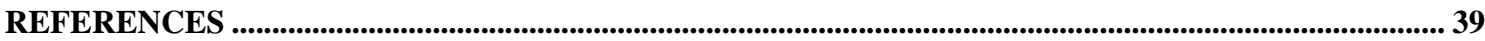




\section{Main text}

\section{INTRODUCTION}

Protein degradation is a highly complex, temporally controlled, and tightly regulated process. Proteasomes play a major role in cytosolic and nuclear proteolysis and are considered to be central to cellular physiology $[1,2]$. These abundant multicatalytic proteases are essential for the regulation of cellular protein quality and quantity in all forms of life. Some substrates are degraded by the proteasome without prior ubiquinylation [3], but many are tagged with multiple ubiquitin molecules to ensure their destruction by proteasomes (Figure 1).

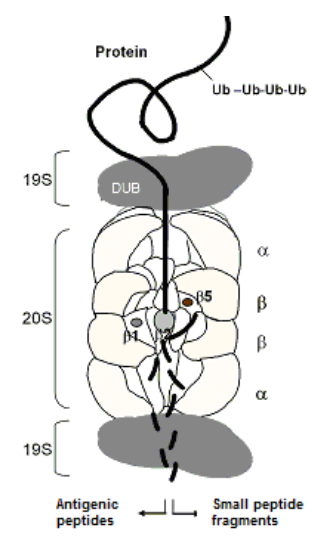

Fig (1). Schematic structure of the eukaryotic 26S proteasome showing the catalytic particle CP (or 20S proteasome) capped by two 19S regulatory particles. These particles are responsible for recognizing and unfolding ubiquinylated proteins, removing their ubiquitin tags, and moving the untagged proteins into the $\mathrm{CP}$, where they are degraded. There are two of each of the three distinct catalytically active subunits $\beta 1, \beta 2$ and $\beta 5$. Ub, ubiquitin; DUB, deubiquitinylating enzyme.

The architecture of constitutive proteasomes and immunoproteasomes is complex. The central part is a catalytic particle $(\mathrm{CP})$, the $20 \mathrm{~S}$ proteasome $(\sim 700,000 \mathrm{Da})$. The eukaryote $\mathrm{CP}$ is composed of 28 subunits arranged in four stacked rings, each having 7 subunits (two outer $\alpha 1$-7-rings and two inner $\beta 1$-7-rings) that form three continuous chambers. Only three of the $\beta$ subunits are catalytically active, providing the chymotrypsin-like (CT-L) activity $(\beta 5)$, trypsin-like (T-L) activity $(\beta 2)$, and caspase-like or post-acid (PA) activity $(\beta 1)$. The immunoproteasome found in mammals is composed of alternative catalytic subunits $(\beta 1 \mathrm{i}, \beta 2 \mathrm{i}$, $\beta 5 i)$ that are induced by immune stress. The immunoproteasome generates certain antigenic 
peptides that are presented to major histocompatibility complex (MHC) class I. The constitutive housekeeping proteasomes also generate antigenic peptides. The $\mathrm{CP}$ has a gate through which substrates enter; this gate is plugged by the $\alpha$-ring $N$-terminal domains [4]. It is opened by the association of the CP and regulatory particles. Proteasomes $20 \mathrm{~S}$ may be capped by regulatory particles like 19S RP, 11S activator (PA28, PA26, REG) and PA-200 (B1m10 in yeast) [5]. The 19S RP contains 6 ATPases that help to unfold globular proteins. Both the access to the active sites of protein substrates and the release of their breakdown products (peptides of 2-23 amino acids) are controlled. Proteasomes are a novel type of protease belonging to the Ntn ( $N$-terminal nucleophile) hydrolases [6]. The carbonyl carbon of a protein substrate's scissile bond is attacked by Thr1- $\mathrm{O}^{\gamma}$, the $N$-terminal threonine of the mature $\beta$ subunits that is obtained by autolysis (Figure 2).

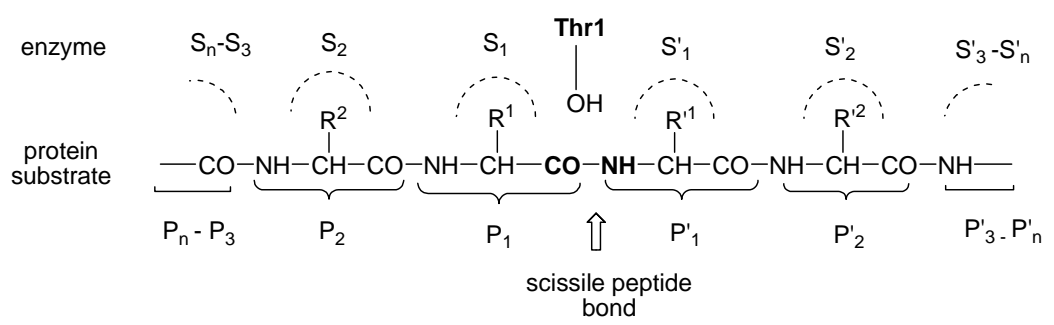

Fig (2). Schematic representation of the extended binding site of a proteasome catalytic $\beta$ subunit showing the $S$ and $S$ ' specificity pockets, and the unprimed $P$ residues on the left of the scissile peptide bond and the primed P' residues on its right. After Schechter and Berger nomenclature [7].

Crystallographic studies indicate that the nucleophilic attack is assisted by $N$-terminal Thr 1 through a water molecule (Figure 3) [8,9]. The oxyanion of the resulting tetrahedral intermediate is stabilized by the by hydrogen bonding with the Gly Gly47-N (oxyanion hole). The acyl-enzyme is hydrolyzed via a water molecule activated by the deprotonated Thr 1 amino group with regeneration of the Thr1-OH for a subsequent catalytic cycle. 


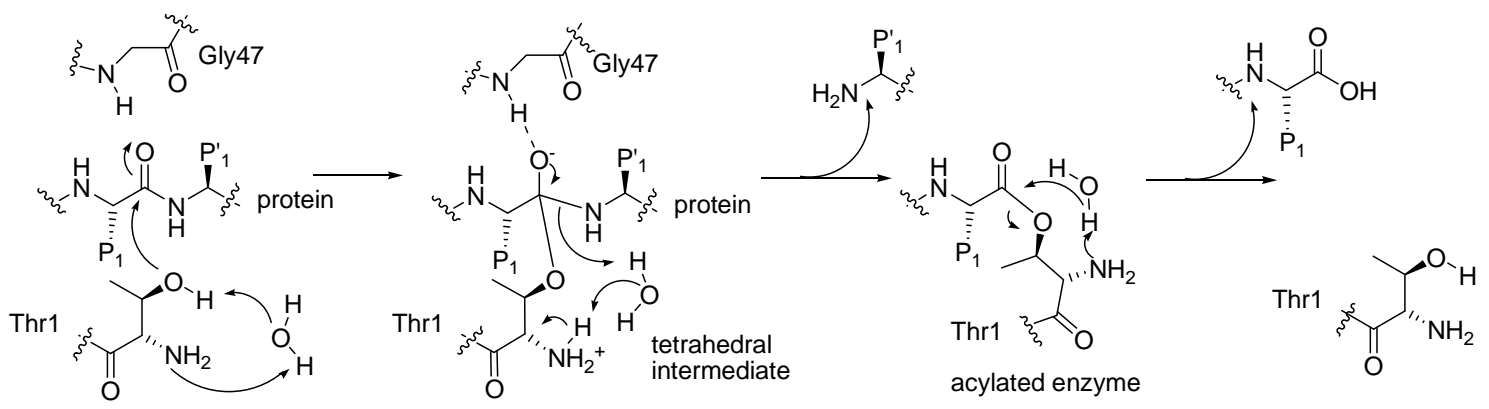

Fig (3). Proposed mechanism for the proteasome-catalyzed hydrolysis of peptides.

Proteasomes are responsible for various cellular processes including protein quality control, antigen processing, signal transduction, cell differentiation, cell-cycle progression and apotosis [2]. A highly selective inhibitor of proteasome, the peptide boronate bortezomib $\left(\right.$ Velcade $^{\circledR}$ ) has been approved for treating patients with relapsed or refractory multiple myeloma, and mantle lymphoma [10,11]. Bortezomib stabilizes p21, p27, p53, the proapoptotic Bid and Bax proteins, caveolin-1, and the inhibitor $\mathrm{I} \kappa \mathrm{B}-\alpha$ preventing activation of NF- $\kappa \mathrm{B}$ cell survival pathways [12]. As bortezomib inhibits NF- $\kappa \mathrm{B}$ pathways, it sensitizes cancer cells to chemo-, radio- and immuno-therapy. This is a solid biological foundation for the use of proteasome inhibitors in combination with standard anticancer drugs to enhance the sentivity of cells to drugs, and to overcome drug resistance [13]. There are many opportunities for pharmacological intervention with protein degradation catalyzed by proteasomes. Proteasome inhibitors are potential drugs for treating several diseases including immunologic, inflammatory, metabolic and neurological disorders, viral diseases, muscular dystrophies, and tuberculosis $[14,15]$.

The number of studies on proteasome inhibition has grown exponentionally since the discovery of the first inhibitors [16] and crystallographic description of the active sites (figure 4) $[17,18]$. This subject has been regularly reviewed [4,5,19-29] and highlighted [30-33]. This article summarizes recent advances in the design, synthesis and biological characterization of proteasome inhibitors. Several natural products, whose formula are framed, are potent proteasome inhibitors and are also reviewed. Proteasome inhibitors are classified according to their chemical structure and their mechanism of inhibition. Covalent inhibitors are generally electrophilic and react with the catalytic $\gamma$-hydroxyl of Thr1 in the active sites, to reversibly or irreversibly inhibit the proteasome, depending on the strength of the chemical bond. We will highlight advances in non-covalent inhibitors, which have no reactive group, as they should not have the inherent drawbacks associated with reactive warhead inhibitors. 


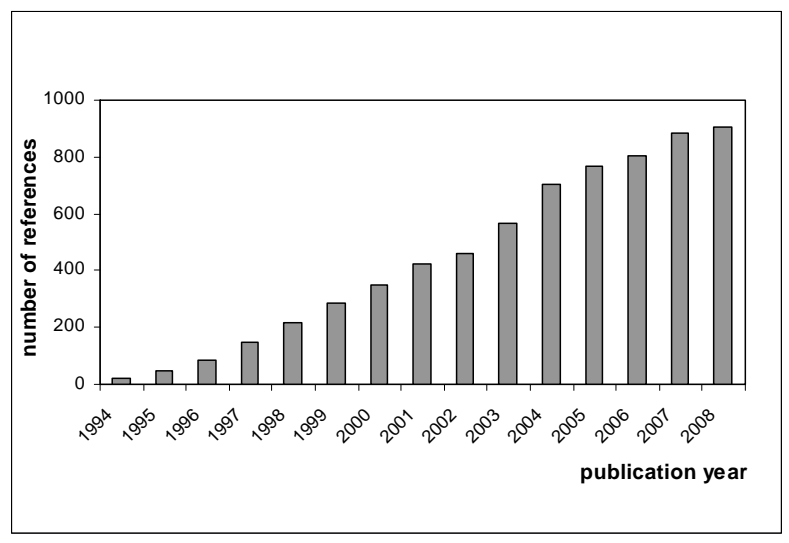

Fig. (4). Papers about proteasome inhibition in Chemical Abstracts database (SciFinder).

\section{COVALENT INHIBITORS}

These inhibitors possess an electrophilic reactive group that can react with the catalytic Thr1$\mathrm{O}^{\gamma}$. This group is usually attached to the $C$-terminal end of a peptide, or within a non-peptide molecule.

\section{Peptide aldehydes}

The first reported proteasome inhibitors were the synthetic peptide aldehyde ALLN (Ac-LeuLeu-Nle-H also called calpain inhibitor I) and natural leupeptin (figure 5a) [16]. The first information about architecture of the proteolytic active site was obtained from the crystal structure of ALLN complexed with the archaebacterium proteasome [17] or yeast proteasome [18]. The electrophilic aldehyde function reacts with the six catalytic $N$-terminal threonines to form the hemiacetal adduct 1 (figure $5 \mathrm{~b}$ ). The bound inhibitor has a $\beta$-conformation and forms an antiparallel $\beta$-sheet structure with the protein [4]. Peptide aldehydes inhibitors bind slowly and reversibly to proteasome. Although they block a broad range of serine or cysteine proteases and are rapidly oxidized to inactive carboxylic acids, they are widely used for in vitro and in vivo studies because they enter cells and their effects may be reversed when they are removed [19]. For example, the commercially available MG132 (Z-Leu-Leu-Leu-H), a potent inhibitor of CT-L activity $\left(\mathrm{K}_{\mathrm{i}}=0.004 \mu \mathrm{M}\right.$, rabbit 20S proteasome) [34] is one of the most popular proteasome inhibitors (figure 5a). Studies on peptide aldehydes as potent proteasome inhibitors have been extensively reviewed [1,4,18-21,23,25,27], hence only recent developments are reported here. 
Though tripeptide aldehydes are very flexible, three-dimensional quantitative structureactivity models that predict their inhibition of proteasome CT-L activity have been obtained by analysing 45 known inhibitors [35]. Derivatives 2 of tyropeptin $2 a\left(R^{1}=i \operatorname{Pr}, R^{2}=R^{3}=H\right)$, a natural proteasome inhibitor produced by Kitasatospora sp. [36], were designed by molecular modelling in order to improve inhibition and then synthesized (figure 5c) [37]. The most potent derivative $\mathbf{2 b}$ was 20 -times more active than tyropeptin (figure $5 \mathrm{c}$ ). Compound 2c, also called TP110, inhibits selectively the CT-L activity of the human 20S proteasome $\left(\mathrm{IC}_{50}=0.03 \mu \mathrm{M}\right)$ and poorly $\alpha$-chymotrypsin $\left(\mathrm{IC}_{50}=24 \mu \mathrm{M}\right)$ (figure 5c) [37]. It strongly inhibits the growth of several cell lines in vitro $\left(\mathrm{IC}_{50}=0.01-0.1 \mu \mathrm{M}\right)[38]$ and induces apoptosis in human prostate cancer PC-3 cells [39].

Fellutamide B is a natural product isolated from Penicillium fellutanum that is a potent stimulator of the release of nerve growth factor from fibroblasts and glial-derived cells. It is also a potent inhibitor of the human 20S proteasome CT-L activity $\left(\mathrm{IC}_{50}=0.009 \mu \mathrm{M}\right)$ and a less potent of T-L $\left(\mathrm{IC}_{50}=2 \mu \mathrm{M}\right)$ and PA $\left(\mathrm{IC}_{50}=1 \mu \mathrm{M}\right)$ activities (figure 5c) [40]. The X-ray structure of fellutamide in complex with yeast proteasome has revealed new aspects of binding to active sites [40]. Fellutamide B and other proteasome inhibitors increase the transcription of the nerve growth factor gene, which may lead to a new strategy for developing neurotrophic agents [40].

The $N$-(2-diethylaminoethyl)benzamide group has been linked to peptide aldehydes so as to selectively deliver the proteasome inhibitor to malignant melanoma cells (figure 5d) $[41,42]$. Compound $3\left(\mathrm{R}^{1}=\right.$ pyrrolidino- $\left.\mathrm{N}=\mathrm{N}\right)$ inhibits the growth of several melanoma cells $\left(\mathrm{IC}_{50}=\right.$ 0.02-0.2 $\mu \mathrm{M})$ (figure $5 \mathrm{c}$ ). Studies using radiolabelled $3\left(\mathrm{R}^{1}={ }^{125} \mathrm{I}\right)$ and mice carrying melanoma have shown that 3 retains some selectivity toward malignant tissues in vivo [42]. A series of peptidyl-aldehydes was screened in order to identify those with relative specificity for the immunoproteasome [43]. The most potent immunoproteasome-specific inhibitor, IPSI001 (figure 5c), preferentially targeted the $\beta 1 \mathrm{i}$ subunit of the immunoproteasome in vitro and in cellulo. This agent induced accumulation of ubiquitin-protein conjugates, proapoptotic proteins, and activated caspase-mediated apoptosis. IPSI-001 potently inhibited proliferation in myeloma patient samples and other hematologic malignancies. Importantly, IPSI-001 was able to overcome conventional and novel drug resistance, including resistance to bortezomib [43]. 

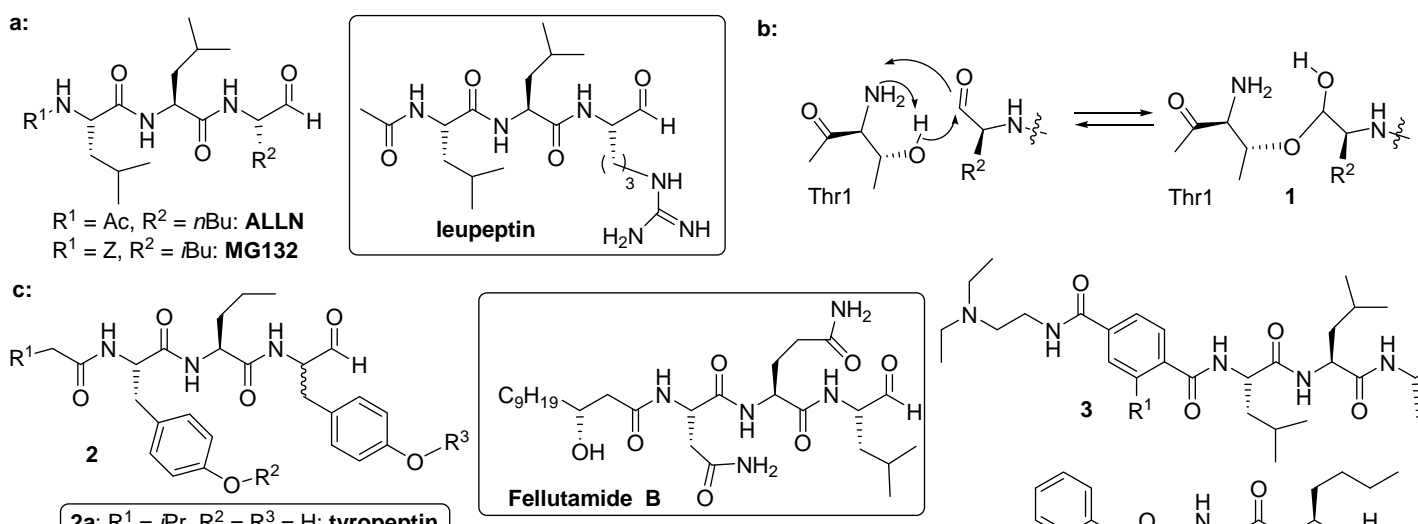

2a: $\mathrm{R}^{1}=i \mathrm{Pr}, \mathrm{R}^{2}=\mathrm{R}^{3}=\mathrm{H}$ : tyropeptin

2b: $\mathrm{R}^{1}=1$-naphtyl, $\mathrm{R}^{2}=\mathrm{R}^{3}=\mathrm{H}$

2c: $R^{1}=1$-naphtyl, $R^{2}=R^{3}=M e$
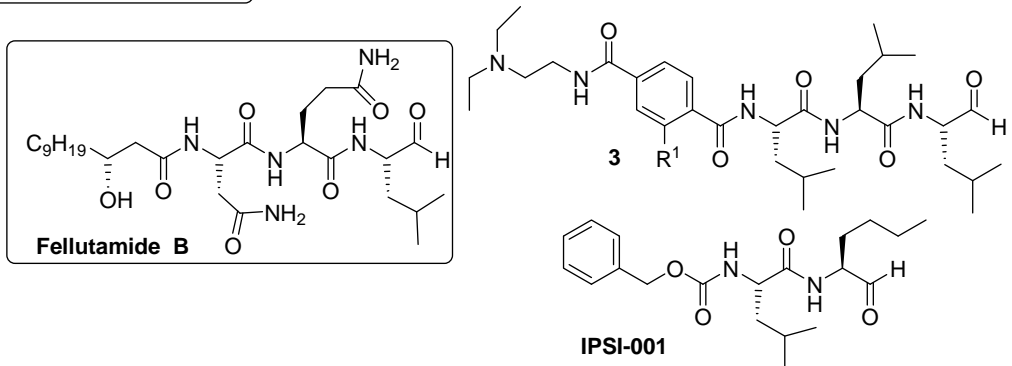

Fig. (5). Structures of some peptide aldehydes (a). Their binding to the catalytic threonine leading to the reversible adduct 1 identified from the crystal structure of proteasome/peptide aldehydes complexes $[4,40]$ (b). Structures of recently discovered peptide aldehydes: fellutamide B, compounds 2, 3 and IPSI-001 (c).

\section{Peptide boronates}

The U.S. FDA approved the first proteasome inhibitor bortezomib [34] (PS-341 or Velcade ${ }^{\circledR}$ of Millenium Pharmaceuticals, Cambridge, MA) (figure 6) for treating of multiple myeloma in 2003 and mantle cell lymphoma in 2006 [44-46]. Since then, peptide boronates have become one of the most popular and best known family of proteasome inhibitors. The many studies and developments in this area, especially with bortezomib, have been well reviewed $[4,19,47]$. We will only summarize the main results and focus on the most recent advances. Boronic acid derivatives are more active and selective than their structurally analogous aldehydes, and have no effect on cysteine proteases [4,19]. The CT-L activity is preferentially inhibited by low nanomolar concentrations $[4,19]$. X-ray diffraction studies have shown that the inhibitor boron atom reacts covalently with the active site $\mathrm{Thr} 1-\mathrm{O}^{\gamma}$ to form a quasiirreversible tetrahedral boronate adduct 4 (figure 6) [4]. Bortezomib is currently being evaluated in several clinical trials for its action on several types of cancer, either alone or combined with conventional chemotherapeutics [45,48-53]. Bortezomib treatment often has severe side effects, including nausea, diarrhea, peripheral neuropathy [52,54,55]. Its use is also restricted by the fact that it must be given intravenously. Cephalon, Inc. company recently developed a new orally active, potent, and selective boronate proteasome inhibitor, CEP-18770 (figure 6) to overcome these drawbacks [56,57]. They first modified the P2 residue of a previously reported boronic ester derivative 5 (figure 6) by replacing the 
nitroarginine moiety of 5 with threonine [56]. Eleven molecules possessing different P3 residues (alkyl, naphthyl, quinolyl, biaryl moieties) were then synthesized and the proteasome inhibitory capacity was evaluated. All the compounds inhibited the CT-L activity of the human erythrocyte $20 \mathrm{~S}$ proteasome with $\mathrm{IC}_{50}$ values from 0.8 to $42 \mathrm{nM}$, and most of them were more potent in vitro than bortezomib [56]. CEP-18770 was found to be the best in terms of several biological and pharmacological properties. It can enter cells and has very good enzymatic $\left(\mathrm{IC}_{50}=3.8 \mathrm{nM}\right)$, cellular $\left(\mathrm{EC}_{50}=13.5 \mathrm{nM}\right.$, human leukemia cell line Molt-4) and antiproliferative $\left(\mathrm{IC}_{50}=13.7 \mathrm{nM}, \mathrm{A} 2780\right.$ ovarian carcinoma cell line) activities [56]. Its selectivity for proteasome is very good. Its oral bioavailability ( $39 \%$ in mice) is better than that of bortezomib (11\%) [56]. Like bortezomib, it has a favorable tumor selectivity profile and so is a good candidate for treating multiple myeloma and other hematologic malignancies [57]. This compound is currently in clinical development (phase I) as an anticancer agent (solid tumors, non Hodgkin lymphoma).

Several less extensive SAR studies have also been reported, leading to the synthesis of other new boronic acid compounds that inhibit purified $20 \mathrm{~S}$ proteasome (figure 6). They include the boronic chalcone derivative [58] AM 114 ( $\mathrm{IC}_{50}=1 \mu \mathrm{M}$ for CT-L activity), the boron peptide 6 analogue of belactosin $\mathrm{C}$ [59] $\left(\mathrm{IC}_{50}=0.28 \mu \mathrm{M}, 8.54 \mu \mathrm{M}\right.$ and $>10 \mu \mathrm{M}$ for CT-L, PA and T-L activities, respectively), the lactam boronic acid based inhibitor [60] 7 ( $\mathrm{IC}_{50}=8 \mathrm{nM}$ for CT-L activity) and the derivative of tyropeptin $8\left(\mathrm{IC}_{50}=6.3 \mathrm{nM}, 5.6 \mu \mathrm{M}\right.$ and $>40 \mu \mathrm{M}$ for CT-L, TL and PA activities, respectively) [61].
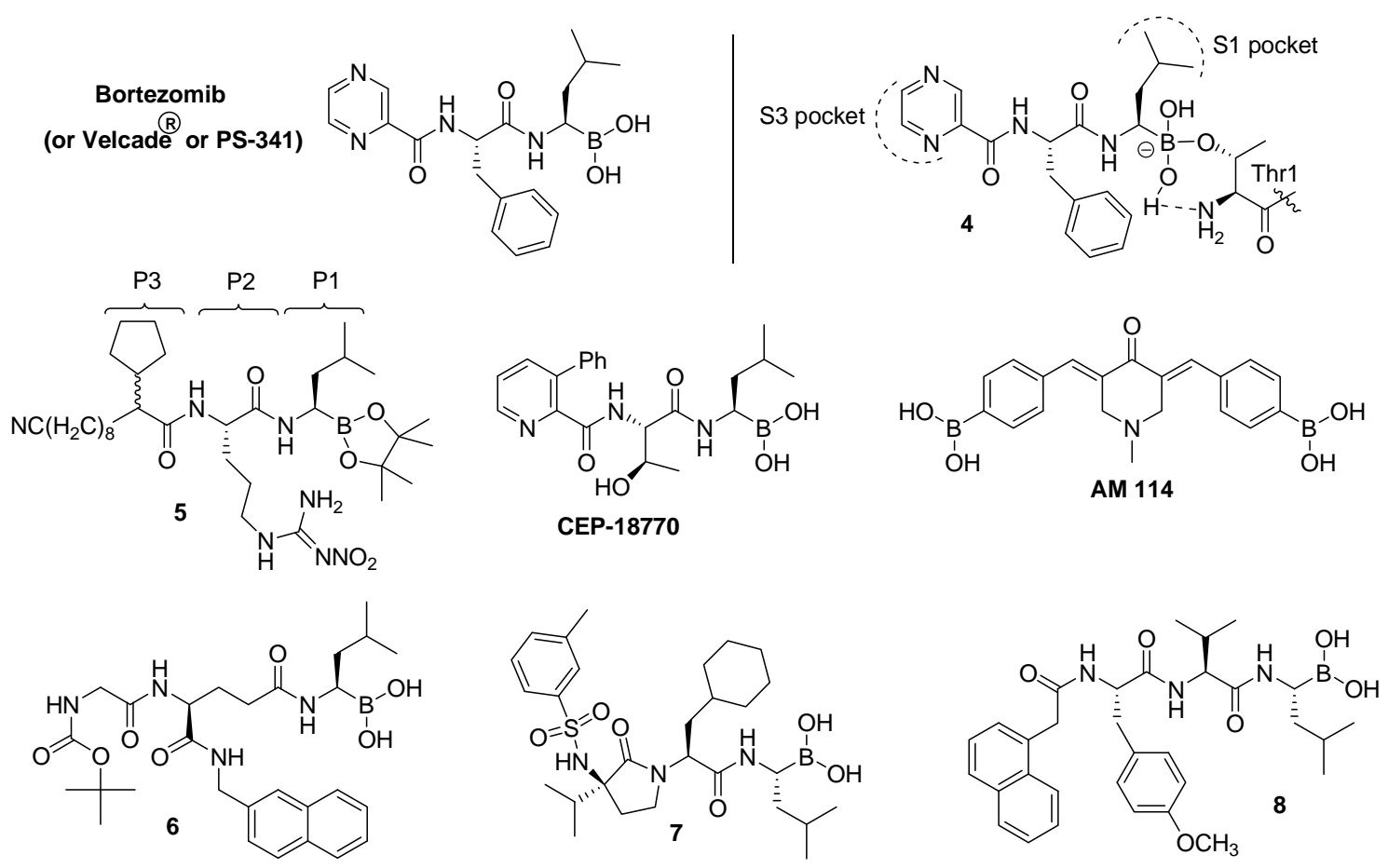


\section{Fig. (6). Structures of bortezomib and its adduct 4 with proteasome. Structures of some recently synthesized boronic acid derivatives: CEP-18770, AM 114, compounds 5-8.}

\section{Epoxyketones}

There was a major development ten years ago when microbial natural products epoxomicin [62] and eponemycin [63] (figure 7), which were isolated because of their in vivo antitumor activity, were shown to be potent irreversible and most specific proteasome inhibitor [20,6467]. The crystal structure of the yeast proteasome in complex with epoxomicin revealed its unique mechanism of action due to its two adjacent electrophilic atoms [4,19,68]. Both Thr1 hydroxyl and amino groups react with the epoxyketone moiety to form a very stable sixmembered morpholino adduct 9 (figure 7). The peptide moiety classically binds in the $\mathrm{S}$ substrate binding pockets of the proteasome active sites. Several other natural epoxyketone derivatives $[69,70]$, isolated from microbial metabolites, have been identified as proteasome inhibitors. Many medicinal chemistry efforts have focused on developing novel more potent epoxomicin analogues with improved in vivo activity. Optimization of the residues P2-P4 by screening aliphatic or aromatic amino acids resulted in the selective inhibitor of proteasome CT-L activity, YU 101 (figure 7), which has excellent antiproliferative and anti-inflammatory properties [71]. The same optimization strategy was used to develop a series of PA selective peptide epoxyketone inhibitors including the more efficient molecule YU 102 (figure 7) [72]. The success of bortezomib obviously stimulated the development of competitive products by other companies and one of the major objectives was to overcome side-effects and resistance to this peptidyl boronic acid. One second-generation proteasome inhibitor is carfilzomib (PR-171) (figure 7), a synthetic tetrapeptide epoxyketone related to epoxomicin that was developed by Proteolix, Inc. (South San Francisco, CA, USA) using a medicinal chemistry approach. Carfilzomib is currently being evaluated in phase I and phase II clinical trials for the treatment of multiple myeloma, non-Hodgkin's lymphoma and solid tumors [73,74]. Carfilzomib is an analogue of YU-101 (figure 7) that has the same activity as bortezomib and salinosporamide A (NPI-0052), but is more selective for the CT-L active site $\left(\mathrm{IC}_{50}=6 \mathrm{nM}\right.$, $3600 \mathrm{nM}, 2400 \mathrm{nM}$ for CT-L, T-L, PA activities of human 20S proteasome). It may be more tolerable in vivo because it is completely specific for proteasome and does not inhibit other proteases at concentration up to $10 \mu \mathrm{M}$ [73]. The $\mathrm{NH}_{2}$-terminal morpholino moiety on carfilzomib also makes it much more soluble in water than YU-101 (figure 7) (>1000-fold), and so easier to use in vivo [73]. Carfilzomib efficiently inhibits proteasome in vivo, promotes apoptosis in a variety of tumor cell lines and allows treatment to continue despite any 
resistance to bortezomib [74]. It is well tolerated even with a much more aggressive schedule than that used with either bortezomib or salinosporamide A [73]. Proteolix, Inc. have recently focused on designing orally available analogues of carfilzomib that do not lose their potency, selectivity and antitumor activity, in order to make treatment more flexible and more convenient for patients than intravenously administered agents. They have completed a systematic SAR optimization and in vivo pharmacodynamic screening [75]. Initial results show that tripeptide epoxyketones are better than tetrapeptides derivatives when given orally. More than $100 \mathrm{~N}$-cap variants, including a variety of five- or six-membered aromatic or nonaromatic heterocyclic amides and ureas, have been evaluated and thirty natural and nonnatural amino acids have been tested for P1-P3 modifications [75]. One of the many analogues synthesized, PR-047 (figure 7), has been found to be potent and has favorable pharmacological properties [75,76]. This optimized tripeptide epoxyketone selectively inhibits the CT-L activity of the human proteasome with an $\mathrm{IC}_{50}$ of $36 \mathrm{nM}$ (ELISA-based active site binding assay with intact cells). It is completely bioavailable when given orally and its antitumor activity is comparable to that of intravenously administered carfilzomib in several animal models [75]. Thus PR-047 (figure 7) is a promising molecule that will certainly give rise to further developments in the treatment of malignant diseases.

PR-957 is the first proteasome inhibitor that selectively inhibits the chymotrypsin-like subunit of immunoproteasome (figure 7) [77]. This epoxiketone is related to carfilzomib and selectively inhibits low-molecular mass polypeptide 7 (LMP7). PR-957 blocks presentation of LMP7-specific, MHC-I-restricted antigens in vitro and in vivo. It also blocks the production of IL-23 by activated monocytes and interferon- $\gamma$ and IL-2 by $\mathrm{T}$ cells. It attenuates progression of experimental arthritis in mouse. 

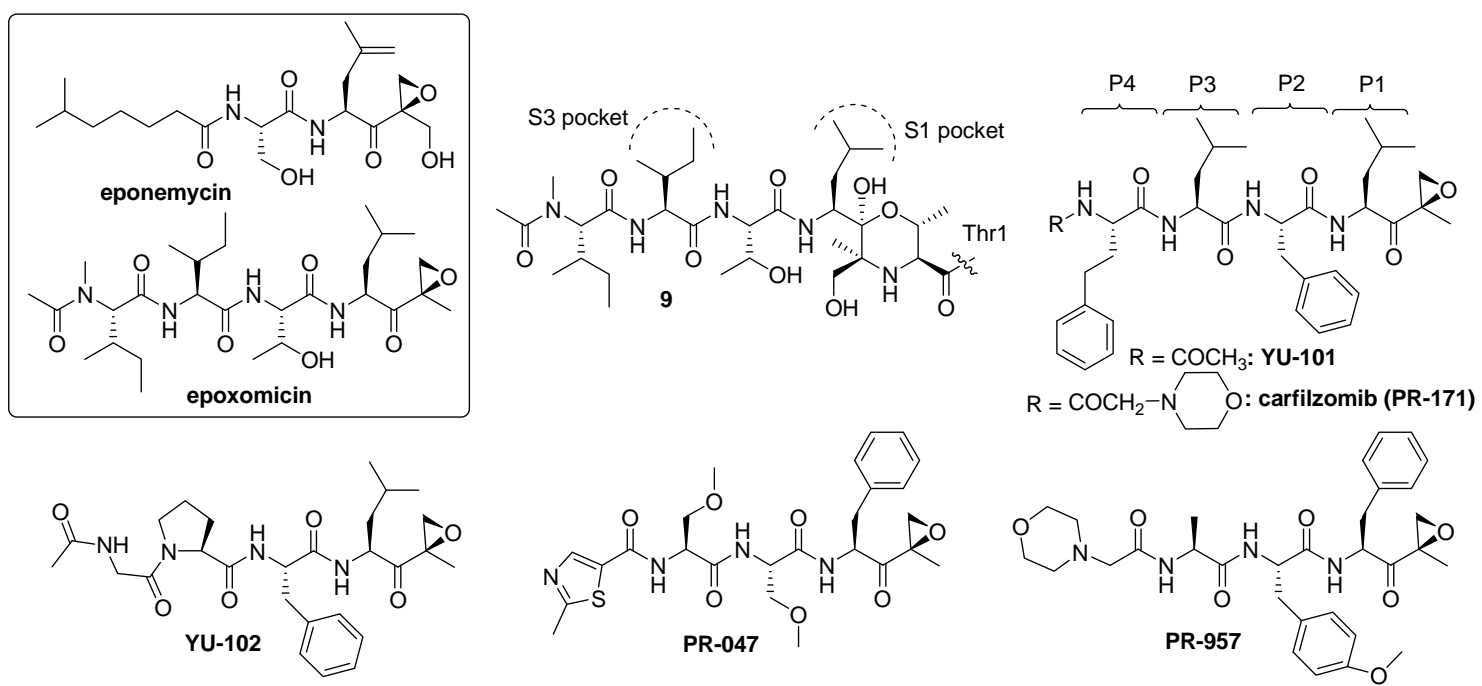

Fig. (7). Structures of some epoxyketones and the morpholino irreversible adduct 9 formed between yeast proteasome and epoxomicin.

\section{$\beta$-Lactones and derivatives}

\section{Lactacystin and derivatives}

Another very important family of covalent proteasome is the $\gamma$-lactam- $\beta$-lactones. There have been promising developments in both fundamental research and therapeutic applications of these compounds. The first natural non-peptidic proteasome inhibitor identified was $(+)-$ lactacystin (figure 8a) [78,79]. It was isolated from a strain of Streptomyces and acts as a prodrug in vivo, where it spontaneously generates the cell permeable biologically active clastolactacystin- $\beta$-lactone, also known as omuralide (figure 8a), with the concomitant elimination of $\mathrm{N}$-acetylcysteine $[80,81]$. Low nanomolar concentrations of omuralide efficiently inhibit proteasome CT-L activity, but do not inhibit various serine and cysteine proteases, except for cathepsin A and cytosolic tripeptidyl peptidase II $[80,82,83]$. Analysis of the crystal structure of the yeast proteasome/omuralide complex demonstrated that the prone to nucleophilic opening $\beta$-lactone moiety is crucial for inhibition and reacts only with the catalytic Thr1 of subunit $\beta 5$ to form a stable covalent ester adduct 10 (figure $8 b$ ) $[4,84]$. This mechanism is novel in that the resulting hydroxyl group $\mathrm{C}-6-\mathrm{OH}$ of the adduct $\mathbf{1 0}$ is well positioned to block the access of nucleophilic water and thus prevents hydrolysis of the inhibitor-Thr1 ester bond [4]. The threonine amino group, which is bound by a hydrogen bond in the adduct 10, is also partially protonated and so cannot catalyze the deacylation step. The dimethyl group of omuralide also plays a significant role in selectivity by allowing non-covalent hydrophobic interactions with the $\mathrm{S} 1$ pocket of the CT-L active site. There is growing interest in omuralide 
because it is a low-molecular-weight molecule that is a very potent and selective proteasome inhibitor. Its interesting biological properties and original chemical structure have made this molecule a challenge for many synthetic chemists. Several strategically important syntheses and biological evaluations of omuralide and its analogs have so been reported and reviewed $[81,85-88]$. The SAR requirements are very stringent and most changes to the structure of the natural product omuralide led to a dramatic loss of activity (figure $8 \mathrm{c}$ ). The $\beta$-lactone ring, the non-alkylated lactam moiety, and all stereochemical features are essential. Omuralide is nearly optimal for inactivation of $20 \mathrm{~S}$ proteasome and only replacement of the C-7 methyl group by longer aliphatic chains enhanced its inhibitory potency 2 to 3 -fold. The analog with a C-7 n-propyl substituent, PS-519 (also known as MLN-519, Millenium, Inc.) has been evaluated in phase I clinical trials clinical for acute stroke [89].

a:

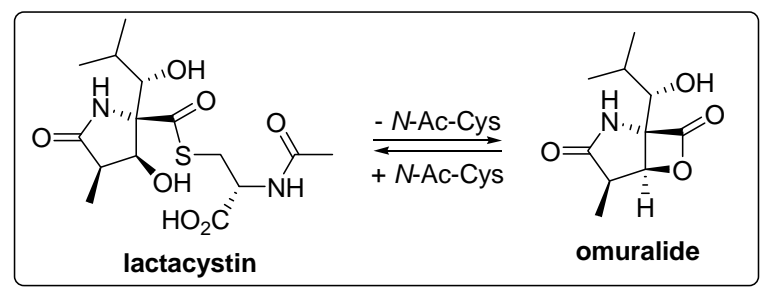

c:

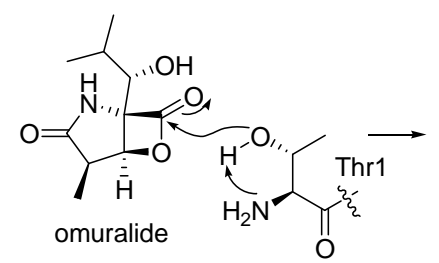

b:

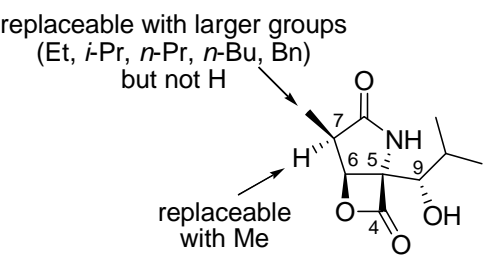

Fig. (8). Structures of the natural lactacystin and its active form omuralide obtained spontaneously in aqueous medium (a). Omuralide inhibits proteasome by forming of a stable acyl-enzyme 10, as deduced from X-ray crystallography (b). Summary of SAR studies (c). Doted line indicates a hydrogen bond.

\section{Salinosporamide and derivatives}

Another very promising natural $\gamma$-lactam- $\beta$-lactone is salinosporamide A [90] (also known as NPI-0052 and developed by Nereus Pharmaceuticals, Inc.) (figure 9a). It was recently isolated from the marine actinomycete Salinispora tropica and is currently in clinical trials for the treatment of multiple myeloma and other cancers [91]. This molecule is given by i.v. injection and can be used with patients who have developed resistance to several classical anticancer agents since it remains effective on multiple myeloma cells isolated from patients refractory/resistant to bortezomib, lenalidomide and/or thalidomide [91]. Salinosporamide A 
is 35-times more potent than omuralide and irreversibly inhibits all three catalytic functions of the rabbit $20 \mathrm{~S}$ proteasome $\left(\mathrm{IC}_{50}=2.6,21\right.$ and $430 \mathrm{nM}$ for CT-L, T-L, PA activities, respectively) [92]. It is also very selective since it is at least 1000-times less potent against other proteases like chymotrypsin, trypsin, cathepsin A and cathepsin B [93]. Salinosporamide A (figure 9a) has a fused $\gamma$-lactam- $\beta$-lactone bicyclic ring like omuralide, but has a unique substituent pattern including a methyl group at the ring junction, a cyclohexene instead of an isopropyl group and more importantly, a chloroethyl group replacing the C-7 methyl substituent in omuralide [90]. The crystal structure of salinosporamide A in complex with the yeast $20 \mathrm{~S}$ proteasome provided fundamental informations that has led to better understanding of how its acts [84,94]. As with omuralide, the catalytic threonine first reacts with the $\beta$-lactone moiety to form an ester adduct, but the chlorine atom subsequently acts as a leaving group giving rise to a cyclic ether end product 11 (figure 9b). The full protonation of the threonine amino group and the ether position prevent hydrolysis of the ester linkage [4,95]. Although the factors responsible for the great potency and irreversibility of salinosporamide A remain to be fully elucidated, the chlorine atom elimination seems to be a crucial step $[94,95]$. Nereus, Inc. have also carried out an extensive SAR studies program (figure 9c), with biological evaluation of both natural analogs (salinosporamides B [96] and D-J [97]) and synthetic or semi-synthetic analogs [92,95,98]. Analogs bearing substituents with good leaving potential $(\mathrm{Cl}, \mathrm{Br}, \mathrm{I}$, OMs, OTs, ODs) irreversibly inhibit rabbit $20 \mathrm{~S}$ proteasome CT-L activity with $\mathrm{IC}_{50} \mathrm{~S}$ of 2.5 to $4.3 \mathrm{nM}$ [92,95]. The fluorosalinosporamide [95] analog with weak living potential has intermediate properties and reversibly inhibits proteasome CT-L activity with an $\mathrm{IC}_{50}$ of $10 \mathrm{nM}$, similar to those of congeners having no leaving group ( $\mathrm{IC}_{50} \mathrm{~S} 7.5$ to $26 \mathrm{nM}$ ) [92,95]. The inhibitory properties can then be fine tuned by changing the nature of the leaving group [99]. Other structural modifications such as removal [97], oxidation or epimerization of the $\mathrm{C}-5-\mathrm{OH}$ [92], $\mathrm{C}-2$ epimerization [92], extension of the carbon side chain of the C-3 substituent [92], hydrogenation of the cyclohexene ring or halohydrin formation [92], lead to significant to dramatic decrease in inhibitory potency. In contrast, epoxidation of the cyclohexene ring seems to be quite well tolerated since the best corresponding analog was only 2- to 4-fold less potent than salinosporamide A [92]. Finally Corey's group synthesized "antiprotealide" (figure 10) [100], a hybrid of salinosporamide A and omuralide. This was also recently identified as natural product metabolite of Salinospora tropica [101]. However replacement of the salinosporamide A cyclohexene ring by the omuralide-derived isopropyl group results in a 8fold less potent inhibitor of rabbit 20S proteasomal CT-L activity [101]. Despite all these 
structural modifications, the natural product salinosporamide A is cost-efficiently produced by fermentation and remains the most therapeutically promising compound of the $\gamma$-lactam- $\beta$ lactone family [91].

a:

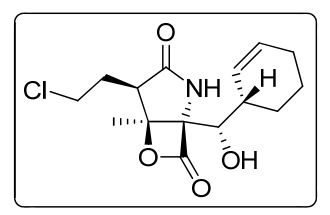

salinosporamide A

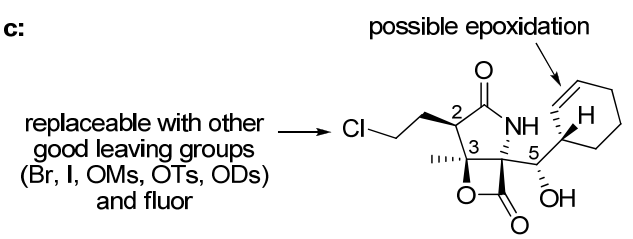

b:

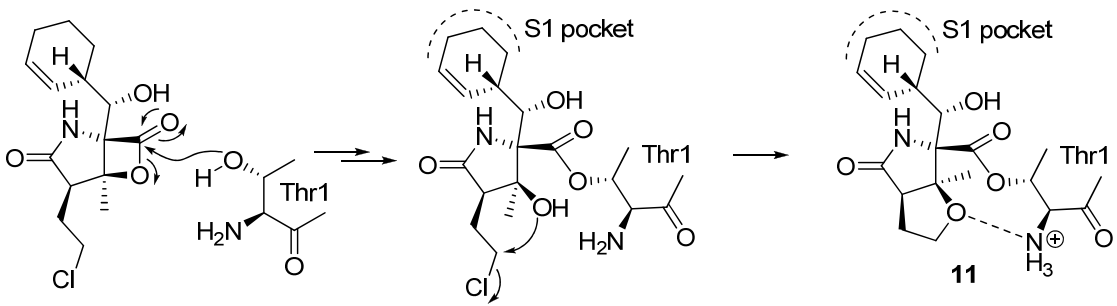

Fig. (9). Structure of the natural salinosporamide A (a). Mechanism of inhibition leading to the formation of adduct 11 between salinosporamide $A$ and the proteasome (b). Summary of SAR studies (c).

\section{Cinnabaramides and derivatives}

This class of inhibitors was recently expanded by the isolation of cinnabaramides A-G [102], from a terrestrial strain of Streptomyces. These molecules have the essential features of both salinosporamide A and lactacystin. The most potent of them, cinnabaramides A, F and G (figure 10) $\left(\mathrm{IC}_{50}=1,6\right.$ and $0.6 \mathrm{nM}$ for human $20 \mathrm{~S}$ proteasomal CT-L activity, respectively) are about as potent as salinosporamide A and are 43 to 430 -fold more potent than lactacystin [102]. But why these molecules, which have no leaving group to allow the formation of a cyclic ether, are active has not yet been elucidated. Similarly, cinnabaramides have yet to be shown to have the same anticancer properties as salinosporamide A.

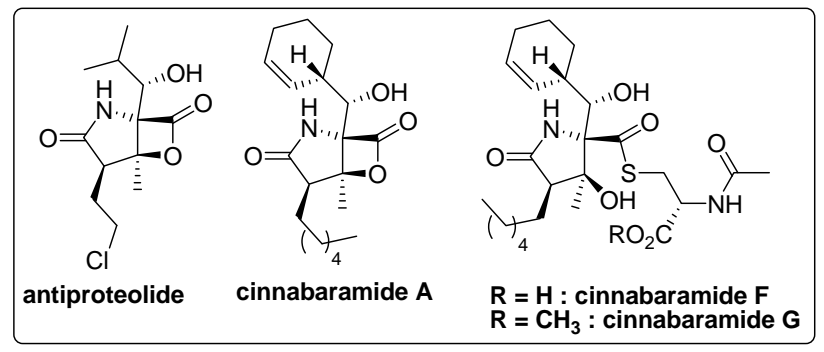

Fig. (10). Structures of the natural antiproteolide and cinnabaramides A, F and G. 


\section{Belactosin and derivatives}

Belactosins A and C (figure 11) were isolated from Streptomyces sp. UCK14 and have interesting antitumor activity. They inhibit the growth of human cancer HeLa S3 cells with $\mathrm{IC}_{50}$ values of 51 and $200 \mu \mathrm{M}$ respectively $[103,104]$. The in vitro capacities of belactosins $\mathrm{A}$ and $\mathrm{C}$ to inhibit the $\mathrm{CT}-\mathrm{L}$ activity of rabbit $20 \mathrm{~S}$ proteasome $\left(\mathrm{IC}_{50} \approx 0.21 \mu \mathrm{M}\right)$ is comparable to that of lactacystin [104]. The CT-L active site threonine residue is acylated via opening of the belactosin $\beta$-lactone ring [4]. This is analogous to the way omuralide acts. Some structural modifications of these natural products such as acetylation of the free amino group or esterification of the carboxyl group significantly increase their antitumor activity. The more cell permeable benzyl ester derivative KF33955 (figure 11) is a much more potent (100-times) inhibitor of the growth of HeLa S3 cells $\left(\mathrm{IC}_{50}=0.46 \mu \mathrm{M}\right)$ than is belactosin A. It inhibits rabbit 20S proteasome CT-L activity $\left(\mathrm{IC}_{50}=0.048 \mu \mathrm{M}\right)$ more efficiently than belactosin $\mathrm{A}$ and is very selective, since it does not inhibit other proteases like elastase, ICE or cathepsin B) [104]. A series of more potent stereo- and regioisomeric analogs of belactosin $\mathrm{A}(<2$-fold $)$ were described during a SAR study using a stereochemical diversity strategy focusing on the central cyclopropane amino acid segment $[105,106]$. One of the synthetic precursors, the tripeptide lactone 12 (figure 11), is a highly efficient proteasome inhibitor $\left(\mathrm{IC}_{50}\right.$ value of 15 $\mathrm{nM}$ for CT-L activity of the human $20 \mathrm{~S}$ proteasome), which is 20 -times more active than belactosin A 5-times more active than lactacystin [106]. Finally synthetic homobelactosin C (figure 11) [107], with low nanomolar $\mathrm{IC}_{50}$ values against human pancreoma and colon cancer cells, has attracted special attention because of the unique way it complexes with the proteasome $\beta 5$ subunit $[4,108]$. Homobelactosin C, like other lactones, is covalently linked to Thrl via an ester function, but it is the only proteasome inhibitor identified to date that binds via its aminocarbonyl side chain to the $S$ ' specificity pockets $[4,108]$.

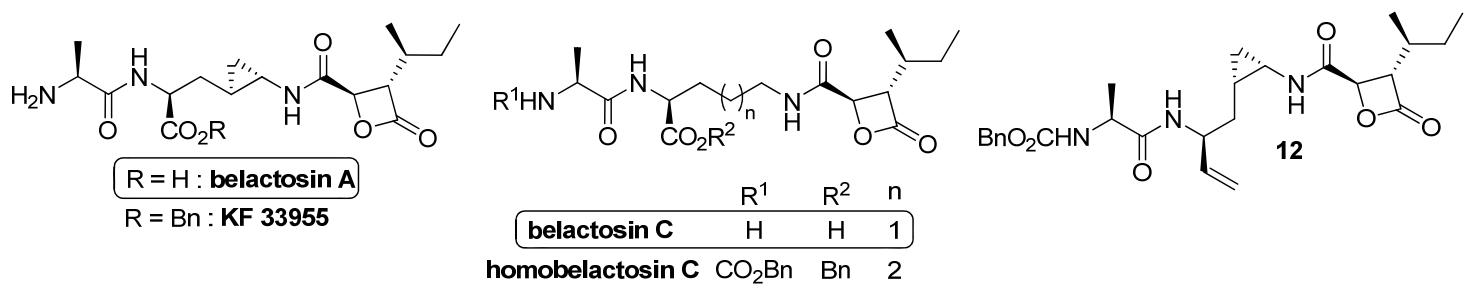

Fig. (11). Structures of belactosin derivatives and one of their synthetic precursors.

\section{Related $\beta$-lactams}

One of the major drawbacks of $\beta$-lactones is their poor stability in water. To overcome it, $\beta$ lactam derivatives have been designed as proteasome inhibitors. Compound 13 (figure 12), 
which is related to omuralide, inhibits proteasome more slowly but is more stable under physiological conditions [109]. Four highly potent $\beta$-lactam compounds 14a-d (figure 12) have been designed based on molecular modeling studies [110]. These molecules have $\mathrm{IC}_{50}$ values of $1.4 \mathrm{nM}$ to $20 \mathrm{nM}$, and the $\mathrm{IC}_{50} \mathrm{~S}$ for three of them are below $5 \mathrm{nM}$ (human $20 \mathrm{~S}$ proteasome CT-L activity). They are also at least 350-times less potent against the TL and PA activities [110]. In addition, they have pronounced antiproliferative effect $\left(\mathrm{IC}_{50}=1200-32 \mathrm{nM}\right.$ for human breast carcinoma cells) [110]. Mass spectroscopy showed that they interact covalently with the proteasome and the $R$ configuration at C-3 is a key structural requirement, since $S$-epimers are 70 - to 2000 -times less potent [110].
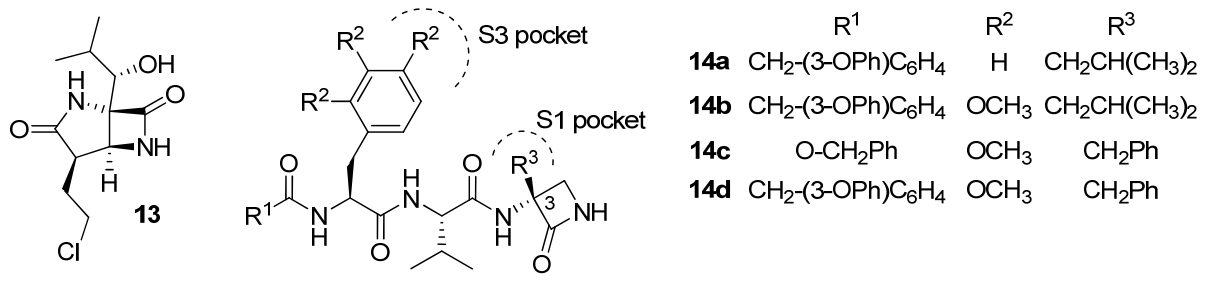

Fig. (12). Structures of some synthetic $\beta$-lactam proteasome inhibitors.

\section{Polyphenols}

Considerable research has been directed towards identifying new proteasome inhibitors from natural sources. Interest has recently focused on natural polyphenols, especially those found in green tea, because of their wide spectrum of biological activities, including chemopreventive and antitumor effects (figure 13) [111,112]. Their use in the prevention and the treatment of cancer is now well documented and phase I-III clinical trials are currently under way to explore the anticancer activities of green tea in humans [111,112]. However, it was recently reported that green tea polyphenols block the anticancer effects of bortezomib $[113,114]$.

Dou et al. reported that tea polyphenols containing ester bond-containing potently and selectively inhibit the CT-L activities of prokaryotic $20 \mathrm{~S}$ proteasome $\left(\mathrm{IC}_{50}=86-194 \mathrm{nM}\right)$ and 26S proteasome of living tumor Jurkat cells $(1-10 \mu \mathrm{M})$ at concentrations similar to those found in the serum of green tea drinkers [115]. One of the major components of green and black tea, (-)-epigallocatechin-3-gallate [(-)-EGCG] (figure 13), has the greatest inhibitory activity with good selectivity (no inhibition of other proteases like calpain-I and caspase-3) and induces apoptosis at concentrations of 1 to $10 \mu \mathrm{M}$. It is not very toxic for normal cells. Several SAR studies have been performed. Those based on the EGCG skeleton were done to design more effective novel anti-cancer agents [115-126]. The ester bond [115], all rings 
[116], the number of free hydroxyl groups in the B- or D-rings [117-123] are essential features of a potent inhibitor, but the oxygen in $\mathrm{C}$ ring can be replaced with the $\mathrm{CH}_{2}$ isostere [116]. Replacing the ester bond-oxygen of (-)-EGCG with nitrogen (EGCG-amide) decreases inhibitory potency 3-fold [124]. Synthetic enantiomeric analogues are as potent and selective as the respective natural catechin gallate esters for inhibiting proteasome CT-L activity in vitro and in vivo, probably due to the partial symmetry of the A-C rings $[119,124,126]$. In silico docking and determination of nucleophilic susceptibility led the authors to propose that the irreversible and time-dependent inhibition of proteasomal CT-L activity by ester bondcontaining flavonoids, especially (-)-EGCG, is due to acylation of the active site Thr1 and that the aromatic rings bind to the hydrophobic S1 pocket, thus increasing the stability of the polyphenols/proteasome complex [124], [127]. However, introducing a hydrophobic benzyl group into the A-ring of EGCG analogs does not significantly affect inhibitory potency [117]. The instability and poor bioavailability of (-)-EGCG in physiological conditions compromise its use as anti-cancer agent, but the peracetylated analogue (Pro-E) (figure 13) is a potential potent prodrug as it is more stable, readily bioavailable and inhibits the growth of several tumor cell lines up to 2 fold than natural (-)-EGCG [118,122,128]. Analogues bearing a paraamino group in the D-ring in place of the hydroxyl group are also more effective inhibitors of proteasome activity and induce apoptosis [125]. Some other natural flavonoids have been examined for their ability to inhibit proteasome and induce apoptosis in human tumor cells. The four most potent compounds are apigenin, quercetin, kaempferol and myricetin (figure 13 ); their $\mathrm{IC}_{50}$ values against the prokaryotic $20 \mathrm{~S}$ proteasome CT-L activity are $1.8,3.5,10.5$ and $10 \mu \mathrm{M}$ [129]. Genistein (figure 13) inhibits rabbit 20S proteasome CT-L activity with an $\mathrm{IC}_{50}$ of $26 \mu \mathrm{M}$ [130]. However no extended SAR studies on these tricyclic molecules have yet been performed.

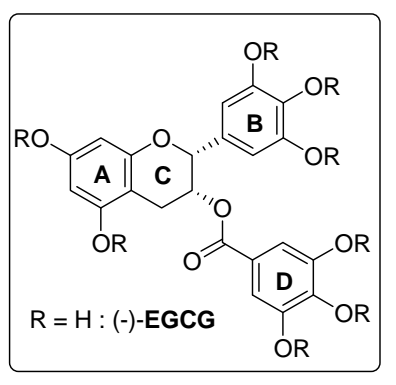

$\mathrm{R}=\mathrm{Ac}:$ Pro-E

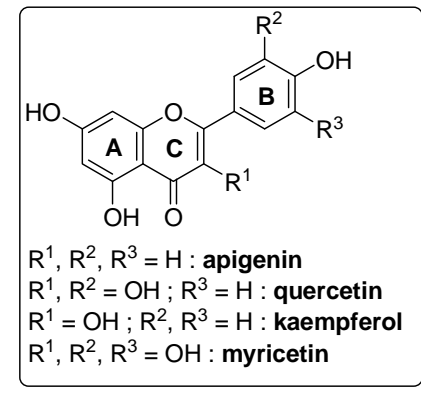

$\mathrm{R}^{1}=\mathrm{OH} ; \mathrm{R}^{2}, \mathrm{R}^{3}=\mathrm{H}$ : kaempfer $\mathrm{R}^{1}, \mathrm{R}^{2}, \mathrm{R}^{3}=\mathrm{OH}:$ myricetin

Fig. (13). Examples of natural and synthetic polyphenols. 


\section{Terpenoids}

There has been growing interest the past few years in the potential of chemopreventive or antitumor natural terpenoids as original proteasome inhibitors. Seven natural ginsenosides isolated from Panax ginseng used in traditional herbal medicine have been screened for their ability to inhibit pig $26 \mathrm{~S}$ proteasome (figure 14) [131]. All these steroid saponins selectively inhibit CT-L activity, but they are not very potent: the $\mathrm{IC}_{50}$ of the best compound, ginsenoside Rd (figure 14), is $107.5 \mu \mathrm{M}$. Combining ginsenosides does not increase their inhibitory potency. Similarly, 10 naturally occurring agosterols, isolated from a marine sponge, were tested. Agosterol C (figure 14) is the most efficient and inhibits CT-L activity of partially purified rat liver proteasome with an $\mathrm{IC}_{50}$ of $19 \mu \mathrm{M}$ [132]. Celastrol [133] and Withaferin $\mathrm{A}$ [134] (figure 14), two natural triterpenes used in traditional medicine, have been found to inhibit rabbit 20S proteasome CT-L activity $\left(\mathrm{IC}_{50}=2.5\right.$ and $4.5 \mu \mathrm{M}$, respectively) and the $26 \mathrm{~S}$ proteasome of human prostate cancer cellular ( $\mathrm{IC}_{50} \approx 2.5$ and $20 \mu \mathrm{M}$, respectively). They also inhibit tumor growth in vivo in xenografts (54 to $93 \%$, daily treatments of $1-3 \mathrm{mg} / \mathrm{kg}$ and 4-8 $\mathrm{mg} / \mathrm{kg}$, respectively) [133], [134]. Computer modelling and SAR studies have shown that the conjugated ketone moiety $\left(\mathrm{C}_{2}\right.$ and $\mathrm{C}_{6}$ in Celasterol and $\mathrm{C}_{1}$ and $\mathrm{C}_{24}$ in Withaferin $\left.\mathrm{A}\right)$ is critical and could react with Thr1-O ${ }^{\gamma}$, suggesting that inhibition is covalent $[133,134]$. Two other natural pentacyclic triterpenes, betulinic acid [135] (activates CT-L activity with an $\mathrm{EC}_{50}$ of $5.5 \mu \mathrm{M}$ ) and glycyrrhetinic acid [136] (selectively inhibits CT-L activity with an $\mathrm{IC}_{50}$ of 22.3 $\mu \mathrm{M}$ ), were identified during a search for proteasome modulators (Fig. 14). The hydroxyl group and the carboxylic acid moiety were further chemically modified. These modifications of the betulinic acid activator resulted in seven analogues that preferentially inhibit CT-L activity at medium/low micromolar concentrations [135]. The best compound 15 (figure 14) inhibits the CT-L $\left(\mathrm{IC}_{50}=6.7 \mu \mathrm{M}\right)$ and $\mathrm{T}-\mathrm{L}\left(\mathrm{IC}_{50}=20.1 \mu \mathrm{M}\right)$ activities of human $20 \mathrm{~S}$ proteasome but not the PA activity [135]. In the same way, modifications of the glycyrrhetinic acid hydroxyl group gave proteasome inhibitors that are 3- to 100-times more potent [136]. Twenty one analogues were synthesized. Five compounds 16a-e (figure 14), which are acylated with aromatic or long chain aliphatic carboxylic diacid, inhibit CT-L activity of human $20 \mathrm{~S}$ proteasome at a submicromolar level $\left(\mathrm{IC}_{50}=0.22-0.87 \mu \mathrm{M}\right)$, but are less potent inhibitors of T-L and PA activities [136]. The most potent compound 16e is also active against MT4 living cells [136].

Flavonoids and terpenoids extracted from abundant natural sources have structural features different from those of other known proteasome inhibitors. Chemical modifications could lead 
to drugs for treating diseases such as cancers and inflammatory diseases. However no crystallographic structures of these molecules in complex with proteasome are yet available and their inhibitory mechanisms and modes of action remain to be clarified.
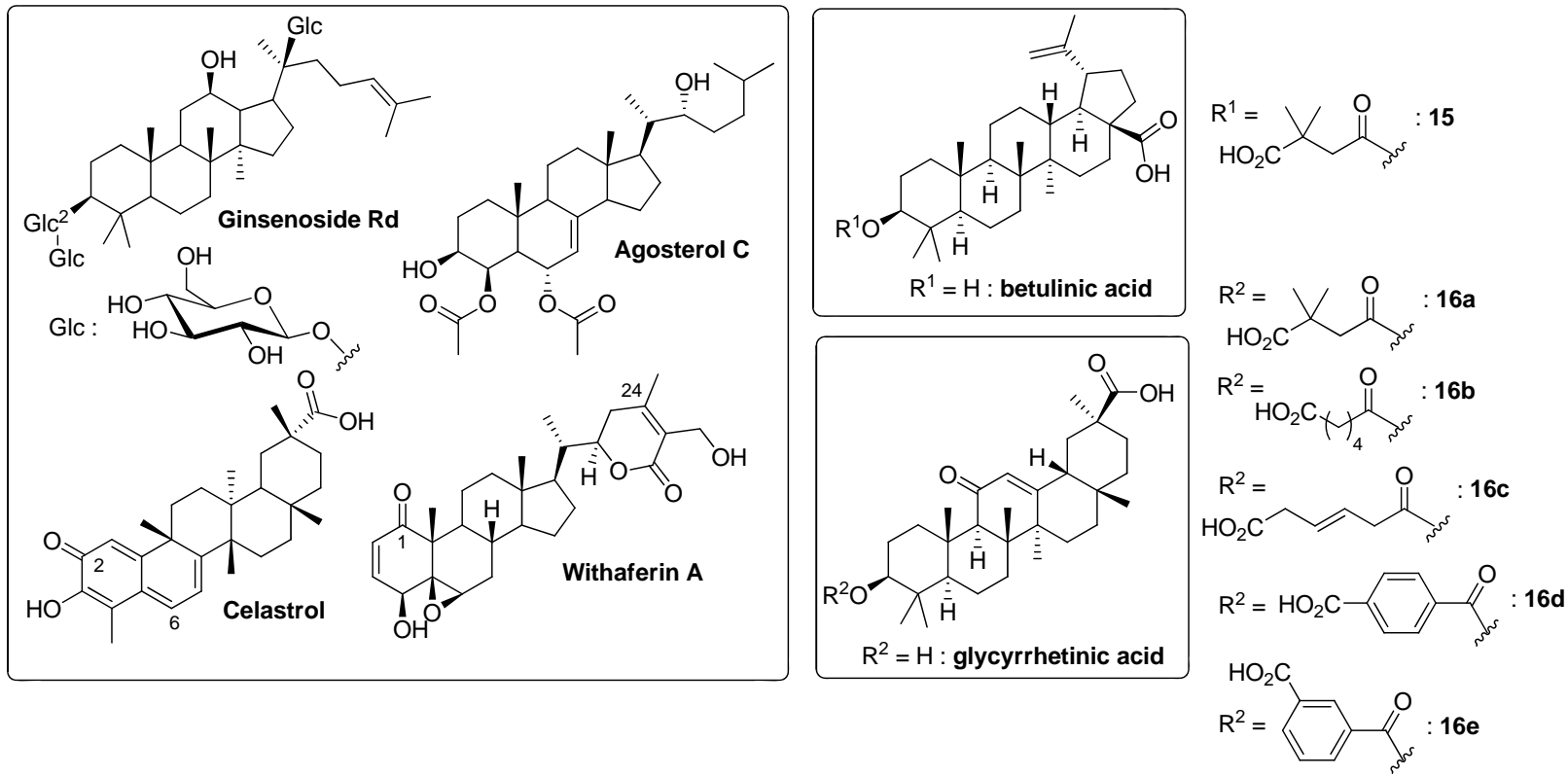

Fig. (14). Examples of natural and synthetic terpenoids.

\section{Peptide vinyl derivatives}

Three classes of vinyl derivatives substituted by electron withdrawing groups (sulfone, ester or amide) are proteasome inhibitors that behave as Michael acceptors of the catalytic Thr1 hydroxyl group.

\section{Peptide vinyl sulfones}

Synthetic peptide vinyl sulfones 17-18 were originally designed to target cysteine proteases [137] but were found to be potent irreversible proteasome inhibitors twelve years ago (figure 15a) $[138,139]$. The cell permeable reference compound at that time was $17 a\left(R^{1}=M e, R^{2}=\right.$ $\mathrm{R}^{3}=\mathrm{R}^{4}=i \mathrm{Bu}, \mathrm{R}^{5}=\mathrm{Z}$ ), also called Z-Leu-Leu-Leu-VS (VS for vinyl sulfone). More than 800 tripeptide or tetrapeptide compounds $\mathbf{1 7}$ or $\mathbf{1 8}$ have been prepared, mainly by combinatorial approaches in order to optimize inhibition of one, two or three activities of $20 \mathrm{~S}$ proteasome by varying the nature of $\mathrm{R}^{1}-\mathrm{R}^{7}$ substituents [138-144]. The selectivity for inhibiting proteasome rather than cysteine proteases like the cathepsins was also optimized to reach at least 4 orders of magnitude. For instance, compound 18a $\left(\mathrm{R}^{1}=\mathrm{Me}, \mathrm{R}^{2}=i \mathrm{Bu}, \mathrm{R}^{3}=\mathrm{Me}, \mathrm{R}^{4}=\left(\mathrm{CH}_{2}\right)_{2} \mathrm{CO}_{2} t \mathrm{Bu}\right.$, $\mathrm{R}^{6}=$ CHEtMe, $\left.\mathrm{R}^{7}=\mathrm{Z}\right)$ is a potent inhibitor of human $20 \mathrm{~S}$ proteasome CT-L activity $\left(\mathrm{IC}_{50}=\right.$ 
$2.5 \mathrm{nM})$, and is a poor inhibitor of cathepsin $\mathrm{B}\left(\mathrm{IC}_{50}=29 \mathrm{mM}\right)$ and cathepsin $\mathrm{S}(36 \mu \mathrm{M})$ [143]. Compound 18b $\left(\mathrm{R}^{1}=\mathrm{Me}, \mathrm{R}^{2}=\mathrm{CH}_{2} \mathrm{CONH}_{2}, \mathrm{R}^{3}=i \mathrm{Bu}, \mathrm{R}^{4}=\left(\mathrm{CH}_{2}\right)_{3} \mathrm{NHC}(\mathrm{NH}) \mathrm{NH}_{2}, \mathrm{R}^{6}\right.$ $=$ side chain of proline, $\mathrm{R}^{7}=\mathrm{Ac}$ ) irreversibly inhibits the T-L activity of the $20 \mathrm{~S}$ proteasome while compound 18c $\left(\mathrm{R}^{1}=\mathrm{Me}, \mathrm{R}^{2}=\mathrm{CH}_{2} \mathrm{CONH}_{2}, \mathrm{R}^{3}=i \mathrm{Bu}, \mathrm{R}^{4}=i \mathrm{Bu}, \mathrm{R}^{6}=\mathrm{CH}_{2} \mathrm{C}_{6} \mathrm{H}_{4} \mathrm{OH}, \mathrm{R}^{7}\right.$ $=$ Ac) blocks all proteasome active sites [140]. The crystal structures of compounds 18b and 18c in complex with yeast proteasome show that the covalent adduct 19 with proteasome $\mathrm{N}$ terminal threonines is formed. The inhibitor part of the adduct has similar conformations within the three S1 pockets (figure 15b) [8]. Their selectivity is due to favourable interactions of the $\mathrm{R}^{4}$ residue with the $\mathrm{S} 3$ pockets of the three types of active sites [8]. A number of compounds 18 compounds inhibit the growth of the human prostate cancer cell line PC3 at submicromolar concentrations [143]. The main advantage of using peptide vinyl sulfones is that radioactive [138,141], affinity [138,141,145,146] or fluorescent [147-149] probes can be attached to their $N$-terminus (figure 15c). Figure 15c shows representative labelled vinyl sulfone peptides 20, 21 and 22. Their efficient covalent bonding allows the labelling and visualization of the targeted $\beta 1, \beta 2$ or $\beta 5$ proteasome subunits. Their many applications include clinical profiling of proteasome activity, analysis of the subunit specificity of inhibitors, and analysis of proteasome function and dynamics in living cells $[29,148,150]$.
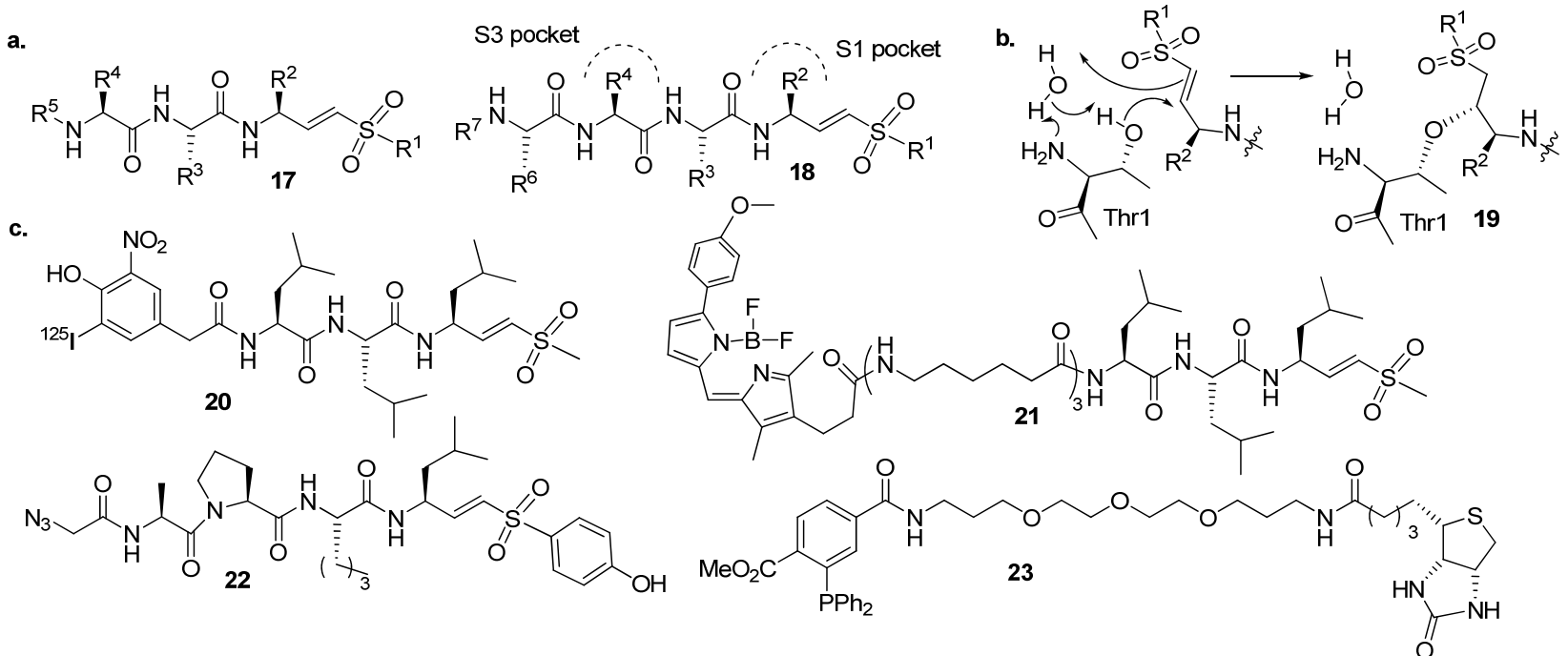

Fig. (15). Structures of peptide vinyl sulfones 17-18 (a). Mechanism of their binding to the catalytic threonine and formula of the irreversible adduct 19 identified by $X$-Ray crystallography (b). Proteasome inhibitors 20-22 used to label proteasome active sites and derivative 23 used for Staudinger ligation (c). 
Compound 20 is a radio label for the $\beta 5$ subunit [138]. The highly fluorescent compound 21 reacts with the proteasome terminal threonine. It can be used to rapidly and sensitively detect active proteasome subunits by in-gel detection and fluorescent microscopy in living cells [147]. Compound 22 binds irreversibly to terminal threonine of PA active site. Staudinger ligation with 23 followed by SDS-PAGE and Western blotting enables direct visualization of proteasome $\beta 1$ and $\beta$ 1i subunit $[145,146]$.

\section{Peptide vinyl esters}

The vinyl ester moiety, which is an excellent Michael acceptor has been introduced at the $C$ terminal end of peptides. About 70 compounds 24 with various structures at $\mathrm{R}^{1}, \mathrm{R}^{2}$ and $\mathrm{R}^{3}$ have been prepared and assayed for their capacity to inhibit human (lymphoblastoid cell lines) 20S proteasome (figure 16) [151-154]. These compounds are potent, selective inhibitors of the T-L activity $\left(\mathrm{IC}_{50}=0.02-0.04 \mu \mathrm{M}\right.$ for $\left.24 \mathrm{a}-\mathbf{d}\right)$ : CT-L activity is more weakly inhibited $\left(\mathrm{IC}_{50}=2-10 \mu \mathrm{M}\right.$ for $\left.\mathbf{2 4 a - d}\right)$ and PA activity not inhibited. No structural data are yet available on the way compounds $\mathbf{2 4}$ bind to proteasome. Enzymatic assays carried out with 24a and 24b indicate that inhibition is irreversible, suggesting that the conjugate double bond is susceptible to Michael addition of the catalytic Thr1- $\mathrm{O}^{\gamma}$ in T-L site [151]. They are strickingly different from the analogous Z-Leu-Leu-Leu-VS: Z-Leu-Leu-Leu-VS selectively inhibits CT$\mathrm{L}$ activity (under the same conditions as for $24 \mathrm{a}, \mathrm{IC}_{50}=0.061 \mu \mathrm{M}$ for CT-L activity and $\mathrm{IC}_{50}$ $=2.43 \mu \mathrm{M}$ for T-L activity) [153]. Compounds 24c-d can enter cell and inhibit the T-L activity of proteasome in cells $\left(\mathrm{IC}_{50}=0.05-0.2 \mu \mathrm{M}\right)$. [154] These vinyl ester derivatives 24 are quite stable in culture medium $\left(\mathrm{t}_{1 / 2}>200 \mathrm{~min}\right)$ and do not significantly inhibit other proteases $\left(\mathrm{IC}_{50}>10 \mu \mathrm{M}\right)$ [152]. Compounds 24a-b do not affect cell proliferation and modulate the generation and presentation of immunogenic peptides presented by MHC class I molecules [151].

Constrained pseudopeptide vinyl esters at the $C$-terminal end 25 and $\mathbf{2 6}$ have also been prepared (figure 16) [155]. The dehydrophenylalanine derivative 25a inhibits TL and CT-L activities of human $20 \mathrm{~S}$ proteasome to the same degree ( $\mathrm{IC}_{50}$ sof 1.3 and $0.9 \mu \mathrm{M}$ ), while $25 \mathbf{b}$ selectively inhibits the T-L activity $\left(\mathrm{IC}_{50}=0.08 \mu \mathrm{M}\right)$. The tetrahydroisoquinoline derivatives 26 inhibit the PA activity of human $20 \mathrm{~S}$ proteasome $\left(\mathrm{IC}_{50}=0.9 \mu \mathrm{M}\right.$ for $\left.\mathrm{R}^{1}=\mathrm{R}^{2}=\mathrm{R}^{3}=i \mathrm{Bu}\right)$.

Molecular modelling of cyclic analogues of vinyl ester derivatives that can adopt a $\beta$-sheet secondary structure led to the synthesis and evaluation of vinyl ester-based cyclopeptides 27 (figure 16) [156,157]. Compounds 27 potently and selectively inhibit the CT-L activity of the 
human 20S proteasome $\left(\mathrm{IC}_{50}=0.04 \mu \mathrm{M}\right.$ for 27a) [156] or PA activity $\left(\mathrm{IC}_{50}=0.07 \mu \mathrm{M}\right.$ for 27b), depending on their structure [157]. Simulation of the interaction of derivative 27a with the CT-L active site of the yeast 20S proteasome suggests that the vinyl ester reacts with the proteasome catalytic threonine [156]. Compounds 27 are also resistant to proteolysis and can permeate cell membranes [156,157].

A total of 30 peptidyl vinyl esters 28 bearing different $\mathrm{R}^{1}$ substitutents were designed using computer-aided drug design protocols and prepared (figure 16) [158]. The best of them weakly inhibits the proteasome CT-L activity $\left(\mathrm{IC}_{50}=48 \mu \mathrm{M}, \mathrm{R}^{1}=(3 S)-2-\right.$ oxo-3pyrrolidinylmethyl) and has weak antiproliferative activity.

A vinyl ester tripeptide has been recently incorporated at the $C$-end of a gene delivery peptide [159]. The resulting peptide forms DNA condensates that enhance gene expression 100-fold compared to a control peptide lacking the inhibitor. It is also not toxic to cells in culture. Intrinsic proteasome inhibition may also be used to boost the efficiency of peptide-mediated non viral gene delivery.

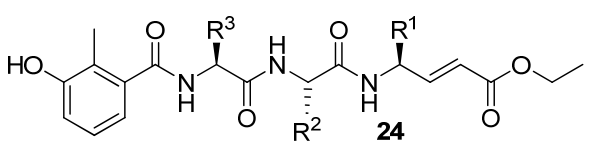

24a: $\mathrm{R}^{1}=\mathrm{R}^{2}=\mathrm{R}^{3}=i \mathrm{Bu}$

24b: $\mathrm{R}^{1}=i \mathrm{Bu}, \mathrm{R}^{2}=\mathrm{CH}_{2} \mathrm{OH}, \mathrm{R}^{3}=i \mathrm{Pr}$

24c: $\mathrm{R}^{1}=i \mathrm{Bu} \mathrm{R}^{2}=\left(\mathrm{CH}_{2}\right)_{2} \mathrm{CONH}_{2}, \mathrm{R}^{3}=i \mathrm{Pr}$

24d: $\mathrm{R}^{1}=i \mathrm{Bu} ; \mathrm{R}^{2}=\left(\mathrm{CH}_{2}\right)_{2} \mathrm{CONH}_{2}, \mathrm{R}^{3}=\mathrm{CH}_{2} \mathrm{Ph}$

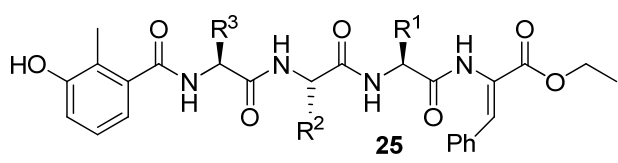

25a: $\mathrm{R}^{1}=\mathrm{R}^{2}=\mathrm{R}^{3}=i \mathrm{Bu}$

25b: $\mathrm{R}^{1}=i \mathrm{Bu}, \mathrm{R}^{2}=\mathrm{CH}_{2} \mathrm{OH}, \mathrm{R}^{3}=i \mathrm{Pr}$

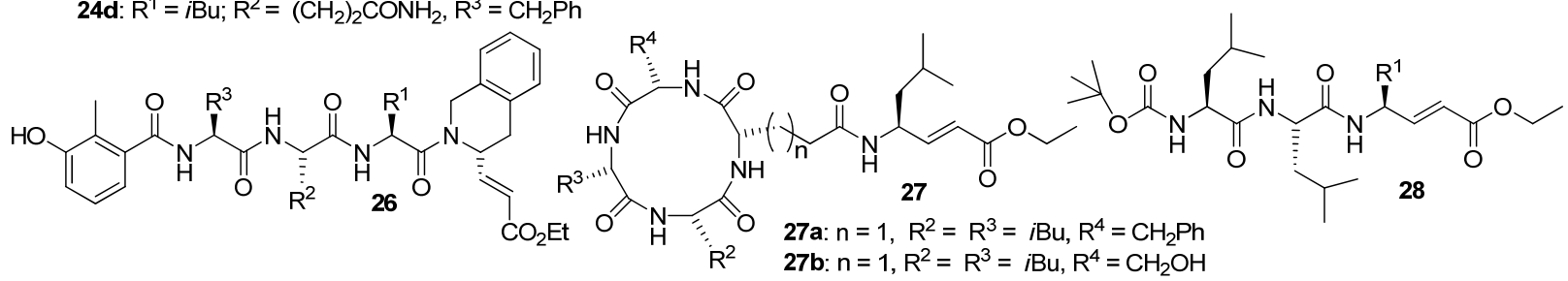

Fig. (16). Structures of peptide vinyl esters derivatives 24-28.

\section{Syrbactins}

The class of syrbactins refers to potent natural proteasome inhibitors that share biosynthetic pathways by related gene clusters. These 12-membered macrocyclic lactams contain an $\alpha, \beta-$ unsaturated carboxamide function and are linked to a pseudopeptidic side chain (figure 17) $[160,161]$. Syringolins $[162,163]$ and glidobactins $[164,165]$ are natural products that belong to this class. Syringolin A is produced by strains of the plant pathogen Pseudomonas syringae pv. Syringae. It has been recently identified as a virulent factor that facilitates infection by inhibiting the plant cell proteasome (figure 17) [160]. In vitro biochemical assays show that it irreversibly inhibited all three catalytic activities of human erythrocyte $20 \mathrm{~S}$ proteasome. It 
inhibits CT-L $\left(\mathrm{K}_{\mathrm{i}}^{\prime}=0.85 \mu \mathrm{M}\right)$ and $\mathrm{T}-\mathrm{L}\left(\mathrm{K}_{\mathrm{i}}^{\prime}=6.7 \mu \mathrm{M}\right)$ activities best. Crystallographic analysis of syringolin A in complex with yeast proteasome indicates that syringolin A binds covalently to the catalytic threonine of the three active sites to form the adduct $\mathbf{2 9}$, resulting in a Michael addition of the Thr1 hydroxyl group to the $\alpha, \beta$-unsaturated carboxamide function activated by Gly 47 (figure 17) [160]. Syringolin A also inhibits proteasome function in vivo (in Arabidopsis seedlings and human cultured cells) [160] and has antiproliferative and proapoptotic effects on ovarian and neuroblastoma cancer cells [166]. Syringolin A methyl ester has been prepared; it inhibits human $20 \mathrm{~S}$ proteasome in a way similar to syringolin $\mathrm{A}$, as might be expected from their X-ray structures [161]. Syringolin B inhibits human 20S proteasome, but it is at least 10-times less potent than syringolin A (figure 17).

Glidobactins A-F have been isolated from several bacteria. They have a broad spectrum of antifungal activities. They are cytotoxic to tumor cell lines and prolong the life span of mice inoculated with P388 leukemia cells [164,167]. Glidobactin A (figure 17) irreversibly inhibits the CT-L and T-L activities of the human 20S proteasome, with respective $\mathrm{K}_{\mathrm{i}}^{\prime}$ values of 0.05 $\mu \mathrm{M}$ and $2 \mu \mathrm{M}$ but does not inhibit PA activity at $20 \mu \mathrm{M}$ [160]. Studies on the crystal structure of glidobactin A in complex with the yeast proteasome reveal that it inactivates the CT-L and T-L activities in the same way as syringolin A [160]. Analysis of the binding modes of syringolin A, syringolin B and glidobactin A led to the design and synthesis of analogue $\mathbf{3 0}$, which contains the more constrained and favorable di-unsaturated macrocycle as well as a lipophilic side chain (figure 17). Analogue 30 is a very potent proteasome inhibitor, with $\mathrm{K}_{\mathrm{i}}^{\prime}$ values of $8 \mathrm{nM}$ for CT-L, $80 \mathrm{nM}$ for T-L and $900 \mathrm{nM}$ for PA activities [161].

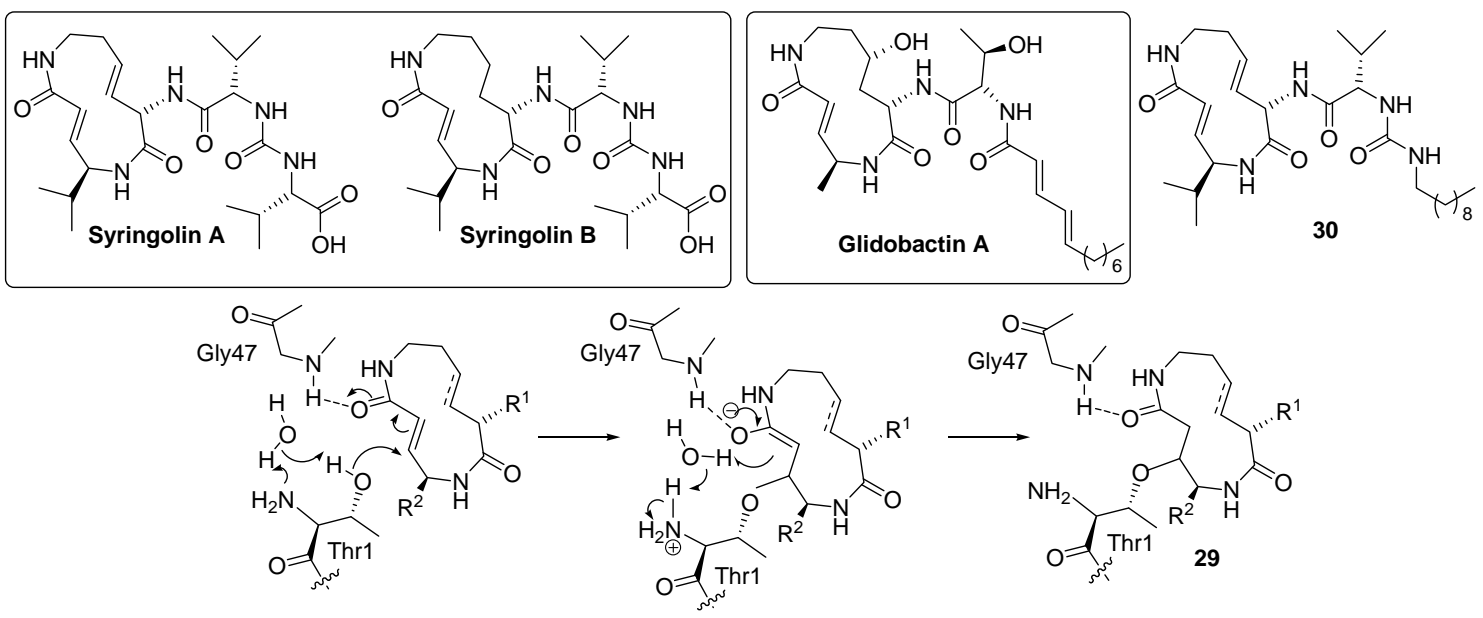


Fig. (17). Structures of syrbactins and their synthetic derivative 30. Mechanism of action of syrbactins with the catalytic threonine and formula of the irreversible adduct 29 identified by X-Ray crystallography. Doted lines indicate hydrogen bond.

\section{Other peptides or pseudopeptides bearing an electrophilic warhead}

Other electrophilic warheads have been introduced at the $C$-terminus of peptides or pseudopeptides in order to target the nucleophilic Thr1- $\mathrm{O}^{\gamma}$. Early studies using $\alpha$-keto aldehyde [168] or $\alpha$-keto amide functions [169] have been reviewed previously [23,25]. The carboxyl function at the $C$-terminus end of tripeptides based on the Leu-Asp-Leu or Leu-LeuLeu sequences has been replaced by hydroxymetyl, carboxaldehyde, dichlorovinyl or $\alpha$ ketoamide substituents [170]. The 22 prepared compounds include selective inhibitors of one or two proteasomal activities. The most efficient derivatives 31 (figure 18) inhibit the human $20 \mathrm{~S}$ proteasome $\mathrm{CT}-\mathrm{L}$ activity $\left(\mathrm{IC}_{50}=0.07\right.$ to $\left.1 \mu \mathrm{M}\right)$, are cell permeable and induce accumulation of polyubiquitinated proteins and apoptosis of HeLa cells [170].

Electrophilic bromomethylene or boronic acid functional groups have been inserted into peptidomimetics 32 in order to obtain better physiological stability (figure 18) [171]. Although these compounds inhibit the growth of cancer cells $\left(\mathrm{IC}_{50}=0.6-80 \mu \mathrm{M}\right)$, they are not good inhibitors of 20S proteasome CT-L activity $\left(\mathrm{IC}_{50}>50 \mu \mathrm{M}\right)$.

Compounds 33 [143] and 34 [172] (figure 18) contain the $\alpha$-keto heterocycle functionality, which is often used in used in active-site-directed inhibitors of diverse serine and cysteine proteases [173]. The $\alpha$-keto 1,3,4-oxadiazole derivative 33 is a reversible, very potent, selective inhibitor of human 20S proteasome CT-L activity $\left(\mathrm{K}_{\mathrm{i}}=0,0007 \mu \mathrm{M}\right.$, about 1000 -fold lower than that for cathepsin inhibition). It inhibits the growth of the human prostate cancer PC3 cells at submicromolar concentrations [143]. The $\alpha$-keto furane derivative 34 is far less active $\left(\mathrm{IC}_{50}=7.8 \mu \mathrm{M}\right)$ against CT-L activity of 20S proteasome [172].

Semicarbazones 35 (figure 18), which are stable derivatives of aldehydes that contain the electrophilic $\mathrm{C}=\mathrm{N}-\mathrm{N}-\mathrm{CO}-\mathrm{N}$ motif, are selective, efficient inhibitors of $20 \mathrm{~S}$ proteasome $\mathrm{CT}-\mathrm{L}$ activity $\left(\mathrm{IC}_{50}=0.1-1.6 \mu \mathrm{M}\right)$. They are more potent $(\approx 20$-fold $)$ than the corresponding aldehydes [174]. Nanomolar concentrations of compound $35\left(\mathrm{R}^{1}=\mathrm{CH}_{2} \mathrm{Ph}, \mathrm{R}^{2}=\mathrm{R}^{3}=\right.$ $\mathrm{CH}_{2}$ indole, $\mathrm{R}^{4}=\mathrm{OCH}_{2} \mathrm{Ph}$ ) block the activation of $\mathrm{NF} \kappa \mathrm{B}$ and induce apoptosis in myeloma cell lines and purified primary patient cells [175]. Preliminary in vivo studies provided the rationale for a preclinical evaluation of $\mathbf{3 5}$ against myeloma [175]. 


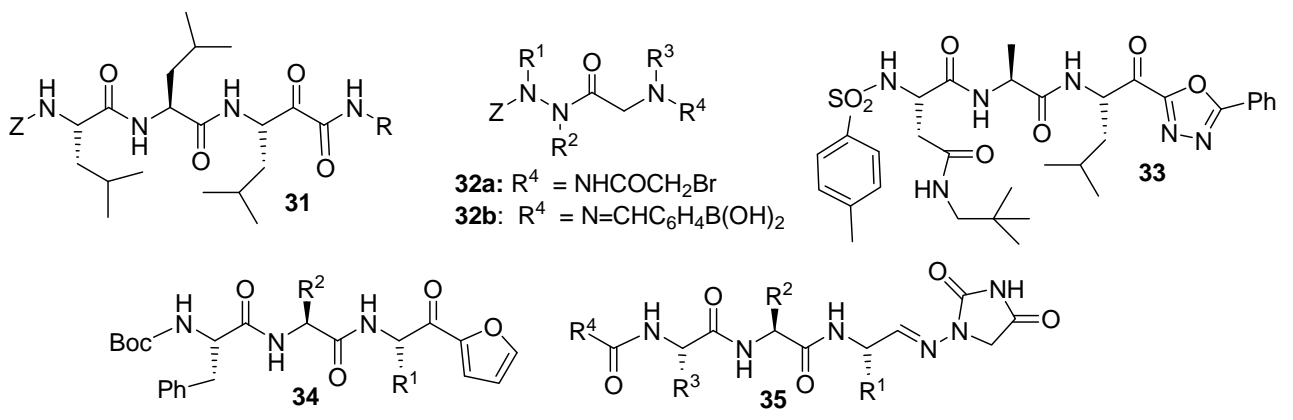

Fig (18). Structures of peptides or pseudopeptides bearing an electrophilic warhead.

\section{NON-COVALENT INHIBITORS}

Non-covalent inhibitors have been investigated less extensively, but they could be of therapeutic interest as they probably have fewer side-effects. They do not have a reactive group, which is often associated with instability, poor specificity, and excessive reactivity [176]. They interact with the proteasome active sites via weak bonds (hydrogen, hydrophobic, electrostatic and/or van der Waals).

\section{Ritonavir, aminobenzylstatin derivatives and analogues}

Clinical observations of HIV-1-infected patients treated by the antiprotease Ritonavir suggest that this compound inhibits the presentation of epitopes by class I MHC (figure 19) [177]. This may due to Ritonavir inhibiting the proteasome CT-L activity by. This transition-state analog of HIV-1 protease contains a benzylstatin moiety $\left(-\mathrm{C}_{\alpha} \mathrm{R}_{\mathrm{i}}-\mathrm{CH}\left(\mathrm{CH}_{2}-\mathrm{C}_{6} \mathrm{H}_{5}\right)-\mathrm{CH}_{2}-\right.$ $\left.\mathrm{CH}(\mathrm{OH})-\mathrm{C}_{\alpha} \mathrm{R}_{\mathrm{i}+1}\right)$ [178]. Ritonavir has cytostatic and cytotoxic effects on glioma cells, but they can develop resistance in vitro [179]. In contrast, it does not control tumor growth in vivo, probably because the therapeutic dose was not reached in the tumor [179].

High-throuput screening by Novartis Pharma AG showed that the synthetic 2aminobenzylstatin derivative 36 that was originally designed to target the HIV-1 protease inhibits proteasome (figure 19) $[21,25,176,180-182]$. This lead compound is a non-covalent proteasome inhibitor [180]. It inhibits the CT-L activity of the human $20 \mathrm{~S}$ proteasome $\left(\mathrm{IC}_{50}=\right.$ $0.9 \mu \mathrm{M})$ much better than the T-L and PA activities $\left(\mathrm{IC}_{50}>20 \mu \mathrm{M}\right)$. It has been optimized using modelling of the interactions of compounds 37 with the proteasome CT-L active site based on X-ray structures of the HIV protease / derivative $\mathbf{3 6}$ and the yeast proteasome / ALLN complexes [181]. Its postulated mode of binding is illustrated in figure 19. A library of 30 compounds 37 was prepared using modular synthetic chemistry (figure 19) [180,182]. The inhibitory activity of the initial hit 36 was improved 100 -fold: compound $37 a\left(\mathrm{R}^{1}=1\right.$ $\mathrm{CH}_{2}$ naphtyl, $\mathrm{R}^{2}=t \mathrm{Bu}, \mathrm{R}^{3}=3,4,5$-triOMe, $\left.\mathrm{R}^{4}=\mathrm{OH}, \mathrm{R}^{5}=\mathrm{OMe}\right)$ potently inhibits CT-L 
activity of human $20 \mathrm{~S}$ proteasome $\left(\mathrm{IC}_{50}=7 \mathrm{nM}\right)$, and also proliferation of MDA-MB-435 cells $\left(\mathrm{IC}_{50}=1.5 \mu \mathrm{M}\right)[182]$. The SAR generated during the optimization of 37a were exploited to design the scaffold of compound $\mathbf{3 8}$ so as to improve cellular activity (figure 19) [176]. The main hypothesis was that the two amide bonds of the tert-leucine residue and the statin 4-benzyl group did not interact with the enzyme. In compound 38, the statin moiety of molecule 37a is replaced by a 3,4,5-trimethoxyphenylalanine residue which interacts with the $\mathrm{S} 3$ pocket; the $N$-terminal part is mimicked by a single phenoxy-substituted benzylic group that interacts with the accessory subsites AS1 and AS2. Compound $\mathbf{3 8}$ is a potent noncovalent inhibitor of human $20 \mathrm{~S}$ proteasome CT-L activity $\left(\mathrm{IC}_{50}=15 \mathrm{nM}\right)$; it is also more active than 37a in cellular settings, since its efficiently blocks proteasome activity in cultured cells $\left(\mathrm{IC}_{50}=20 \mathrm{nM}\right)$ and the proliferation of MDA-MB-435 cells $\left(\mathrm{IC}_{50}=60 \mathrm{nM}\right)$.

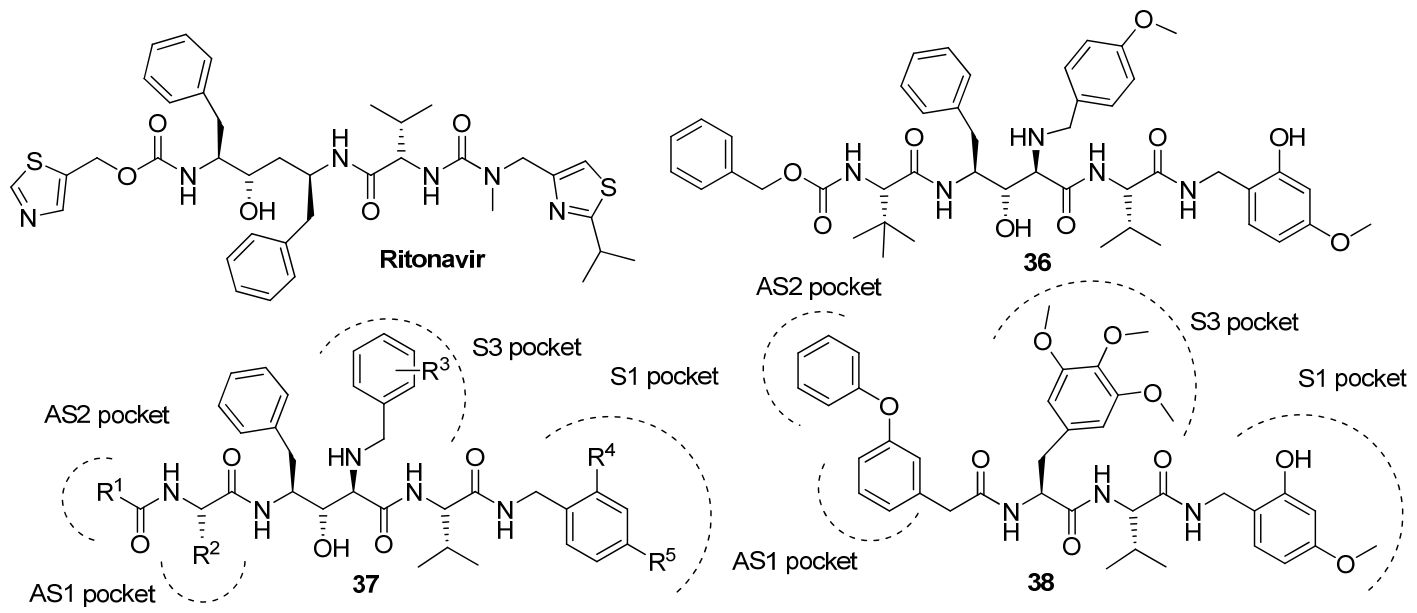

Fig. (19). Structures of Ritonavir and aminobenzylstatin derivatives 36-38. The model of interactions with S1 and S3 CT-L subsites and accessory subsites AS1 and AS2 used to guide the medicinal chemistry optimization is shown.

\section{TMC-95 and derivatives}

Researchers at Tanabe Seiyaku Co Ltd discovered compounds TMC-95A, B, C, and D during the screening of a fermentation broth of Apiospora montagnei Sacc. TC 1093 (isolated from a soil sample) for proteasome inhibitors (figure 20) $[183,184]$. These 4 natural diastereomers have a unique cyclic tripeptidic structure containing L-tyrosine, L-asparagine, highly oxidized L-tryptophane, a biaryl linkage between the aromatic side chains and unusual $N$ - and $C$ terminal groups. TMC-95A is the most abundant stereoisomer that is also the most active [184]. It potently inhibits the CT-L $\left(\mathrm{IC}_{50}=5.4 \mathrm{nM}\right), \mathrm{T}-\mathrm{L}\left(\mathrm{IC}_{50}=200 \mathrm{nM}\right)$ and PA $\left(\mathrm{IC}_{50}=60\right.$ $\mathrm{nM}$ ) activities of human 20S proteasome [184]. TMC-95B inhibits the human proteasome to a similar extent, indicating that the stereogenic center of the $\mathrm{N}$-terminal side chain is not 
important. However, the $\beta$-carbon stereochemistry of the oxidized Trp residue is essential, since TMC95 C and D are 50-times less active than TMC-95A [184]. TMC-95A inhibits the CT-L activity of 20S proteasomes from other species (bovine [185] and yeast [186]) with practically identical potency. However, TMC-95A is a more potent inhibitor of the T-L activity in yeast proteasome than of the T-L activity of human or bovine proteasomes; it inhibits the PA activies in the reverse order.

The crystal structure of TMC-95A in complex with yeast 20S proteasome shows that TMC$95 \mathrm{~A}$ is linked to the three proteolytically active $\beta$-subunits through a tight network of hydrogen bonds without any chemical modification of the $N$-terminal threonines (figure 20) $[4,187]$. These non covalent interactions lead to the formation of an antiparallel $\beta$ sheet between TMC-95A and the amino acid residues of the S1 and S3 binding pockets. An additional hydrogen bond involves the oxygen of the oxindole group. The $C$-terminal $(Z)$ propenyl moiety acts as the $\mathrm{P} 1$ and the asparagine as the $\mathrm{P} 3$ residues. The crystal structure adequately explains relative activities of TMC-95A, B, C and D: the tyrosine residue interacts weakly with the hydrophobic S4 subsite, the $N$-terminal 3-methyl-2-oxopentanoyl group does not seem to contribute to the stabilisation of the complex, and the $\mathrm{R}^{1}$ stereochemistry of the hydroxyl group in TMC-95C and D would cause a steric clash with residue 21.

The selectivity of TMC-95A inhibition is very good: $30 \mu \mathrm{M}$ TMC-95A does not inhibit $m$ calpain, cathepsin L and trypsin [184]. TMC-95A is also cytotoxic against HCT-116 human colon carcinoma cells $\left(\mathrm{IC}_{50}=4.4 \mu \mathrm{M}\right)$ and HL-60 human promyelocytic leukemia cells $\left(\mathrm{IC}_{50}\right.$ $=9.8 \mu \mathrm{M})$ [184]. Lastly, TMC-95A (1 to $20 \mu \mathrm{M})$ induces neurite outgrowth from PC12 cells [188].

Synthetic organic chemists have shown considerable interest in TMC-95A because of its unusual chemical structure, its potency and its unique inhibition mechanism [189]. Several total syntheses have been achieved, but they have not provided sufficient material for broad biological evaluation [190-192]. Simpler and more accessible TMC-95 macrocyclic analogues 39-42 have been synthesized in order to explore their SAR (figure 20) [185,186,193-199]. $\mathrm{X}$-ray structural analysis of TMC-95A in complex with the yeast proteasome led to the design of the 39 molecules, which contain the important TMC-95A structural elements implicated in binding [186,193,194]. Compound 39a $\left(\mathrm{R}^{6}=\mathrm{CH}_{2} \mathrm{CONH}_{2}, \mathrm{R}^{5}=\mathrm{NH} n\right.$-propyl) inhibits all three activities of yeast proteasome. Compound 39a has almost capacity to inhibit T-L activity as TMC-95A, but is significantly less potent against the CT-L activity (100-fold lower), suggesting that the propyl chain does not interact with the subsite $\mathrm{S} 1$ as well as the Z- 
propenamide chain [186,193]. Compounds 39b $\left(\mathrm{R}^{6}=\mathrm{CH}_{2} \mathrm{CHMe}_{2}, \mathrm{R}^{5}=\mathrm{Nle}-\psi\left(\mathrm{COCH}_{2}\right)-\mathrm{Gly}-\right.$ Ala-Ala- $\left.\mathrm{NH}_{2}\right)$ [194] and 39c $\left(\mathrm{R}^{6}=\mathrm{CH}_{2} \mathrm{CHMe}_{2}, \mathrm{R}^{5}=\mathrm{NleNH}_{2}\right)$ [186] were designed to increase selectivity for the CT-L active site of the yeast proteasome, but they were found to be slightly less inhibitory than 39a. Both were weaker inhibitors of the yeast proteasome T-L and PA activities than 39a. The $C$-terminal amide in 39c was also hydrolyzed. Analysis of crystal structures of derivatives 39a or 39c in complex with the yeast 20S proteasome showed noncovalent binding and that the rigidity of the macrocyclic core, although favouring the $\beta$-type backbone conformation, severely limits the choice of groups acting as P1 residues $[4,186]$. This information led to the design of molecules $\mathbf{4 0}$, which have a conformationally less restricted biaryl ether macrocycle (figure 20) [4,27,195,196]. Five compounds 40a-e were studied. Kinetic measurements with compound 40a showed that it inhibits yeast proteasome CT-L $\left(\mathrm{K}_{\mathrm{i}}=5.5 \mu \mathrm{M}\right)$ and T-L $\left(\mathrm{K}_{\mathrm{i}}=74 \mu \mathrm{M}\right)$ activities to a similar degree (two fold lower $\left.\mathrm{K}_{\mathrm{i}}\right)$ as 39a. Compound 40b is a weak inhibitor of only CT-L activity $\left(K_{i}=65 \mu \mathrm{M}\right)$ [195]. The X-ray structures of yeast proteasome in complex with derivatives 40a or 40c indicate a non-covalent binding, but only to the T-L active site. Compounds $40 \mathrm{~d}$ and $40 \mathrm{e}$ with arginine residues were prepared because the S1 pocket of T-L active site accommodates basic residues particularly well. The crystallographic data for derivatives 40d or 40e in complex with yeast proteasome show that a covalent acyl-ester bond is formed with the active site Thr1- ${ }^{\gamma}$ and the $C$-terminal arginine carbonyl group, corresponding to the first step in catalytic amide hydrolysis. Mass spectrometry analysis of the medium after incubation of yeast proteasome with compound 40d showed that the $C$-terminal amide was hydrolysed within 2 hours [196]. Groll and Borissenko have analyzed the limitations of applying crystallographic data to the design of proteasome inhibitors [4].

Ten simpler, more accessible analogues $\mathbf{4 1}$ were designed and prepared by modifying the protocol used in the total synthesis of TMC-95A (figure 20) [185,197]. Replacing the $Z$-propenamide group that interacts with the subsite S1 by the allylamide group resulted in derivative 41a which is closely related to TMC-95A or B but is considerably more accessible. It is fully able to inhibit bovine $20 \mathrm{~S}$ proteasome and is only slightly less potent than the natural products $\left(\sim 3\right.$-fold lower $\mathrm{K}_{\mathrm{i}}$ for CT-L, $\sim 10$-fold lower $\mathrm{K}_{\mathrm{i}}$ for T-L, $\sim 5$-fold lower $\mathrm{K}_{\mathrm{i}}$ for PA). The propyl derivative $\mathbf{4 1 b}$ is less potent (10 to 20 -fold lower $\mathrm{K}_{\mathrm{i}}$ ). The source of stereogenicity in $N$-terminal ketoamide $\left(\mathrm{R}^{7}=(R)\right.$ or $(S)$-COCHMeEt) could be eliminated, since 41c and 41d have almost the same activities as the natural products. The lack of the 
amide group in $\mathrm{R}^{5}\left(\mathrm{R}^{5}=\mathrm{CH}_{2} \mathrm{OH}\right)$ results in analogues that are 1000 -fold less active than the natural products.

Molecules 42 containing the macrocyclic skeleton of TMC-95 were prepared soon after the first total syntheses of TMC-95A. In these, the complex oxindole was replaced by a simple indole $\left(\mathrm{R}^{6}=\mathrm{Me}, \mathrm{iBu}, \mathrm{CH}_{2} \mathrm{CONH}_{2}\right)$ (figure 20) [198]. They proved to be poor inhibitors of the rabbit 20S proteasome [199]. Then linear analogues $\mathbf{4 3}$ and $\mathbf{4 4}$ based on the tripeptide sequence Y-N-W of TMC-95 were prepared in order to determine how the catalytic activities of the $20 \mathrm{~S}$ proteasome are influenced by elements derived from TMC-95 (figure 20). Compounds 43 containing the phenyl indole link but not the peptide sequence did not inhibit rabbit 20S proteasome. However, the linear peptide compounds 44, which are readily prepared, can be optimized to inhibit one, two or all three proteasome activities, mostly by varying the $\mathrm{R}^{6}$ side chain and $C$-terminal $\mathrm{R}^{5}$ group [199]. For instance, compound 44a only inhibited CT-L activity $\left(\mathrm{K}_{\mathrm{i}}=0.48 \mu \mathrm{M}\right)$, while compounds $44 \mathrm{~b}$ and $44 \mathrm{c}$ inhibit both CT-L and T-L activities, and compound 44d inhibits CT-L and PA activities. The CT-L, PA and T-L activities are all inhibited by compounds $44 \mathbf{e}$ or $\mathbf{4 4 f}$ and the inhibition constants are submicromolar, despite the absence of the entropically favourable constrained macrocycle. These readily synthesized linear analogues are reasonably stable in culture medium [199]. The most potent in vitro inhibitors were tested on cancer cells and their cytotoxic effect increased in the order $\mathbf{4 4 c}<\mathbf{4 4 b}<\mathbf{4 4 e}<\mathbf{4 4 d}$. Compound $\mathbf{4 4 d}$ has an $\mathrm{IC}_{50}$ of $15 \mu \mathrm{M}$ on HeLa cells, close to that of TMC-95A for human tumor cell lines [199]. 

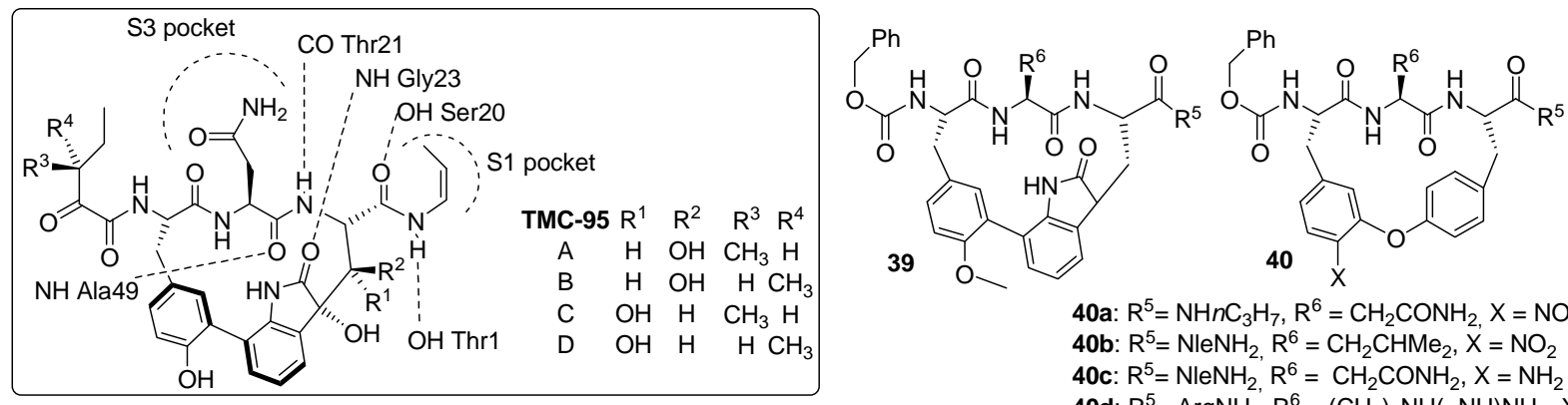

40a: $\mathrm{R}^{5}=\mathrm{NH} n \mathrm{C}_{3} \mathrm{H}_{7}, \mathrm{R}^{6}=\mathrm{CH}_{2} \mathrm{CONH}_{2}, \mathrm{X}=\mathrm{NO}_{2}$ 40b: $R^{5}=\mathrm{NleNH}_{2}, \mathrm{R}^{6}=\mathrm{CH}_{2} \mathrm{CHMe}_{2}, \mathrm{X}=\mathrm{NO}_{2}$ 40c: $R^{5}=\mathrm{NleNH}_{2}, \mathrm{R}^{6}=\mathrm{CH}_{2} \mathrm{CONH}_{2}, X=\mathrm{NH}_{2}$ 40d: $R^{5}=\operatorname{ArgNH}_{2}, R^{6}=\left(\mathrm{CH}_{2}\right)_{3} \mathrm{NH}(=\mathrm{NH}) \mathrm{NH}_{2}, X=\mathrm{NO}_{2}$ 40e: $R^{5}=\operatorname{ArgNH}_{2}, R^{6}=\left(\mathrm{CH}_{2}\right)_{3} \mathrm{NH}(=\mathrm{NH}) \mathrm{NH}_{2}, X=\mathrm{NH}_{2}$
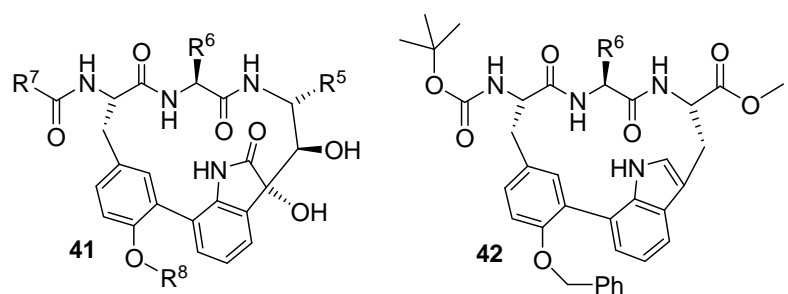

41a: $\mathrm{R}^{5}=$ CONHallyl, $\mathrm{R}^{6}=\mathrm{CH}_{2} \mathrm{CONH}_{2}$, $\mathrm{R}^{7}=(R)$ or $(\mathrm{S}) \mathrm{COCHMe} \mathrm{Et,} \mathrm{R}^{8}=\mathrm{H}$

41b: $\mathrm{R}^{5}=\mathrm{CONHpropyl,} \mathrm{R}^{6}=\mathrm{CH}_{2} \mathrm{CONH}_{2}$,

$\mathrm{R}^{7}=(R)$ or $(\mathrm{S}) \mathrm{COCHMe} \mathrm{Et,} \mathrm{R}^{8}=\mathrm{H}$

41c: $\mathrm{R}^{5}=(\mathrm{Z}) \mathrm{CONHCH}=\mathrm{CHMe}, \mathrm{R}^{6}=\mathrm{CH}_{2} \mathrm{CONH}_{2}$,

$R^{7}=\mathrm{COCH}_{2} \mathrm{CHMe}_{2} \mathrm{R}^{8}=\mathrm{H}$

41d: $\mathrm{R}^{5}=(\mathrm{Z}) \mathrm{CONHCH}=\mathrm{CHMe}, \mathrm{R}^{6}=\mathrm{CH}_{2} \mathrm{CONH}_{2}$,

$\mathrm{R}^{7}=\mathrm{COCHMe}_{2}, \mathrm{R}^{8}=\mathrm{H}$

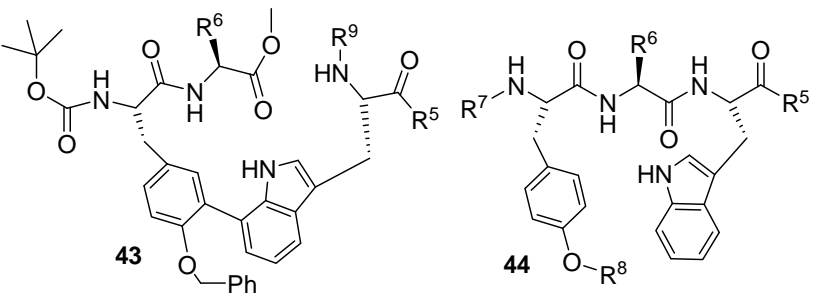

44a: $\mathrm{R}^{5}=\mathrm{NHBn}, \mathrm{R}^{6}=\mathrm{CH}_{3}, \mathrm{R}^{7}=\mathrm{H}, \mathrm{R}^{8}=\mathrm{Bn}$

44b: $R^{5}=\mathrm{NHBn}, \mathrm{R}^{6}=\left(\mathrm{CH}_{2}\right)_{4} \mathrm{NH}_{2}, \mathrm{R}^{7}=\mathrm{H}, \mathrm{R}^{8}=\mathrm{Bn}$

44c: $\mathrm{R}^{5}=\mathrm{NHC}_{6} \mathrm{H}_{4} \mathrm{OH}, \mathrm{R}^{6}=\left(\mathrm{CH}_{2}\right)_{4} \mathrm{NH}_{2}, \mathrm{R}^{7}=\mathrm{H}$, $\mathrm{R}^{8}=\mathrm{Bn}$

44d: $\mathrm{R}^{5}=\mathrm{NHC}_{6} \mathrm{H}_{4} \mathrm{OH}, \mathrm{R}^{6}=\mathrm{CH}_{3}, \mathrm{R}^{7}=\mathrm{Boc}, \mathrm{R}^{8}=\mathrm{Bn}$

44e: $\mathrm{R}^{5}=\mathrm{NHBn}, \mathrm{R}^{6}=\left(\mathrm{CH}_{2}\right)_{3} \mathrm{NH}(=\mathrm{NH}) \mathrm{NH}_{2}, \mathrm{R}^{7}=\mathrm{Boc}$, $\mathrm{R}^{8}=\mathrm{H}$

44f: $\mathrm{R}^{5}=\mathrm{NH}\left(\mathrm{CH}_{2}\right)_{4} \mathrm{NH}_{2}, \mathrm{R}^{6}=\mathrm{iBu}, \mathrm{R}^{7}=\mathrm{H}, \mathrm{R}^{8}=\mathrm{Bn}$

Fig. (20). Structures of the natural compounds TMC-95A-D and their synthetic cyclic (39-42) and linear $(43,44)$ derivatives. The hydrogen bond network of TMC-95A in complex with the T-L active site of the yeast proteasome is shown as broken lines (schematic representation from X-ray structure). The interactions with the proteasome S1 and S3 subsites are shown.

\section{Peptides and pseudopeptides}

\section{Natural peptides: argyrin $A, P R-39$ and $P R-11$}

Argyrin A is a natural cyclic octapeptide isolated from the myxobactrium Archangium gephyra [200]. It has been identified as a potent antitumor drug (figure 21) [201], that inhibits human 20S proteasome as efficiently as bortezomib [201]. Its mechanism of inhibition has not yet been elucidated. Xenotransplanted tumors in mice (human colon cancer) are significantly reduced after argirin A injections, in a way comparable or even more pronounced than the response to bortezomib. Argyrin A acts by preventing the breakdown of the cyclin kinase 
inhibitor $\mathrm{p} 27^{\mathrm{kip} 1}$ degradation [201]. The way argyrin A kills cancer cells is distinct from that of bortezomib [202].

A natural proline-rich, arginine-rich antibacterial peptide (39 amino acid residues), PR39, stimulates angiogenesis and inhibits inflammatory responses. It acts as a non-competitive and reversible inhibitor of the proteasome CT-L $\left(\mathrm{K}_{\mathrm{i}}=0.025 \mu \mathrm{M}\right.$, human 20S proteasome $)$ and PA activities [203]. Its $N$-terminal fragment containing eleven residues, PR11 (RRRPRPPYLPR), is the shortest sequence that inhibits proteasome. Compounds PR-39 and PR-11 also inhibit myocardial ischemia-reperfusion injury in rats [204].

\section{Synthetic modified peptides}

The arecoline peptides $\mathbf{4 5}$ and $\mathbf{4 6}$ were designed to be covalent inhibitors, but they seem to inhibit human proteasome without forming a covalent bond with the catalytic threonines (figure 21) [205]. Arecoline 47, a natural amino vinyl ester that could be a potential Michael acceptor for the catalytic threonine, was introduced as the $C$-terminal residue of peptide $\mathbf{4 5}$ or $N$-terminal residue of peptides 46 (figure 21). The arecoline moiety in compound $\mathbf{4 5}$ does not improve the inhibitory activity of the reference compound Z-Leu-Leu-Leu-NHBn, indicating that it does not react with the proteasome $N$-terminal threonine. The $N$-terminal conjugates 46

significantly inhibited the CT-L and T-L activities of human proteasome. Respective $\mathrm{IC}_{50}$ values were $0.5 \mu \mathrm{M}$ and $2.2 \mu \mathrm{M}$ for $46 \mathrm{a}\left(\mathrm{R}^{2}=\mathrm{CH}_{2} \mathrm{OH}, \mathrm{R}^{3}=i \operatorname{Pr}\right)$. Compounds 45 and $\mathbf{4 6}$ also inhibited proteasome in cellular settings and had good stability in culture media $\left(\mathrm{t}_{1 / 2}>300\right.$ $\min )[205]$.

Lipotripeptides 48 (figure 21) and lipohexapeptides $\left(\mathrm{CH}_{3}-\left(\mathrm{CH}_{2}\right)_{\mathrm{n}}-\mathrm{CO}-\mathrm{TITFDY}, \mathrm{n}=4-16\right)$ inhibit the CT-L and PA activities of yeast $20 \mathrm{~S}$ proteasome at micromolar concentrations [206]. The structural features can be varied to selectively inhibit one or more of the three types of proteasome activities. The non specific lipid group may have two actions: to improve inhibition and deliver the inhibitor to the cell membrane [206]. The fluorinated pseudopeptides that incorporate a trifluoromethyl- $\beta$-hydrazino acid scaffold 49 [207] are new inhibitors of the rabbit 20S proteasome, that are easily synthesized (figure 21). Their differential capacities to inhibit CT-L, T-L and PA activities vary with their structure. For compound 49a $\left(\mathrm{R}^{1}=\mathrm{CH}_{2}\right)_{4} \mathrm{NH}_{2}$ and $\mathrm{R}^{2}=\mathrm{CO}-\mathrm{CH}_{2}$-(3-phenoxy) phenyl) $\mathrm{IC}_{50}$ values were 1.6 $\mu \mathrm{M}$ (CT-L activity), $2.7 \mu \mathrm{M}$ (PA activity) and $8.4 \mu \mathrm{M}$ (T-L activity). Compounds 49 have no effect on the challenging proteolytic enzymes calpain I and cathepsin B. 


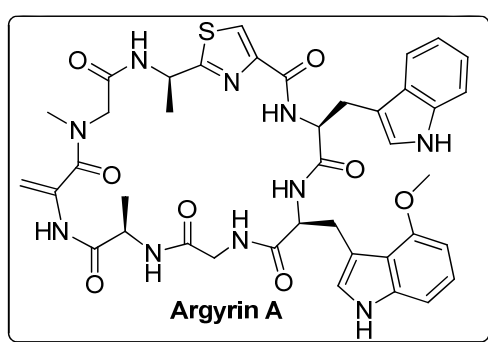

$\mathrm{CO}_{2} \mathrm{H}$

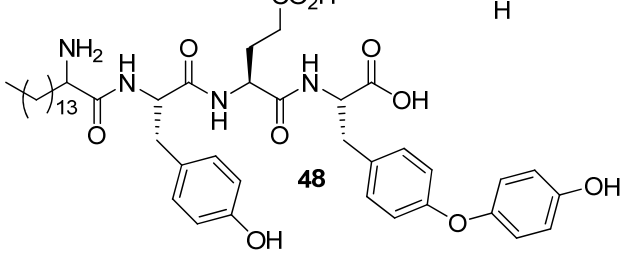

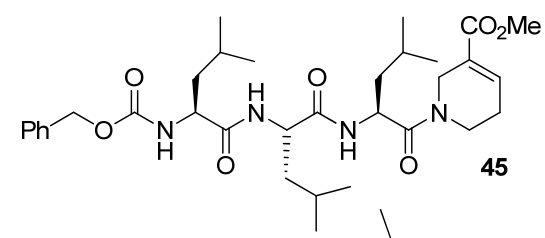

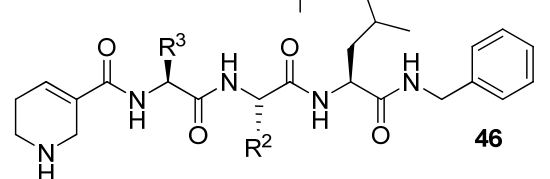

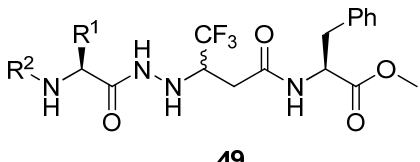

Fig. (21). Structures of peptides or pseudopeptides which inhibit $20 \mathrm{~S}$ proteasome.

\section{Non peptide molecules with no electrophilic function}

Aclacinomycin A (or aclarubicin) is an anthracycline drug used to treat cancers; it targets topoisomerase II and interferes with DNA synthesis (figure 22) [208]. It also inhibits bovine $20 \mathrm{~S}$ proteasome and is selective for the CT-L activity [209]. Tetra-acridine 50 (figure 22) and several analogues are inhibitors of topoisomerase II-mediated DNA decatenation [210]. However, cytotoxicity studies using sensitive and resistant cancer cell lines and reference inhibitors indicate that topoisomerase II is not the only target of these molecules. The way compound 50 inhibits the CT-L, T-L and PA activities of human $20 \mathrm{~S}$ proteasome $\left(\mathrm{IC}_{50}=0.2\right.$, $5,1 \mu \mathrm{M})$ in vitro explains its potent cytoxocity. This dual activity could represent a novel anti-cancer approach that circumvents tumor resistance [210].

The macrocyclic polyketide kendomycin has antibacterial activity and is strongly cytotoxic against several tumor cell lines (figure 22). Investigation of its mode of action in mammalian cells showed that the cytoxocity effects of kendomycin are at least partly due to proteasome inhibition [211].
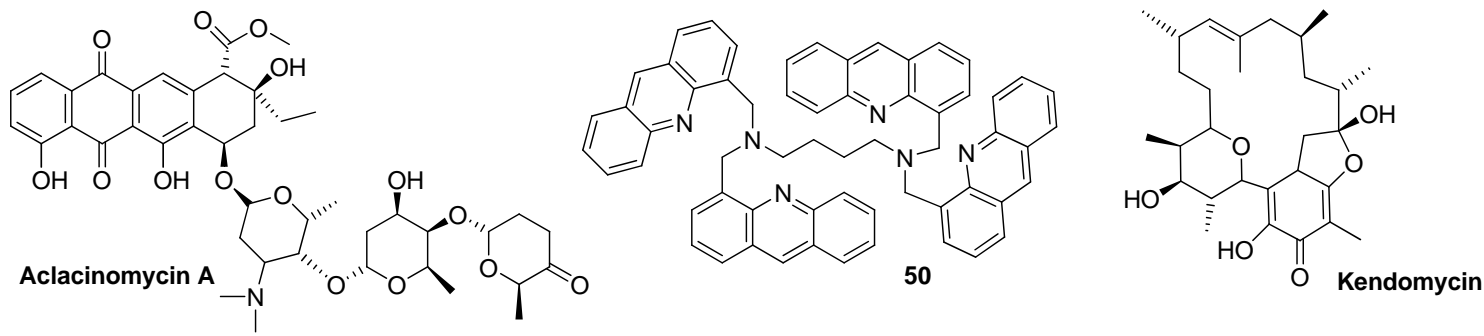

Fig. (22). Structures of organic inhibibitors with no electrophilic function. 


\section{MisCELLANEOUS: ORGANOMETALLIC COMPLEXES}

Organometallic complexes play crucial roles in many biological processes and are widely used in medicine to treat various diseases [212,213]. The best known example is the anticancer agent cisplatin complex $\mathrm{PtCl}_{2}\left(\mathrm{NH}_{3}\right)_{2}$ [214]. A few years ago, screening of the NCI Diversity Set Library identified the copper complex NCI-109268 (figure 23) as an inhibitor of the proteasome CT-L activity $\left(\mathrm{IC}_{50}\right.$ of $\left.6 \mu \mathrm{M}\right)$ of both Jurkat $\mathrm{T}$ cell extract and rabbit $20 \mathrm{~S}$ proteasome [215]. Organometallic complexes were later investigated more intensively as possible proteasome inhibitors. The screening of a series of metal salts with a two oxidation state $\left(\mathrm{Cu}^{2+}, \mathrm{Ni}^{2+}, \mathrm{Mn}^{2+}, \mathrm{Co}^{2+}, \mathrm{Cr}^{2+}, \mathrm{Fe}^{2+}, \mathrm{Cd}^{2+}, \mathrm{Zn}^{2+}, \mathrm{Ag}^{2+}, \mathrm{Mo}^{2+}, \mathrm{Mg}^{2+}, \mathrm{Ca}^{2+}\right)$ showed that only copper salts are potent, selective inhibitors of rabbit $20 \mathrm{~S}$ proteasome $\mathrm{CT}-\mathrm{L}$ activity $\left(\mathrm{IC}_{50}\right.$ $=1-6 \mu \mathrm{M})$ [215]. While both inorganic and organic copper compounds inhibit proteasome in vitro in a time-dependent and irreversible manner, only organic copper derivatives cause ubiquitinated proteins to accumulate in cells and induce apoptosis in vivo [215-221]. The organic ligands quinoline [215-217], dithiocarbamate [216,218-220] and phenol derivatives [221] have been shown to generate the most promising complexes. Complexes 51 [217] and 52 [221] (figure 23) inhibit the proteasome CT-L activity in several prostate cancer cells (51, $\left.\mathrm{IC}_{50} \approx 4 \mu \mathrm{M}\right)$ and in intact human leukemia Jurkat T-cells $\left(52, \mathrm{IC}_{50}=3.82 \mu \mathrm{M}\right)$. The disulfiram-copper complex 53a (figure 23) is also a potent proteasome inhibitor of rabbit 20S proteasome CT-L activity $\left(\mathrm{IC}_{50}=7.5 \mu \mathrm{M}\right)$. Treatment for $24 \mathrm{~h}$ with $20 \mu \mathrm{M}$ of compound 53a decreased the activity of the $26 \mathrm{~S}$ proteasome in breast cancer cells by $95 \%$ and triggered apoptosis [218]. Complex 53a (figure 23) is also very selective for tumor cells since it is not toxic for normal breast cells [218]. Cancer cells contain high concentrations of copper and it has been demonstrated that the non-toxic ligand disulfiram binds to this endogenous metal to generate complex 53a in situ (figure 23). When cultured breast cancer cells containing copper at concentrations similar to those found in patients were treated with the disulfiram ligand alone, their proteasome were inhibited and they became apoptotic. Disulfiram significantly inhibits tumor growth (by 74\%) when given to mice bearing tumor xenografts [218]. These results suggest that copper accumulated in breast cancer cells and tissues could be used in selective chemotherapy. Metals other than copper, such as zinc (II) [222], gallium(III) [223] and gold(III) [224,225] can generate proteasome inhibitor complexes. Zinc 54a, gallium 54b and gold 53b (figure 23) complexes inhibit the CT-L activity of rabbit $20 \mathrm{~S}$ proteasome $\left(\mathrm{IC}_{50}\right.$ $=11.7,16$ and $7.4 \mu \mathrm{M}$, respectively) and $26 \mathrm{~S}$ proteasome in cells $\left(\mathrm{IC}_{50}=17 \mu \mathrm{M}\right.$ in intact human prostate cancer $\mathrm{C} 4-2 \mathrm{~B}$ cells, $54 \mathrm{a} ; \mathrm{IC}_{50}=4.4 \mu \mathrm{M}$ in human prostate cancer $\mathrm{C} 4-2 \mathrm{~B}$ cells 
extract, 54b; $>80 \%$ inhibition of breast cancer cells growth at $20 \mu \mathrm{M}, \mathbf{5 3 b}$ ). Gallium 54b and gold 53b complexes (figure 23) can also have the same effect in vivo, inhibiting the growth of of xenografted tumor in mice (66\% for $\mathbf{5 4 b}$ and $50 \%$ for $\mathbf{5 3 b}$ after treatment for 29 days) by inhibiting proteasome and triggering apoptosis. The inorganic $\mathrm{KAuBr}_{4}$ salt inhibits rabbit $20 \mathrm{~S}$ proteasome $\left(\mathrm{IC}_{50}=1.2 \mu \mathrm{M}\right.$ for T-L activity) as does copper (II), but it does not inhibit cellular 26S proteasome [224]. One hypothesis is that the metal ion inhibits the proteasome and that the organic ligand carries this ion into the tumor cells and prevents the metal from nonspecifically interacting with many proteins [218]. Exactly how these organometallic complexes inhibit proteasome has not yet been elucidated, but they probably act by the coordination of the metal center to amino acids in the active sites, such as the amino-terminal threonine residue [221]. The greater inhibitory activity of several organometallics against $26 \mathrm{~S}$ proteasome in cells rather than the $20 \mathrm{~S}$ catalytic particle may be because they target the JAMM domain of the 19S caps in the 26S proteasome [219]. Metal-based proteasome inhibitors require further investigation as they may open up a new approach to the design and development of more potent, more specific therapeutic agents, especially anti-cancer drugs.
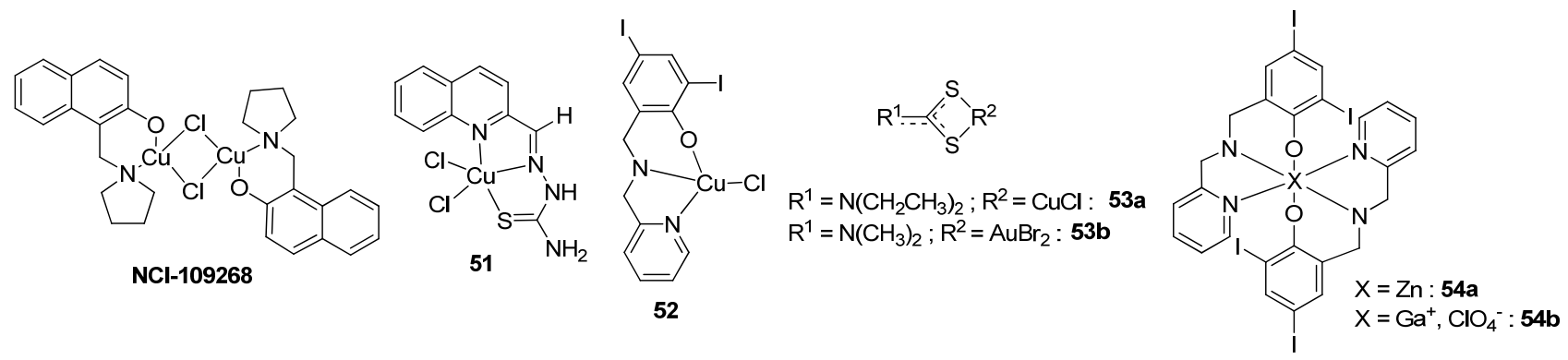

Fig. (23). Structures of some organometallic complexes acting as proteasome inhibitors

\section{CONCLUSION}

The ubiquitin-proteasome system plays a central role in a broad array of basic cellular processes. Modulation of its activity may provide ways of treating many diseases. The proteasome, which is an enzyme common to the entire pathway, has emerged as a promising target for cancer therapy. The proteasome inhibitor bortezomib is used to treat multiple myeloma and mantle lypmhoma. In cancer, proteasome inhibitors may inhibit the activation of the pro-apototic NF- $\kappa \mathrm{B}$ or the degradation of several cell cycle regulators. But the margin between the beneficial effects of proteasome inhibitors and their toxicity may be narrow, 
especially when treatment is prolonged. That is why the discovery of suitable proteasome inhibitors is still a challenge, and we especially need inhibitors with fewer side-effects. Considerable efforts have been made over the past few years to discover structurally different proteasome inhibitors using medicinal chemistry or isolation from a variety of living organisms. Analysis of crystals of proteasome-inhibitor complexes has contributed significantly to this development, although some interactions between the enzyme and the inhibitor are still not clear. Inhibitors may be peptides or non-peptides and may act without forming a covalent bond or by forming a covalent bond with the active site $\mathrm{Thr} 1-\mathrm{O}^{\gamma}$. Some natural compounds, such as the non-covalent TMC-95A, and covalent epoxomicin and syringolin have original mechanisms of action that can be used to inspire the design of novel synthetic compounds. In silico screening is also useful for discovering new compounds that interact with one and more of the three types of proteasome active sites as recently reported for small organic compounds [226]. The potential of the less-well investigated non covalent inhibitors must be explored, as they should not have the inherent drawbacks often associated with reactive warhead groups. In cancer therapy, proteasome inhibitors have been associated with sensitizing effects when given in association with chemotherapy or radiotherapy. A combination of a poorly toxic proteasome inhibitor with standard drugs is a strategy that should be explored for treating a wide variety of tumors including solid ones. Finally, proteasome inhibitors may be useful for treating a variety of other disorders, such as immune diseases, neurodegeneration, stroke, cachexia, inflammatory and viral diseases. This suggests that research to discover agents that block proteasome activities will be very active in the coming years.

\section{ACKNOWLEDGEMENTS}

We thank the 'Association Française des Myopathies' (AFM) for financial support. The English text was edited by Dr Owen Parkes.

\section{AbBreviations}

Ac: acetyl

\section{ALLN: Ac-Leu-Leu-Nle-H}

Arg: arginine

Asp: aspartic acid

Bn: benzyl

CP: catalytic particle 
CT-L: chymotrypsin-like

D: aspartic acid

DNA: deoxyribonucleic acid

Ds: dansyl or 5-(dimethylamino)naphthalene-1-sulfonyl

DUB: deubiquitinylating enzyme

Et: ethyl

$\mathrm{F}$ : phenylalanine

Gly: glycine

i.v.: intravenous

I: isoleucine

$i \mathrm{Bu}$ : isobutyl or 2-methylpropyl

IL: interleukin

iPr: isopropyl or 1-methylethyl

L: leucine

Leu: leucine

LMP7: low-molecular mass polypeptide 7

Me: methyl

MHC: major histocompatibility complex

Ms: mesyl or methanesulfonyl

$\mathrm{N}$ : asparagine

Nle: norleucine

Ntn: $N$-terminal nucleophile

$\mathrm{P}$ : proline

PA: post-acid or caspase-like

Ph: phenyl

$\mathrm{R}$ : arginine

SAR: structure-activity relationships

$\mathrm{T}$ : threonine

$t \mathrm{Bu}$ : tert-butyl or 1,1-dimethylethyl

Thr: threonine

T-L: trypsin-like

Ts: tosyl or para-toluenesulfonyl

Ub: ubiquitin

$\mathrm{W}$ : tryptophan 
Y: tyrosine

Z: benzyloxycarbonyl

\section{REFERENCES}

[1] Coux, O.; Tanaka, K.; Goldberg, A. L., Structure and functions of the 20S and 26S proteasomes. Annu. Rev. Biochem. 1996, 65, 801-847.

[2] Hershko, A.; Ciechanover, A., The ubiquitin system. Annu. Rev. Biochem 1998, 67, 425479.

[3] Mao, I.; Liu, J.; Li, X.; Luo, H., REG $\gamma$, a proteasome activator and beyond? Cell. Mol. Life Sci. 2008, 65, 3971-3980.

[4] Borissenko, L.; Groll, M., 20S Proteasome and Its Inhibitors: Crystallographic Knowledge for Drug Development. Chem. Rev. 2007, 107, 687-717.

[5] Marques, A. n. J.; Palanimurugan, R.; Matias, A. C.; Ramos, P. C.; Dohmen, R. J. r., Catalytic Mechanism and Assembly of the Proteasome. Chem. Rev. 2009, 109, 1509-1536.

[6] Brannigan, J. A.; Dodson, G.; Duggleby, H. J.; Moody, P. C.; Smith, J. L.; Tomchick, D. R.; Murzin, A. G., A protein catalytic framework with an N-terminal nucleophile is capable of self-activation. Nature 1995, 378, 416-419.

[7] Schechter, I.; Berger, A., On the size of the active site in proteases. I. Papain. Biochem. Biophys. Res. Commun. 1967, 27, 157-62.

[8] Groll, M.; Nazif, T.; Huber, R.; Bogyo, M., Probing Structural Determinants Distal to the Site of Hydrolysis that Control Substrate Specificity of the 20S Proteasome. Chem. Biol. 2002, 9, 655-662.

[9] Groll, M.; Huber, R.; Potts, B. C. M., Crystal Structures of Salinosporamide A (NPI-0052) and B (NPI-0047) in Complex with the 20S Proteasome Reveal Important Consequences of beta -Lactone Ring Opening and a Mechanism for Irreversible Binding. J. Am. Chem. Soc. 2006, 128, 5136-5141.

[10] Adams, J., The development of proteasome inhibitors as anticancer drugs. Cancer Cell 2004, 5, 417-421.

[11] Orlowski, R. Z.; Kuhn, D. J., Proteasome inhibitors in cancer therapy: lessons from the first decade. Clin. Cancer Res. 2008, 14, 1649-1657.

[12] Boccadoro, M.; Morgan, G.; Cavenagh, J., Preclinical evaluation of the proteasome inhibitor bortezomib in cancer therapy. Cancer Cell Int. 2005, 5, 18.

[13] Adams, J., The proteasome: a suitable antineoplastic target. Nat. Rev. Cancer 2004, 4, 349-360. 
[14] Meiners, S.; Ludwig, A.; Stangl, V.; Stangl, K., Proteasome inhibitors: Poisons and remedies. Med. Res. Rev. 2008, 28, 309-327.

[15] Jung, T.; Catalgol, B.; Grune, T., The proteasomal system. Molecular Aspects of Medicine 2009, 30, 191-296.

[16] Vinitsky, A.; Michaud, C.; Powers, J. C.; Orlowski, M., Inhibition of the chymotrypsinlike activity of the pituitary multicatalytic proteinase complex. Biochemistry 1992, 31, 94218.

[17] Loewe, J.; Stock, D.; Jap, B.; Zwickl, P.; Baumeister, W.; Huber, R., Crystal structure of the 20S proteasome from the archaeon T. acidophilum at 3.4 .ANG. resolution. Science 1995, 268, 533-9.

[18] Groll, M.; Ditzel, L.; Loewe, J.; Stock, D.; Bochtler, M.; Bartunik, H. D.; Huber, R., Structure of $20 \mathrm{~S}$ proteasome from yeast at 2.4 .ANG. resolution. Nature 1997, 386, 463-471.

[19] Kisselev, A. F.; Goldberg, A. L., Proteasome inhibitors: from research tools to drug candidates. Chem. Biol. 2001, 8, 739-758.

[20] Myung, J.; Kim, K. B.; Crews, C. M., The ubiquitin-proteasome pathway and proteasome inhibitors. Med. Res. Rev. 2001, 21, 245-273.

[21] Garcia-Echeverria, C., Recent advances in the identification and development of $20 \mathrm{~S}$ proteasome inhibitors. Mini-Rev. Med. Chem. 2002, 2, 247-259.

[22] Reboud-Ravaux, M., Proteasome inhibitors. In. Protein Degradation in Health and Diseases, Progress in Molecular and Subcellular Biology 29, Reboud-Ravaux, M., Ed. Springer, 2002; pp 109-117

[23] Delcros, J. G.; Floc'h, M. B.; Prigent, C.; Arlot-Bonnemains, Y., Proteasome inhibitors as therapeutic agents: Current and future strategies. Curr. Med. Chem 2003, 10, 479-503.

[24] Adams, J., Proteasome Inhibitors in Cancer Therapy. Humana Press Inc.: Totowa, NJ, 2004; p 328.

[25] Garcia-Echeverria, C., Peptide and peptide-like modulators of 20S proteasome enzymatic activity in cancer cells. Int. J. Pept. Res. Ther. 2006, 12, 49-64.

[26] Bayot, A.; Basse, N.; Lee, I.; Gareil, M.; Pirotte, B.; Bulteau, A.-L.; Friguet, B.; ReboudRavaux, M., Towards the control of intracellular protein turnover: Mitochondrial Lon protease inhibitors versus proteasome inhibitors. Biochimie 2008, 90, 260-269.

[27] Groll, M.; Huber, R.; Moroder, L., The persisting challenge of selective and specific proteasome inhibition. J. Pept. Sci. 2009, 15, 58-66.

[28] Huang, L.; Chen, C. H., Proteasome regulators: activators and inhibitors. Curr. Med. Chem. 2009, 16, 931-939. 
[29] Verdoes, M.; Florea, B. I.; van der Marel, G. A.; Overkleeft, H. S., Chemical Tools To Study the Proteasome. Eur. J. Org. Chem. 2009, 3301-3313.

[30] Kisselev, A. F., Joining the Army of Proteasome Inhibitors. Chem. Biol. 2008, 15, 419421.

[31] Moore, B. S.; Eustaquio, A. S.; McGlinchey, R. P., Advances in and applications of proteasome inhibitors. Curr. Opin. Chem. Biol 2008, 12, 434-440.

[32] Kim, K. B.; Crews, C. M., Chemical Genetics: Exploring the Role of the Proteasome in Cell Biology Using Natural Products and Other Small Molecule Proteasome Inhibitors. J. Med. Chem. 2008, 51, 2600-2605.

[33] Wehenkel, M.; Hong, J. T.; Kim, K. B., Proteasome modulators: essential chemical genetic tools for understanding human diseases. Mol. BioSyst. 2008, 4, 280 - 286.

[34] Adams, J.; Behnke, M.; Chen, S.; Cruickshank, A. A.; Dick, L. R.; Grenier, L.; Klunder, J. M.; Ma, Y.-T.; Plamondon, L.; Stein, R. L., Potent and selective inhibitors of the proteasome: dipeptidyl boronic acids. Bioorg. Med. Chem. Lett. 1998, 8, 333-338.

[35] Zhu, Y.-Q.; Pei, J.-F.; Liu, Z.-M.; Lai, L.-H.; Cui, J.-R.; Li, R.-T., 3D-QSAR studies on tripeptide aldehyde inhibitors of proteasome using CoMFA and CoMSIA methods. Bioorg. Med. Chem. 2006, 14, 1483-1496.

[36] Momose, I.; Sekizawa, R.; Hashizume, H.; Kinoshita, N.; Homma, Y.; Hamada, M.; Iinuma, H.; Takeuchi, T., Tyropeptins A and B, new proteasome inhibitors produced by Kitasatospora sp. MK993-dF2. I. Taxonomy, isolation, physico-chemical properties and biological activities. J. Antibiot. 2001, 54, 997-1003.

[37] Momose, I.; Umezawa, Y.; Hirosawa, S.; Iinuma, H.; Ikeda, D., Structure-based design of derivatives of tyropeptin $\mathrm{A}$ as the potent and selective inhibitors of mammalian $20 \mathrm{~S}$ proteasome. Bioorg. Med. Chem. Lett 2005, 15, 1867-1871.

[38] Momose, I.; Umezawa, Y.; Hirosawa, S.; Iijima, M.; Iinuma, H.; Ikeda, D., Synthesis and activity of tyropeptin A derivatives as potent and selective inhibitors of mammalian $20 \mathrm{~S}$ proteasome. Biosci., Biotechnol., Biochem. 2005, 69, 1733-1742.

[39] Momose, I.; Iijima, M.; Kawada, M.; Ikedo, D., A New Proteasome Inhibitor, TP-110, Induces Apoptosis in Human Prostate Cancer PC-3 Cells. Biosci. Biotechnol. Biochem. 2007, $71,1036-1043$.

[40] Hines, J.; Groll, M.; Fahnestock, M.; Crews, C. M., Proteasome Inhibition by Fellutamide B Induces Nerve Growth Factor Synthesis. Chem. Biol. 2008, 15, 501-512. 
[41] Vivier, M.; Jarrousse, A.-S.; Bouchon, B.; Galmier, M.-J.; Auzeloux, P.; Sauzieres, J.; Madelmont, J.-C., Preliminary Studies of New Proteasome Inhibitors in the Tumor Targeting Approach: Synthesis and in Vitro Cytotoxicity. J. Med. Chem. 2005, 48, 6731-6740.

[42] Vivier, M.; Rapp, M.; Papon, J.; Labarre, P.; Galmier, M.-J.; Sauziere, J.; Madelmont, J.C., Synthesis, radiosynthesis, and biological evaluation of new proteasome inhibitors in a tumor targeting approach. J. Med. Chem. 2008, 51, 1043-1047.

[43] Kuhn, D. J.; Hunsucker, S. A.; Chen, Q.; Voorhees, P. M.; Orlowski, M.; Orlowski, R. Z., Targeted inhibition of the immunoproteasome is a potent strategy against models of multiple myeloma that overcomes resistance to conventional drugs and nonspecific proteasome inhibitors. Blood 2009, 113, 4667-4676.

[44] Richardson, P. G.; Sonneveld, P.; Schuster, M. W.; Irwin, D.; Stadtmauer, E. A.; Facon, T.; Harousseau, J.-L.; Ben-Yehuda, D.; Lonial, S.; Goldschmidt, H.; Reece, D.; San-Miguel, J. F.; Blade, J.; Boccadoro, M.; Cavenaugh, J.; Dalton, W. S.; Boral, A. L.; Esseltine, D. L.; Porter, J. B.; Schenkein, D.; Anderson, K. C., Bortezomib or high-dose dexamethasone for relapsed multiple myeloma. N. Engl. J. Med. 2005, 352, 2487-2498.

[45] Adams, J.; Elliott, P. J.; Bouchard, P., Preclinical development of bortezomib (VELCADE): rationale for clinical studies. Proteasome Inhibitors in Cancer Therapy 2004, 233-269.

[46] Orlowski, R. Z.; Zeger, E. L., Targeting the proteasome as a therapeutic strategy against haematological malignancies. Expert Opin. Invest. Drugs 2006, 15, 117-130.

[47] Adams, J., Proteasome inhibitors as therapeutic agents. Expert Opin. Ther. Pat. 2003, 13, 45-57.

[48] Adams, J., Proteasome inhibition: a novel approach to cancer therapy. Trends Mol. Med. 2002, 8, (4, Suppl.), S49-S54.

[49] Richardson, P. G.; Mitsiades, C.; Hideshima, T.; Anderson, K. C., Bortezomib: Proteasome Inhibition as an Effective Anticancer Therapy. Annual Review of Medicine 2006, $57,33-47$.

[50] Richardson, P. G.; Mitsiades, C. S.; Hideshima, T.; Anderson, K. C., Novel biological therapies for the treatment of multiple myeloma. Best Pract. Res., Clin. Haematol. 2005, 18, 619-634.

[51] Anargyrou, K.; Dimopoulos, M.-A.; Sezer, O.; Terpos, E., Novel anti-myeloma agents and angiogenesis. Leukemia and Lymphoma 2008, 49, 677 - 689.

[52] Adams, J., Potential for proteasome inhibition in the treatment of cancer. Drug Discovery Today 2003, 8, 307-315. 
[53] Mesa, R. A.; Verstovsek, S.; Rivera, C.; Pardanani, A.; Hussein, K.; Lasho, T.; Wu, W.; Tefferi, A., Bortezomib therapy in myelofibrosis: a phase II clinical trial. Leukemia 2008, 22, $1636-1638$.

[54] Ludwig, H.; Khayat, D.; Giaccone, G.; Facon, T., Proteasome inhibition and its clinical prospects in the treatment of hematologic and solid malignancies. Cancer 2005, 104, 17941807.

[55] Argyriou, A. A.; Iconomou, G.; Kalofonos, H. P., Bortezomib-induced peripheral neuropathy in multiple myeloma: a comprehensive review of the literature. 2008, 112, 15931599.

[56] Dorsey, B. D.; Iqbal, M.; Chatterjee, S.; Menta, E.; Bernardini, R.; Bernareggi, A.; Cassara, P. G.; D'Arasmo, G.; Ferretti, E.; De Munari, S.; Oliva, A.; Pezzoni, G.; Allievi, C.; Strepponi, I.; Ruggeri, B.; Ator, M. A.; Williams, M.; Mallamo, J. P., Discovery of a Potent, Selective, and Orally Active Proteasome Inhibitor for the Treatment of Cancer. J. Med. Chem. 2008, 51, 1068-1072.

[57] Piva, R.; Ruggeri, B.; Williams, M.; Costa, G.; Tamagno, I.; Ferrero, D.; Giai, V.; Coscia, M.; Peola, S.; Massaia, M.; Pezzoni, G.; Allievi, C.; Pescalli, N.; Cassin, M.; di Giovine, S.; Nicoli, P.; de Feudis, P.; Strepponi, I.; Roato, I.; Ferracini, R.; Bussolati, B.; Camussi, G.; Jones-Bolin, S.; Hunter, K.; Zhao, H.; Neri, A.; Palumbo, A.; Berkers, C.; Ovaa, H.; Bernareggi, A.; Inghirami, G., CEP-18770: a novel, orally active proteasome inhibitor with a tumor-selective pharmacologic profile competitive with bortezomib. Blood 2008, 111, $2765-2775$.

[58] Achanta, G.; Modzelewska, A.; Feng, L.; Khan, S. R.; Huang, P., A Boronic-Chalcone Derivative Exhibits Potent Anticancer Activity through Inhibition of the Proteasome. Mol Pharmacol 2006, 70, 426-433.

[59] Nakamura, H.; Watanabe, M.; Ban, H. S.; Nabeyama, W.; Asai, A., Synthesis and biological evaluation of boron peptide analogues of Belactosin $\mathrm{C}$ as proteasome inhibitors. Bioorg. Med. Chem. Lett. 2009, 19, 3220-3224.

[60] Purandare, A. V.; Wan, H.; Laing, N.; Benbatoul, K.; Vaccaro, W.; Poss, M. A., Identification of a potent and rapidly reversible inhibitor of the 20S-proteasome. Bioorg. Med. Chem. Lett. 2004, 14, 4701-4704.

[61] Watanabe, T.; Momose, I.; Abe, M.; Abe, H.; Sawa, R.; Umezawa, Y.; Ikeda, D.; Takahashi, Y.; Akamatsu, Y., Synthesis of boronic acid derivatives of tyropeptin: Proteasome inhibitors. Bioorg. Med. Chem. Lett. 2009, 19, 2343-2345. 
[62] Hanada, M.; Sugawara, K.; Kaneta, K.; Toda, S.; Nishiyama, Y.; Tomita, K.; Yamamoto, H.; Konishi, M.; Oki, T., Epoxomicin, a new antitumor agent of microbial origin. J. Antibiot. 1992, 45, 1746-52.

[63] Sugawara, K.; Hatori, M.; Nishiyama, Y.; Tomita, K.; Kamei, H.; Konishi, M.; Oki, T., Eponemycin, a new antibiotic active against B16 melanoma. I. Production, isolation, structure and biological activity. J. Antibiot. 1990, 43, 8-18.

[64] Sin, N.; Kim, K. B.; Elofsson, M.; Meng, L.; Auth, H.; Kwok, B. H. B.; Crews, C. M., Total synthesis of the potent proteasome inhibitor epoxomicin: a useful tool for understanding proteasome biology. Bioorg. Med. Chem. Lett. 1999, 9, 2283-2288.

[65] Kim, K. B.; Myung, J.; Sin, N.; Crews, C. M., Proteasome inhibition by the natural products epoxomicin and dihydroeponemycin: insights into specificity and potency. Bioorg. Med. Chem. Lett. 1999, 9, 3335-3340.

[66] Meng, L.; Mohan, R.; Kwok, B. H. B.; Elofsson, M.; Sin, N.; Crews, C. M., Epoxomicin, a potent and selective proteasome inhibitor, exhibits in vivo antiinflammatory activity. Proc. Natl. Acad. Sci. U. S. A. 1999, 96, 10403-10408.

[67] Meng, L.; Kwok, B. H. B.; Sin, N.; Crews, C. M., Eponemycin exerts its antitumor effect through the inhibition of proteasome function. Cancer Res. 1999, 59, 2798-2801.

[68] Groll, M.; Kim, K. B.; Kairies, N.; Huber, R.; Crews, C. M., Crystal structure of epoxomicin:20S proteasome reveals a molecular basis for selectivity of alpha ',beta 'epoxyketone proteasome inhibitors. J. Am. Chem. Soc. 2000, 122, 1237-1238.

[69] Koguchi, Y.; Kohno, J.; Suzuki, S.-I.; Nishio, M.; Takahashi, K.; Ohnuki, T.; Komatsubara, S., TMC-86A, B and TMC-96, new proteasome inhibitors from Streptomyces sp. TC 1084 and Saccharothrix sp. TC 1094. II. Physico-chemical properties and structure determination. J. Antibiot. 2000, 53, 63-65.

[70] Koguchi, Y.; Nishio, M.; Suzuki, S.-I.; Takahashi, K.; Ohnuki, T.; Komatsubara, S., TMC-89A and B, new proteasome inhibitors from Streptomyces sp. TC 1087. J. Antibiot. 2000, 53, 967-972.

[71] Elofsson, M.; Splittgerber, U.; Myung, J.; Mohan, R.; Crews, C. M., Towards subunitspecific proteasome inhibitors: synthesis and evaluation of peptide alpha ',beta 'epoxyketones. Chem. Biol. 1999, 6, 811-822.

[72] Myung, J.; Kim, K. B.; Lindsten, K.; Dantuma, N. P.; Crews, C. M., Lack of proteasome active site allostery as revealed by subunit-specific inhibitors. Mol. Cell 2001, 7, 411-420.

[73] Demo, S. D.; Kirk, C. J.; Aujay, M. A.; Buchholz, T. J.; Dajee, M.; Ho, M. N.; Jiang, J.; Laidig, G. J.; Lewis, E. R.; Parlati, F.; Shenk, K. D.; Smyth, M. S.; Sun, C. M.; Vallone, M. 
K.; Woo, T. M.; Molineaux, C. J.; Bennett, M. K., Antitumor Activity of PR-171, a Novel Irreversible Inhibitor of the Proteasome. Cancer Res. 2007, 67, 6383-6391.

[74] Kuhn, D. J.; Chen, Q.; Voorhees, P. M.; Strader, J. S.; Shenk, K. D.; Sun, C. M.; Demo, S. D.; Bennett, M. K.; van Leeuwen, F. W. B.; Chanan-Khan, A. A.; Orlowski, R. Z., Potent activity of carfilzomib, a novel, irreversible inhibitor of the ubiquitin-proteasome pathway, against preclinical models of multiple myeloma. Blood 2007, 110, 3281-3290.

[75] Zhou, H.-J.; Aujay, M. A.; Bennett, M. K.; Dajee, M.; Demo, S. D.; Fang, Y.; Ho, M. N.; Jiang, J.; Kirk, C. J.; Laidig, G. J.; Lewis, E. R.; Lu, Y.; Muchamuel, T.; Parlati, F.; Ring, E.; Shenk, K. D.; Shields, J.; Shwonek, P. J.; Stanton, T.; Sun, C. M.; Sylvain, C.; Woo, T. M.; Yang, J., Design and Synthesis of an Orally Bioavailable and Selective Peptide Epoxyketone Proteasome Inhibitor (PR-047). J. Med. Chem. 2009, 52, 3028-3038.

[76] Peese, K., Orally bioavailable proteasome inhibitors: Preclinical development of PR-047. Drug Discov Today 2009, 14, 905-906.

[77] Muchamuel, T.; Basler, M.; Aujay, M. A.; Suzuki, E.; Kalim, K. W.; Lauer, C.; Sylvain, C.; Ring, E. R.; Shields, J.; Jiang, J.; Shwonek, P.; Parlati, F.; Demo, S. D.; Bennett, M. K.; Kirk, C. J.; Groettrup, M., A selective inhibitor of the immunoproteasome subunit LMP7 blocks cytokine production and attenuates progression of experimental arthritis. Nature Medicine 2009, 15, 781 - 787

[78] Omura, S.; Matsuzaki, K.; Fujimoto, T.; Kosuge, K.; Furuya, T.; Fujita, S.; Nakagawa, A., Structure of lactacystin, a new microbial metabolite which induces differentiation of neuroblastoma cells. J. Antibiot. 1991, 44, 117-18.

[79] Omura, S.; Fujimoto, T.; Otoguro, K.; Matsuzaki, K.; Moriguchi, R.; Tanaka, H.; Sasaki, Y., Lactacystin, a novel microbial metabolite, induces neuritogenesis of neuroblastoma cells. J. Antibiot. 1991, 44, 113-16.

[80] Fenteany, G.; Standaert, R. F.; Lane, W. S.; Choi, S.; Corey, E. J.; Schreiber, S. L., Inhibition of proteasome activities and subunit-specific amino-terminal threonine modification by lactacystin. Science 1995, 268, 726-31.

[81] Corey, E. J.; Li, W.-D., Total synthesis and biological activity of lactacystin, omuralide and analogs. Chem. Pharm. Bull. 1999, 47, 1-10.

[82] Ostrowska, H.; Wojcik, C.; Omura, S.; Worowski, K., Lactacystin, a specific inhibitor of the proteasome, inhibits human platelet lysosomal cathepsin A-like enzyme. Biochem. Biophys. Res. Commun. 1997, 234, 729-732. 
[83] Geier, E.; Pfeifer, G.; Wilm, M.; Lucchiari-Hartz, M.; Baumeister, W.; Eichmann, K.; Niedermann, G., A giant protease with potential to substitute for some functions of the proteasome. Science 1999, 283, 978-981.

[84] Groll, M.; Balskus, E. P.; Jacobsen, E. N., Structural Analysis of Spiro beta -Lactone Proteasome Inhibitors. J. Am. Chem. Soc. 2008, 130, 14981-14983.

[85] Masse, C. E.; Adams, J. M.; Adams, J.; Panek, J. S., Syntheses and Biological Evaluation of (+)-Lactacystin and Analogs. Eur. J. Org. Chem. 2000, 2513-2528.

[86] Kang, S. H.; Kang, S. Y.; Lee, H.-S.; Buglass, A. J., Total Synthesis of Natural tertAlkylamino Hydroxy Carboxylic Acids. Chem. Rev. 2005, 105, 4537-4558.

[87] Shibasaki, M.; Kanai, M.; Fukuda, N., Total synthesis of lactacystin and salinosporamide A. Chemistry--An Asian Journal 2007, 2, 20-38.

[88] Balskus, E. P.; Jacobsen, E. N., alpha ,beta -Unsaturated beta -silyl imide substrates for catalytic, enantioselective conjugate additions: A total synthesis of $(+)$-lactacystin and the discovery of a new proteasome inhibitor. J. Am. Chem. Soc. 2006, 128, 6810-6812.

[89] Di Napoli, M.; Papa, F., MLN-519 Millennium/PAION. Curr. Opin. Invest. Drugs 2003, 4, 333-341.

[90] Feling, R. H.; Buchanan, G. O.; Mincer, T. J.; Kauffman, C. A.; Jensen, P. R.; Fenical, W., Salinosporamide A: a highly cytotoxic proteasome inhibitor from a novel microbial source, a marine bacterium of the new genus Salinospora. Angew. Chem., Int. Ed. 2003, 42, $355-357$

[91] Fenical, W.; Jensen, P. R.; Palladino, M. A.; Lam, K. S.; Lloyd, G. K.; Potts, B. C., Discovery and development of the anticancer agent salinosporamide A (NPI-0052). Bioorg. Med. Chem. 2009, 17, 2175-2180.

[92] Macherla, V. R.; Mitchell, S. S.; Manam, R. R.; Reed, K. A.; Chao, T.-H.; Nicholson, B.; Deyanat-Yazdi, G.; Mai, B.; Jensen, P. R.; Fenical, W. F.; Neuteboom, S. T. C.; Lam, K. S.; Palladino, M. A.; Potts, B. C. M., Structure-Activity Relationship Studies of Salinosporamide A (NPI-0052), a Novel Marine Derived Proteasome Inhibitor. J. Med. Chem. 2005, 48, 36843687.

[93] Chauhan, D.; Catley, L.; Li, G.; Podar, K.; Hideshima, T.; Velankar, M.; Mitsiades, C.; Mitsiades, N.; Yasui, H.; Letai, A.; Ovaa, H.; Berkers, C.; Nicholson, B.; Chao, T.-H.; Neuteboom, S. T. C.; Richardson, P.; Palladino, M. A.; Anderson, K. C., A novel orally active proteasome inhibitor induces apoptosis in multiple myeloma cells with mechanisms distinct from bortezomib. Cancer Cell 2005, 8, 407-419. 
[94] Groll, M.; Huber, R.; Potts, B. C., Crystal structures of Salinosporamide A (NPI-0052) and B (NPI-0047) in complex with the 20S proteasome reveal important consequences of beta-lactone ring opening and a mechanism for irreversible binding. J. Am. Chem. Soc. 2006, $128,5136$.

[95] Manam, R. R.; McArthur, K. A.; Chao, T.-H.; Weiss, J.; Ali, J. A.; Palombella, V. J.; Groll, M.; Lloyd, G. K.; Palladino, M. A.; Neuteboom, S. T. C.; Macherla, V. R.; Potts, B. C. M., Leaving Groups Prolong the Duration of 20S Proteasome Inhibition and Enhance the Potency of Salinosporamides. J. Med. Chem. 2008, 51, 6711-6724.

[96] Williams, P. G.; Buchanan, G. O.; Feling, R. H.; Kauffman, C. A.; Jensen, P. R.; Fenical, W., New cytotoxic salinosporamides from the marine actinomycete Salinispora tropica. $J$. Org. Chem. 2005, 70, 6196-6203.

[97] Reed, K. A.; Manam, R. R.; Mitchell, S. S.; Xu, J.; Teisan, S.; Chao, T.-H.; DeyanatYazdi, G.; Neuteboom, S. T. C.; Lam, K. S.; Potts, B. C. M., Salinosporamides D-J from the Marine Actinomycete Salinispora tropica, Bromosalinosporamide, and Thioester Derivatives Are Potent Inhibitors of the 20S Proteasome. J. Nat. Prod. 2007, 70, 269-276.

[98] McGlinchey, R. P.; Nett, M.; Eustaquio, A. S.; Asolkar, R. N.; Fenical, W.; Moore, B. S., Engineered Biosynthesis of Antiprotealide and Other Unnatural Salinosporamide Proteasome Inhibitors. J. Am. Chem. Soc. 2008, 130, $7822-7823$.

[99] Groll, M.; McArthur, K. A.; Macherla, V. R.; Manam, R. R.; Potts, B. C., Snapshots of the Fluorosalinosporamide/20S Complex Offer Mechanistic Insights for Fine Tuning Proteasome Inhibition. J. Med. Chem. 2009, 52, 5420-5428.

[100] Reddy, L. R.; Fournier, J.-F.; Reddy, B. V. S.; Corey, E. J., An Efficient, Stereocontrolled Synthesis of a Potent Omuralide-Salinosporin Hybrid for Selective Proteasome Inhibition. J. Am. Chem. Soc. 2005, 127, 8974-8976.

[101] Manam, R. R.; Macherla, V. R.; Tsueng, G.; Dring, C. W.; Weiss, J.; Neuteboom, S. T. C.; Lam, K. S.; Potts, B. C., Antiprotealide is a natural product. J. Nat. Prod. 2009, 72, 295297.

[102] Stadler, M.; Bitzer, J.; Mayer-Bartschmid, A.; Mueller, H.; Benet-Buchholz, J.; Gantner, F.; Tichy, H.-V.; Reinemer, P.; Bacon, K. B., Cinnabaramides A-G: Analogues of Lactacystin and Salinosporamide from a Terrestrial Streptomycete. J. Nat. Prod.2007, 70, 246-252.

[103] Asai, A.; Hasegawa, A.; Ochiai, K.; Yamashita, Y.; Mizukami, T., Belactosin A, a novel antitumor antibiotic acting on Cyclin/CDK mediated cell cycle regulation, produced by Streptomyces sp. J. Antibiot 2000, 53, 81-83. 
[104] Asai, A.; Tsujita, T.; Sharma, S. V.; Yamashita, Y.; Akinaga, S.; Funakoshi, M.; Kobayashi, H.; Mizukami, T., A new structural class of proteasome inhibitors identified by microbial screening using yeast-based assay. Biochem. Pharmacol. 2004, 67, 227-234.

[105] Yoshida, K.; Yamaguchi, K.; Sone, T.; Unno, Y.; Asai, A.; Yokosawa, H.; Matsuda, A.; Arisawa, M.; Shuto, S., Synthesis of 2,3- and 3,4-methanoamino acid equivalents with stereochemical diversity and their conversion into the tripeptide proteasome inhibitor belactosin A and its highly potent cis-cyclopropane stereoisomer. Org. Lett. 2008, 10, 35713574 .

[106] Yoshida, K.; Yamaguchi, K.; Mizuno, A.; Unno, Y.; Asai, A.; Sone, T.; Yokosawa, H.; Matsuda, A.; Arisawa, M.; Shuto, S., Three-dimensional structure-activity relationship study of belactosin A and its stereo- and regioisomers: development of potent proteasome inhibitors by a stereochemical diversity-oriented strategy. Org. Biomol. Chem. 2009, 7, 1868-1877.

[107] Larionov, O. V.; De Meijere, A., Enantioselective Total Syntheses of Belactosin A, Belactosin C, and Its Homoanalogue. Org. Lett. 2004, 6, 2153-2156.

[108] Groll, M.; Larionov, O. V.; Huber, R.; de Meijere, A., Inhibitor-binding mode of homobelactosin $\mathrm{C}$ to proteasomes: new insights into class I MHC ligand generation. Proc. Natl. Acad. Sci. U. S. A. 2006, 103, 4576-4579.

[109] Hogan, P. C.; Corey, E. J., Proteasome inhibition by a totally synthetic $\beta$-lactam related to salinosporamide A and omuralide. J. Am. Chem. Soc. 2005, 127, 15386-15387.

[110] Imbach, P.; Lang, M.; Garcia-Echeverria, C.; Guagnano, V.; Noorani, M.; Roesel, J.; Bitsch, F.; Rihs, G.; Furet, P., Novel beta -lactam derivatives: Potent and selective inhibitors of the chymotrypsin-like activity of the human $20 \mathrm{~S}$ proteasome. Bioorg. Med. Chem. Lett. 2007, 17, 358-362.

[111] Bonfili, L.; Cecarini, V.; Amici, M.; Cuccioloni, M.; Angeletti, M.; Keller, J. N.; Eleuteri, A. M., Natural polyphenols as proteasome modulators and their role as anti-cancer compounds. FEBS J. 2008, 275, 5512-5526.

[112] Dou, Q. P.; Landis-Piwowar, K. R.; Chen, D.; Huo, C.; Wan, S. B.; Chan, T. H., Green tea polyphenols as a natural tumour cell proteasome inhibitor. Inflammopharmacology 2008, 16, 208-212.

[113] Shah, J. J.; Kuhn, D. J.; Orlowski, R. Z., Bortezomib and EGCG: no green tea for you? Blood 2009, 113, 5695-5696.

[114] Golden, E. B.; Lam, P. Y.; Kardosh, A.; Gaffney, K. J.; Cadenas, E.; Louie, S. G.; Petasis, N. A.; Chen, T. C.; Schonthal, A. H., Green tea polyphenols block the anticancer 
effects of bortezomib and other boronic acid-based proteasome inhibitors. Blood 2009, 113, 5927-5937.

[115] Nam, S.; Smith, D. M.; Dou, Q. P., Ester bond-containing tea polyphenols potently inhibit proteasome activity in vitro and in vivo. J. Biol. Chem. 2001, 276, 13322-13330.

[116] Kazi, A.; Wang, Z.; Kumar, N.; Falsetti, S. C.; Chan, T.-H.; Dou, Q. P., Structureactivity relationships of synthetic analogs of (-)-epigallocatechin-3-gallate as proteasome inhibitors. Anticancer Res. 2004, 24, (2B), 943-954.

[117] Wan, S. B.; Landis-Piwowar, K. R.; Kuhn, D. J.; Chen, D.; Dou, Q. P.; Chan, T. H., Structure-activity study of epi-gallocatechin gallate (EGCG) analogs as proteasome inhibitors. Bioorg. Med. Chem.2005, 13, 2177-2185.

[118] Osanai, K.; Huo, C.; Landis-Piwowar, K. R.; Dou, Q. P.; Chan, T. H., Synthesis of (2R,3R)-epigallocatechin-3-O-(4-hydroxybenzoate), a novel catechin from Cistus salvifolius, and evaluation of its proteasome inhibitory activities. Tetrahedron 2007, 63, 7565-7570.

[119] Smith, D. M.; Wang, Z.; Kazi, A.; Li, L.; Chan, T. H.; Dou, Q. P., Synthetic analogs of green tea polyphenols as proteasome inhibitors. Mol. Med. 2002, 8, 382-392.

[120] Daniel, K. G.; Landis-Piwowar, K. R.; Chen, D.; Wan, S. B.; Chan, T.-H.; Dou, Q. P., Methylation of green tea polyphenols affects their binding to and inhibitory poses of the proteasome beta 5 subunit. Int. J. Mol. Med 2006, 18, 625-632.

[121] Landis-Piwowar, K. R.; Wan, S. B.; Wiegand, R. A.; Kuhn, D. J.; Chan, T. H.; Dou, Q. P., Methylation suppresses the proteasome-inhibitory function of green tea polyphenols. $J$. Cell. Physiol. 2007, 213, 252-260.

[122] Lam, W. H.; Kazi, A.; Kuhn, D. J.; Chow, L. M. C.; Chan, A. S. C.; Dou, Q. P.; Chan, T. H., A potential prodrug for a green tea polyphenol proteasome inhibitor: evaluation of the peracetate ester of (-)-epigallocatechin gallate [(-)-EGCG]. Bioorg. Med. Chem. 2004, 12, $5587-5593$.

[123] Lambert, J. D.; Sang, S.; Hong, J.; Kwon, S.-J.; Lee, M.-J.; Ho, C.-T.; Yang, C. S., Peracetylation as a Means of Enhancing in Vitro Bioactivity and Bioavailability of Epigallocatechin-3-Gallate. Drug Metab Dispos 2006, 34, 2111-2116.

[124] Smith, D. M.; Daniel, K. G.; Wang, Z.; Guida, W. C.; Chan, T.-i.; Dou, Q. P., Docking studies and model development of tea polyphenol proteasome inhibitors: Applications to rational drug design. Proteins: Struct., Funct., Bioinf. 2004, 54, 58-70.

[125] Osanai, K.; Landis-Piwowar, K. R.; Dou, Q. P.; Chan, T. H., A para-amino substituent on the D-ring of green tea polyphenol epigallocatechin-3-gallate as a novel proteasome inhibitor and cancer cell apoptosis inducer. Bioorg. Med. Chem. 2007, 15, 5076-5082. 
[126] Wan, S. B.; Chen, D.; Ping Dou, Q.; Hang Chan, T., Study of the green tea polyphenols catechin-3-gallate (CG) and epicatechin-3-gallate (ECG) as proteasome inhibitors. Bioorg. Med. Chem. 2004, 12, 3521-3527.

[127] Mozzicafreddo, M.; Cuccioloni, M.; Cecarini, V.; Eleuteri, A. M.; Angeletti, M., Homology Modeling and Docking Analysis of the Interaction between Polyphenols and Mammalian 20S Proteasomes. J. Chem. Inf. Model. 2009, 49, 401-409.

[128] Lambert, J. D.; Sang, S.; Hong, J.; Kwon, S. J.; Lee, M. J.; Ho, C. T.; Yang, C. S., Peracetylation as a means of enhancing in vitro bioactivity and bioavailability of epigallocatechin-3-gallate. Drug. Metab. Dispos. 2006, 34, 2111-2116.

[129] Chen, D.; Daniel, K. G.; Chen, M. S.; Kuhn, D. J.; Landis-Piwowar, K. R.; Dou, Q. P., Dietary flavonoids as proteasome inhibitors and apoptosis inducers in human leukemia cells. Biochem. Pharmacol. 2005, 69, 1421-1432.

[130] Kazi, A.; Daniel, K. G.; Smith, D. M.; Kumar, N. B.; Dou, Q. P., Inhibition of the proteasome activity, a novel mechanism associated with the tumor cell apoptosis-inducing ability of genistein. Biochem. Pharmacol. 2003, 66, 965-976.

[131] Chang, T.-L.; Ding, H.-Y.; Kao, Y.-W., Role of Ginsenoside Rd in Inhibiting 26S Proteasome Activity. J. Agric. Food Chem. 2008, 56, 12011-12015.

[132] Tsukamoto, S.; Tatsuno, M.; Van Soest, R. W. M.; Yokosawa, H.; Ohta, T., New polyhydroxy sterols: proteasome inhibitors from a marine sponge Acanthodendrilla sp. J. Nat. Prod. 2003, 66, 1181-1185.

[133] Yang, H.; Chen, D.; Cui, Q. C.; Yuan, X.; Dou, Q. P., Celastrol, a Triterpene Extracted from the Chinese "Thunder of God Vine," Is a Potent Proteasome Inhibitor and Suppresses Human Prostate Cancer Growth in Nude Mice. Cancer Res 2006, 66, 4758-4765.

[134] Yang, H.; Shi, G.; Dou, Q. P., The Tumor Proteasome Is a Primary Target for the Natural Anticancer Compound Withaferin A Isolated from "Indian Winter Cherry". Mol Pharmacol 2007, 71, 426-437.

[135] Huang, L.; Ho, P.; Chen, C.-H., Activation and inhibition of the proteasome by betulinic acid and its derivatives. FEBS Lett. 2007, 581, 4955-4959.

[136] Huang, L.; Yu, D.; Ho, P.; Qian, K.; Lee, K.-H.; Chen, C.-H., Synthesis and proteasome inhibition of glycyrrhetinic acid derivatives. Bioorg. Med. Chem. 2008, 16, 6696-6701.

[137] Palmer, J. T.; Rasnick, D.; Klaus, J. L.; Bromme, D., Vinyl Sulfones as MechanismBased Cysteine Protease Inhibitors. J. Med. Chem. 1995, 38, 3193-6.

[138] Bogyo, M.; McMaster, J. S.; Gaczynska, M.; Tortorella, D.; Goldberg, A. L.; Ploegh, H., Covalent modification of the active site threonine of proteasomal beta subunits and the 
Escherichia coli homolog HslV by a new class of inhibitors. Proc. Natl. Acad. Sci. U. S. A. 1997, 94, 6629-6634.

[139] Bogyo, M.; Shin, S.; McMaster, J. S.; Ploegh, H. L., Substrate binding and sequence preference of the proteasome revealed by active-site-directed affinity probes. Chem. Biol. 1998, $5,307-320$.

[140] Nazif, T.; Bogyo, M., Global analysis of proteasomal substrate specificity using positional-scanning libraries of covalent inhibitors. Proc. Natl. Acad. Sci. U. S. A. 2001, 98, 2967-2972.

[141] Kessler, B. M.; Tortorella, D.; Altun, M.; Kisselev, A. F.; Fiebiger, E.; Hekking, B. G.; Ploegh, H. L.; Overkleeft, H. S., Extended peptide-based inhibitors efficiently target the proteasome and reveal overlapping specificities of the catalytic beta -subunits. Chem. Biol. 2001, 8, 913-929.

[142] Bogyo, M., Screening for selective small molecule inhibitors of the proteasome using activity-based probes. Methods Enzymol. 2005, 399, (Ubiquitin and Protein Degradation, Part B), 609-622.

[143] Rydzewski, R. M.; Burrill, L.; Mendonca, R.; Palmer, J. T.; Rice, M.; Tahilramani, R.; Bass, K. E.; Leung, L.; Gjerstad, E.; Janc, J. W.; Pan, L., Optimization of subsite binding to the beta 5 subunit of the human 20S proteasome using vinyl sulfones and 2-keto-1,3,4oxadiazoles: Syntheses and cellular properties of potent, selective proteasome inhibitors. $J$. Med. Chem. 2006, 49, 2953-2968.

[144] Verdoes, M.; Florea, B. I.; Van der Linden, W. A.; Renou, D.; Van den Nieuwendijk, A. M. C. H.; Van der Marel, G. A.; Overkleeft, H. S., Mixing of peptides and electrophilic traps gives rise to potent, broad-spectrum proteasome inhibitors. Org. Biomol. Chem. 2007, 5, 1416-1426.

[145] Ovaa, H.; van Swieten, P. F.; Kessler, B. M.; Leeuwenburgh, M. A.; Fiebiger, E.; van den Nieuwendijk, A. M. C. H.; Galardy, P. J.; van der Marel, G. A.; Ploegh, H. L.; Overkleeft, H. S., Chemistry in living cells: Detection of active proteasomes by a two-step labeling strategy. Angew. Chem., Int. Ed. 2003, 42, 3626-3629.

[146] van Swieten, P. F.; Samuel, E.; Hernandez, R. O.; van den Nieuwendijk, A. M. C. H.; Leeuwenburgh, M. A.; van der Marel, G. A.; Kessler, B. M.; Overkleeft, H. S.; Kisselev, A. F., A cell-permeable inhibitor and activity-based probe for the caspase-like activity of the proteasome. Bioorg. Med. Chem. Lett. 2007, 17, 3402-3405.

[147] Verdoes, M.; Florea, B. I.; Menendez-Benito, V.; Maynard, C. J.; Witte, M. D.; van der Linden, W. A.; van den Nieuwendijk, A. M. C. H.; Hofmann, T.; Berkers, C. R.; van 
Leeuwen, F. W. B.; Groothuis, T. A.; Leeuwenburgh, M. A.; Ovaa, H.; Neefjes, J. J.; Filippov, D. V.; van der Marel, G. A.; Dantuma, N. P.; Overkleeft, H. S., A Fluorescent Broad-Spectrum Proteasome Inhibitor for Labeling Proteasomes In Vitro and In Vivo. Chem. Biol. 2006, 13, 1217-1226.

[148] Berkers, C. R.; van Leeuwen, F. W. B.; Groothuis, T. A.; Peperzak, V.; van Tilburg, E. W.; Borst, J.; Neefjes, J. J.; Ovaa, H., Profiling Proteasome Activity in Tissue with Fluorescent Probes. Mol. Pharmaceutics 2007, 4, 739-748.

[149] Verdoes, M.; Hillaert, U.; Florea, B. I.; Sae-Heng, M.; Risseeuw, M. D. P.; Filippov, D. V.; Van der Marel, G. A.; Overkleeft, H. S., Acetylene functionalized BODIPY dyes and their application in the synthesis of activity based proteasome probes. Bioorg. Med. Chem. Lett. 2007, 17, 6169-6171.

[150] Berkers, C. R.; Verdoes, M.; Lichtman, E.; Fiebiger, E.; Kessler, B. M.; Anderson, K. C.; Ploegh, H. L.; Ovaa, H.; Galardy, P. J., Activity probe for in vivo profiling of the specificity of proteasome inhibitor bortezomib. Nat. Methods 2005, 2, 357-362.

[151] Marastoni, M.; Baldisserotto, A.; Cellini, S.; Gavioli, R.; Tomatis, R., Peptidyl Vinyl Ester Derivatives: New Class of Selective Inhibitors of Proteasome Trypsin-Like Activity. J. Med. Chem. 2005, 48, 5038-5042.

[152] Marastoni, M.; Baldisserotto, A.; Trapella, C.; Gavioli, R.; Tomatis, R., Synthesis and biological evaluation of new vinyl ester pseudotripeptide proteasome inhibitors. Eur. J. Med. Chem. 2006, 41, 978-984.

[153] Marastoni, M.; Baldisserotto, A.; Trapella, C.; Gavioli, R.; Tomatis, R., P3 and P4 position analysis of vinyl ester pseudopeptide proteasome inhibitors. Bioorg. Med. Chem. Lett. 2006, 16, 3125-3130.

[154] Baldisserotto, A.; Marastoni, M.; Trapella, C.; Gavioli, R.; Ferretti, V.; Pretto, L.; Tomatis, R., Glutamine vinyl ester proteasome inhibitors selective for trypsin-like (beta 2) subunit. Eur. J. Med. Chem. 2007, 42, 586-592.

[155] Baldisserotto, A.; Marastoni, M.; Lazzari, I.; Trapella, C.; Gavioli, R.; Tomatis, R., Cterminal constrained phenylalanine as a pharmacophoric unit in peptide-based proteasome inhibitors. Eur. J. Med. Chem. 2008, 43, 1403-1411.

[156] Baldisserotto, A.; Marastoni, M.; Fiorini, S.; Pretto, L.; Ferretti, V.; Gavioli, R.; Tomatis, R., Vinyl ester-based cyclic peptide proteasome inhibitors. Bioorg. Med. Chem. Lett. 2008, 18, 1849-1854.

[157] Baldisserotto, A.; Marastoni, M.; Gavioli, R.; Tomatis, R., New cyclic peptide proteasome inhibitors. Bioorg. Med. Chem. Lett. 2009, 19, 1966-1969. 
[158] Mou, K.; Xu, B.; Ma, C.; Yang, X.; Zou, X.; Yang, L.; Xu, P., Novel CADD-based peptidyl vinyl ester derivatives as potential proteasome inhibitors. Bioorg. Med. Chem. Lett. 2008, 18, 2198-2202.

[159] Martin, M. E.; Rice, K. G., A Novel Class of Intrinsic Proteasome Inhibitory Gene Transfer Peptides. Bioconjugate Chem. 2008, 19, 370-376.

[160] Groll, M.; Schellenberg, B.; Bachmann, A. S.; Archer, C. R.; Huber, R.; Powell, T. K.; Lindow, S.; Kaiser, M.; Dudler, R., A plant pathogen virulence factor inhibits the eukaryotic proteasome by a novel mechanism. Nature 2008, 452, 755-758.

[161] Clerc, J. r. m.; Groll, M.; Illich, D. J.; Bachmann, A. S.; Huber, R.; Schellenberg, B.; Dudler, R.; Kaiser, M., Synthetic and structural studies on syringolin A and B reveal critical determinants of selectivity and potency of proteasome inhibition. Proc. Natl Acad. Sci. U. S. A. 2009, 106, 6507-6512.

[162] Waspi, U.; Blanc, D.; Winkler, T.; Ruedi, P.; Dudler, R., Syringolin, a novel peptide elicitor from Pseudomonas syringae pv. syringae that induces resistance to Pyricularia oryzae in rice. Mol. Plant-Microbe Interact. 1998, 11, 727-733.

[163] Waspi, U.; Hassa, P.; Staempfli, A. A.; Molleyres, L. P.; Winkler, T.; Dudler, R., Identification and structure of a family of syringolin variants: Unusual cyclic peptides from Pseudomonas syringae pv. syringae that elicit defense responses in rice. Microbiol. Res. 1999, 154, 89-93.

[164] Oka, M.; Nishiyama, Y.; Ohta, S.; Kamei, H.; Konishi, M.; Miyaki, T.; Oki, T.; Kawaguchi, H., Glidobactin-a, Glidobactin-B and Glidobactin-C, New Antitumor Antibiotics .1. Production, Isolation, Chemical-Properties and Biological-Activity. J. Antibiot. 1988, 41, $1331-1337$.

[165] Oka, M.; Yaginuma, K.; Numata, K.; Konishi, M.; Oki, T.; Kawaguchi, H., Glidobactin-a, Glidobactin-B and Glidobactin-C, New Antitumor Antibiotics .2. Structure Elucidation. J. Antibiot. 1988, 41, 1338-1350.

[166] Coleman, C. S.; Rocetes, J. P.; Park, D. J.; Wallick, C. J.; Warn-Cramer, B. J.; Michel, K.; Dudler, R.; Bachmann, A. S., Syringolin A, a new plant elicitor from the phytopathogenic bacterium Pseudomonas syringae pv. syringae, inhibits the proliferation of neuroblastoma and ovarian cancer cells and induces apoptosis. Cell Prolif. 2006, 39, 599-609.

[167] Schellenberg, B.; Bigler, L.; Dudler, R., Identification of genes involved in the biosynthesis of the cytotoxic compound glidobactin from a soil bacterium. Environmental Microbiology 2007, 9, 1640-1650. 
[168] Iqbal, M.; Chatterjee, S.; Kauer, J. C.; Mallamo, J. P.; Messina, P. A.; Reiboldt, A.; Siman, R., Potent alpha -ketocarbonyl and boronic ester derived inhibitors of proteasome. Bioorg. Med. Chem. Lett. 1996, 6, 287-90.

[169] Chatterjee, S.; Dunn, D.; Mallya, S.; Ator, M. A., P'-extended alpha -ketoamide inhibitors of proteasome. Bioorg. Med. Chem. Lett. 1999, 9, 2603-2606.

[170] Braun, H. A.; Umbreen, S.; Groll, M.; Kuckelkorn, U.; Mlynarczuk, I.; Wigand, M. E.; Drung, I.; Kloetzel, P.-M.; Schmidt, B., Tripeptide Mimetics Inhibit the 20 S Proteasome by Covalent Bonding to the Active Threonines. J. Biol. Chem. 2005, 280, 28394-28401.

[171] Aubin, S.; Martin, B.; Delcros, J.-G.; Arlot-Bonnemains, Y.; Baudy-Floc'h, M., Retro Hydrazino-azapeptoids as Peptidomimetics of Proteasome Inhibitors. J. Med. Chem. 2005, 48, 330-334.

[172] Fu, Y.; Xu, B.; Zou, X.; Ma, C.; Yang, X.; Ke, M.; Fu, G.; Yang, L.; Xu, P., Design and synthesis of a novel class of furan-based molecules as potential 20S proteasome inhibitors. Bioorg. Med. Chem. Lett. 2007, 17, 1102-1106.

[173] Maryanoff, B. E.; Costanzo, M. J., Inhibitors of proteases and amide hydrolases that employ an alpha -ketoheterocycle as a key enabling functionality. Bioorg. Med. Chem. 2008, $16,1562-1595$.

[174] Leban, J.; Blissea, M.; Kraussa, B.; Ratha, S.; Baumgartner, R.; Seifert, M. H. J., Proteasome inhibition by peptide-semicarbazones Bioorg. Med. Chem. 2008, 16, 4579-4588.

[175] Baumann, P.; Müller, K.; Mandl-Weber, S.; Leban, J.; Doblhofer, R.; Ammendola, A.; Baumgartner, R.; Oduncu, F.; Schmidmaier, R., The peptide-semicarbazone S-2209, a representative of a new class of proteasome inhibitors, induces apoptosis and cell growth arrest in multiple myeloma cells. British Journal of Haematology 2009, 144, 875 - 886.

[176] Furet, P.; Imbach, P.; Noorani, M.; Koeppler, J.; Laumen, K.; Lang, M.; Guagnano, V.; Fuerst, P.; Roesel, J.; Zimmermann, J.; Garcia Echeverria, C., Entry into a New Class of Potent Proteasome Inhibitors Having High Antiproliferative Activity by Structure-Based Design. J. Med. Chem. 2004, 47, 4810-4813.

[177] Andre, P.; Groettrup, M.; Klenerman, P.; De Giuli, R.; Booth, B. L., Jr.; Cerundolo, V.; Bonneville, M.; Jotereau, F.; Zinkernagel, R. M.; Lotteau, V., An inhibitor of HIV-1 protease modulates proteasome activity, antigen presentation, and T cell responses. Proc. Natl. Acad. Sci. U. S. A. 1998, 95, 13120-13124.

[178] Schmidtke, G.; Holzhutter, H.-G.; Bogyo, M.; Kairies, N.; Groll, M.; De Giuli, R.; Emch, S.; Groettrup, M., How an inhibitor of the HIV-I protease modulates proteasome activity. J. Biol. Chem 1999, 274, 35734-35740. 
[179] Laurent, N.; de Boueard, S.; Guillamo, J.-S.; Christov, C.; Zini, R.; Jouault, H.; Andre, P.; Lotteau, V.; Peschanski, M., Effects of the proteasome inhibitor ritonavir on glioma growth in vitro and in vivo. Mol. Cancer Ther. 2004, 3, 129-136.

[180] Garcia-Echeverria, C.; Imbach, P.; France, D.; Furst, P.; Lang, M.; Noorani, M.; Scholz, D.; Zimmermann, J.; Furet, P., A New Structural Class of Selective and Non-covalent Inhibitors of the Chymotrypsin-like Activity of the 20S Proteasome. Bioorg. Med. Chem. Lett. 2001, 11, 1317-1319.

[181] Furet, P.; Imbach, P.; Furst, P.; Lang, M.; Noorani, M.; Zimmermann, J.; GarciaEcheverria, C., Modeling of the Binding Mode of a Non-covalent Inhibitor of the $20 \mathrm{~S}$ Proteasome. Application to Structure-Based Analogue Design. Bioorg. Med. Chem. Lett. 2001, 11, 1321-1324.

[182] Furet, P.; Imbach, P.; Fuerst, P.; Lang, M.; Noorani, M.; Zimmermann, J.; GarciaEcheverria, C., Structure-Based optimization of 2-aminobenzylstatine derivatives: potent and selective inhibitors of the chymotrypsin-Like activity of the human $20 \mathrm{~S}$ proteasome. Bioorg. Med. Chem. Lett. 2002, 12, 1331-1334.

[183] Kohno, J.; Koguchi, Y.; Nishio, M.; Nakao, K.; Kuroda, M.; Shimizu, R.; Ohnuki, T.; Komatsubara, S., Structures of TMC-95A-D: Novel proteasome inhibitors from Apiospora montagnei Sacc. TC 1093. J. Org. Chem. 2000, 65, 990-995.

[184] Koguchi, Y.; Kohno, J.; Nishio, M.; Takahashi, K.; Okuda, T.; Ohnuki, T.; Komatsubara, S., TMC-95A, B, C, and D, novel proteasome inhibitors produced by Apiospora montagnei Sacc. TC 1093. Taxonomy, production, isolation, and biological activities. J. Antibiot. 2000, 53, 105-109.

[185] Yang, Z.-Q.; Kwok, B. H. B.; Lin, S.; Koldobskiy, M. A.; Crews, C. M.; Danishefsky, S. J., Simplified synthetic TMC-95A/B analogues retain the potency of proteasome inhibitory activity. ChemBioChem 2003, 4, 508-513.

[186] Kaiser, M.; Groll, M.; Siciliano, C.; Assfalg-Machleidt, I.; Weyher, E.; Kohno, J.; Milbradt, A. G.; Renner, C.; Huber, R.; Moroder, L., Binding mode of TMC-95A analogues to eukaryotic 20S proteasome. ChemBioChem 2004, 5, 1256-1266.

[187] Groll, M.; Koguchi, Y.; Huber, R.; Kohno, J., Crystal Structure of the 20 S Proteasome:TMC-95A Complex: A Non-covalent Proteasome Inhibitor. J. Mol. Biol. 2001, 311, 543-548.

[188] Inoue, M.; Zhai, H.; Sakazaki, H.; Furuyama, H.; Fukuyama, Y.; Hirama, M., TMC95A, a reversible proteasome inhibitor, induces neurite outgrowth in PC12 cells. Bioorg. Med. Chem. Lett. 2004, 14, 663-665. 
[189] Coste, A.; Couty, F.; Evano, G., TMC-95A-D and analogues: Chemistry and biology. Comptes Rendus Chimie 2008, 11, 1544-1573.

[190] Lin, S.; Danishefsky, S. J., The total synthesis of proteasome inhibitors TMC-95A and TMC-95B: discovery of a new method to generate cis-propenyl amides. Angew. Chem., Int. Ed. 2002, 41, 512-515.

[191] Inoue, M.; Sakazaki, H.; Furuyama, H.; Hirama, M., Total synthesis of TMC-95A. Angew. Chem., Int. Ed. 2003, 42, 2654-2657.

[192] Albrecht, B. K.; Williams, R. M., A concise, total synthesis of the TMC-95A/B proteasome inhibitors. Proc. Natl. Acad. Sci. U. S. A. 2004, 101, 11949-11954.

[193] Kaiser, M.; Groll, M.; Renner, C.; Huber, R.; Moroder, L., The core structure of TMC95A is a promising lead for reversible proteasome inhibition. Angew. Chem., Int. Ed 2002, 41, 780-783.

[194] Kaiser, M.; Siciliano, C.; Assfalg-Machleidt, I.; Groll, M.; Milbradt, A. G.; Moroder, L., Synthesis of a TMC-95A Ketomethylene Analogue by Cyclization via Intramolecular Suzuki Coupling. Org. Lett. 2003, 5, 3435-3437.

[195] Kaiser, M.; Milbradt, A. G.; Siciliano, C.; Assfalg-Machleidt, I.; Machleidt, W.; Groll, M.; Renner, C.; Moroder, L., TMC-95A analogues with endocyclic biphenyl ether group as proteasome inhibitors. Chem. Biodiversity 2004, 1, 161-173.

[196] Groll, M.; Goetz, M.; Kaiser, M.; Weyher, E.; Moroder, L., TMC-95-Based Inhibitor Design Provides Evidence for the Catalytic Versatility of the Proteasome. Chem. Biol. 2006, 13, 607-614.

[197] Lin, S.; Yang, Z.-Q.; Kwok, B. H. B.; Koldobskiy, M.; Crews, C. M.; Danishefsky, S. J., Total Synthesis of TMC-95A and -B via a New Reaction Leading to Z-Enamides. Some Preliminary Findings as to SAR. J. Am. Chem. Soc 2004, 126, 6347-6355.

[198] Berthelot, A.; Piguel, S.; Le Dour, G.; Vidal, J., Synthesis of Macrocyclic Peptide Analogues of Proteasome Inhibitor TMC-95A. J. Org. Chem. 2003, 68, 9835-9838.

[199] Basse, N.; Piguel, S.; Papapostolou, D.; Ferrier-Berthelot, A.; Richy, N.; Pagano, M.; Sarthou, P.; Sobczak-Thepot, J.; Reboud-Ravaux, M.; Vidal, J., Linear TMC-95-Based Proteasome Inhibitors. J. Med. Chem. 2007, 50, 2842-2850.

[200] Sasse, F.; Steinmetz, H.; Schupp, T.; Petersen, F.; Memmert, K.; Hofmann, H.; Heusser, C.; Brinkmann, V.; Von Matt, P.; Hofle, G.; Reichenbach, H., Argyrins, immunosuppressive cyclic peptides from myxobacteria. I. Production, isolation, physico-chemical and biological properties. J. Antibiot. 2002, 55, 543-551. 
[201] Nickeleit, I.; Zender, S.; Sasse, F.; Geffers, R.; Brandes, G.; Soerensen, I.; Steinmetz, H.; Kubicka, S.; Carlomagno, T.; Menche, D.; Guetgemann, I.; Buer, J.; Gossler, A.; Manns, M. P.; Kalesse, M.; Frank, R.; Malek, N. P., Argyrin A reveals a critical role for the tumor suppressor protein p27kip1 in mediating antitumor activities in response to proteasome inhibition. Cancer Cell 2008, 14, 23-35.

[202] McConkey, D. J., A novel role for a familiar protein in apoptosis induced by proteasome inhibition. Cancer Cell 2008, 14, 1-2.

[203] Gaczynska, M.; Osmulski, P. A.; Gao, Y.; Post, M. J.; Simons, M., Proline- and arginine-rich peptides constitute a novel class of allosteric inhibitors of proteasome activity. Biochemistry 2003, 42, 8663-8670.

[204] Bao, J.; Sato, K.; Li, M.; Gao, Y.; Abid, R.; Aird, W.; Simons, M.; Post, M. J., PR-39 and PR-11 peptides inhibit ischemia-reperfusion injury by blocking proteasome-mediated I kappa B alpha degradation. Am. J. Physiol. Heart Circ. Physiol. 2001, 281, H2612-2618.

[205] Marastoni, M.; Baldisserotto, A.; Canella, A.; Gavioli, R.; De Risi, C.; Pollini, G. P.; Tomatis, R., Arecoline Tripeptide Inhibitors of Proteasome. J. Med. Chem. 2004, 47, 15871590

[206] Basse, N.; Papapostolou, D.; Pagano, M.; Reboud-Ravaux, M.; Bernard, E.; Felten, A.S.; Vanderesse, R., Development of lipopeptides for inhibiting 20S proteasomes. Bioorg. Med. Chem. Lett. 2006, 16, 3277-3281.

[207] Formicola, L.; Marechal, X.; Basse, N.; Bouvier-Durand, M.; Bonnet-Delpon, D.; Milcent, T.; Reboud-Ravaux, M.; Ongeri, S., Novel fluorinated pseudopeptides as proteasome inhibitors. Bioorg. Med. Chem. Lett. 2009, 19, 83-86.

[208] Jensen, P. B.; Jensen, P. S.; Demant, E. J.; Friche, E.; Sørensen, B. S.; Sehested, M.; Wassermann, K.; Vindeløv, L.; Westergaard, O.; Hansen, H. H., Antagonistic effect of aclarubicin on daunorubicin-induced cytotoxicity in human small cell lung cancer cells: relationship to DNA integrity and topoisomerase II. Cancer Res. 1991, 51, 5093-5099.

[209] Figueiredo-Pereira, M. E.; Chen, W. E.; Li, J.; Johdo, O., The antitumor drug aclacinomycin A, which inhibits the degradation of ubiquitinated proteins, shows selectivity for the chymotrypsin-like activity of the bovine pituitary $20 \mathrm{~S}$ proteasome. J. Biol. Chem. 1996, 271, 16455-16459.

[210] Vispé, S.; Vandenberghe, I.; Robin, M.; Annereau, J. P.; Créancier, L.; Pique, V.; Galy, J. P.; Kruczynski, A.; Barret, J.-M.; Bailly, C., Novel tetra-acridine derivatives as dual inhibitors of topoisomerase II and the human proteasome. Biochem Pharmacol. 2007, 73, $1863-1872$. 
[211] Elnakady, Y. A.; Rohde, M.; Sasse, F.; Backes, C.; Keller, A.; Lenhof, H.-P.; Weissman, K. J.; Müller, R., Evidence for the Mode of Action of the Highly Cytotoxic Streptomyces Polyketide Kendomycin. ChemBioChem 2007, 8, 1261 - 1272.

[212] Hartinger, C. G.; Dyson, P. J., Bioorganometallic chemistry-from teaching paradigms to medicinal applications. Chem. Soc. Rev. 2009, 38, 391-401.

[213] Bruijnincx, P. C. A.; Sadler, P. J., New trends for metal complexes with anticancer activity. Curr. Opin. Chem. Biol. 2008, 12, 197-206.

[214] Arnesano, F.; Natile, G., Mechanistic insight into the cellular uptake and processing of cisplatin 30 years after its approval by FDA. Coord. Chem. Rev. 2009, 253, 2070-2081.

[215] Daniel, K. G.; Gupta, P.; Harbach, R. H.; Guida, W. C.; Dou, Q. P., Organic copper complexes as a new class of proteasome inhibitors and apoptosis inducers in human cancer cells Biochem. Pharmacol. 2004, 67, 1139-1151.

[216] Daniel, K. G.; Chen, D.; Orlu, S.; Cui, Q. C.; Miller, F. R.; Dou, Q. P., Clioquinol and pyrrolidine dithiocarbamate complex with copper to form proteasome inhibitors and apoptosis inducers in human breast cancer cells. Breast Cancer Res. 2005, 7, R897-R908.

[217] Adsule, S.; Barve, V.; Chen, D.; Ahmed, F.; Dou, Q. P.; Padhye, S.; Sarkar, F. H., Novel Schiff Base Copper Complexes of Quinoline-2 Carboxaldehyde as Proteasome Inhibitors in Human Prostate Cancer Cells. J. Med. Chem. 2006, 49, 7242-7246.

[218] Chen, D.; Cui, Q. C.; Yang, H.; Dou, Q. P., Disulfiram, a Clinically Used AntiAlcoholism Drug and Copper-Binding Agent, Induces Apoptotic Cell Death in Breast Cancer Cultures and Xenografts via Inhibition of the Proteasome Activity. Cancer Res 2006, 66, 10425-10433.

[219] Cvek, B.; Milacic, V.; Taraba, J.; Dou, Q. P., Ni(II), Cu(II), and Zn(II) Diethyldithiocarbamate Complexes Show Various Activities Against the Proteasome in Breast Cancer Cells. J. Med. Chem. 2008, 51, 6256-6258.

[220] Milacic, V.; Chen, D.; Giovagnini, L.; Diez, A.; Fregona, D.; Dou, Q. P., Pyrrolidine dithiocarbamate-zinc(II) and -copper(II) complexes induce apoptosis in tumor cells by inhibiting the proteasomal activity. Toxicol. Appl. Pharmacol. 2008, 231, 24-33.

[221] Hindo, S. S.; Frezzab, M.; Tomco, D.; Heeg, M. J.; Hryhorczuk, L.; McGarvey, B. R.; Dou, Q. P.; Verani, C. N., Metals in Anticancer Therapy: Copper(II) Complexes as Inhibitors of the 20S Proteasome. Eur. J. Med. Chem. 2009, 44, 4353-4361.

[222] Frezza, M.; Hindo, S. S.; Tomco, D.; Allard, M. M.; Cui, Q. C.; Heeg, M. J.; Chen, D.; Dou, Q. P.; Verani, C. N., Comparative Activities of Nickel(II) and Zinc(II) Complexes of 
Asymmetric [NN';O] Ligands as 26S Proteasome Inhibitors. Inorg. Chem. 2009, 48, 59285937.

[223] Chen, D.; Frezza, M.; Shakya, R.; Cui, Q. C.; Milacic, V.; Verani, C. N.; Dou, Q. P., Inhibition of the Proteasome Activity by Gallium(III) Complexes Contributes to Their Anti Prostate Tumor Effects. Cancer Res. 2007, 67, 9258-9265.

[224] Milacic, V.; Chen, D.; Ronconi, L.; Landis-Piwowar, K. R.; Fregona, D.; Dou, Q. P., A Novel Anticancer Gold(III) Dithiocarbamate Compound Inhibits the Activity of a Purified 20S Proteasome and 26S Proteasome in Human Breast Cancer Cell Cultures and Xenografts. Cancer Res 2006, 66, 10478-10486.

[225] Milacic, V.; Dou, Q. P., The tumor proteasome as a novel target for gold(III) complexes: Implications for breast cancer therapy Coord. Chem. Rev. 2009, 253, 1649-1660. [226] Basse, N.; Montes, M.; Maréchal, X.; Qin, L.; Bouvier-Durand, M.; Genin, E.; Vidal, J.; Villoutreix, B. O.; Reboud-Ravaux, M. Novel organic proteasome inhibitors identified by virtual and in vitro screening, J. Med. Chem., 2010, 53, 509-513. 